\title{
Beiträge zur Kenntnis der komplexen Ammoniakhydroxyde des Kupfers, Nickels, Kadmiums, Zinks und Silbers.
}

\author{
Von \\ W. BonsDORFF. \\ Mit 8 Figuren im Text.
}

Einleitung.

Während über die komplexen Ammoniaksalze schon viele Untersuchungen vorliegen, sind die freien Metallammoniakhydroxyde bis in die letzte Zeit ganz im Hintergrund geblieben, was wahrscheinlich darauf beruht, dafs die meisten Metallammoniakhydroxyde nur in Lösung existieren und aufserdem immer einen kleineren oder gröfseren Überschufs von $\mathrm{NH}_{3}$ brauchen, wodurch die Untersuchungen sehr erschwert werden.

Es schien deshalb sehr lohnend zu sein, mit den zu Gebote stehenden physikalisch-chemischen Hilfsmitteln die Metallammoniakhydroxyde näher zu studieren. Meine Absicht war zuerst nur die komplexen Kupriammonikhydroxyde zu untersuchen, aber weil es sich zeigte, dafs es mit unseren Hilfsmitteln sehr schwer war, quantitative Resultate $\mathrm{zu}$ bekommen, habe ich, um Vergleich-Material zu erhalten, auch die Lösungen von Nickel-, Kadmium-, Zink- und Silberhydroxyden in Ammoniak untersucht.

Als ich diese Arbeit über die genannten komplexen $\mathrm{NH}_{3}$ Hydroxyde im Frühling 1902 begann, war, wie gesagt, sehr wenig über sie bekannt. Von Kupferammoniaklösungen lag eine Untersuchung von Dawson und MC $\mathrm{CRAE}^{2}$ vor. Diese Forscher haben gezeigt, dals beim Auflösen von $\mathrm{CuO}$ in $\mathrm{NH}_{3}$ anscheinend $\mathrm{CuO} .2 \mathrm{NH}_{3}$ sich in Lösung bildet. Bei ihren Untersuchungen war der Ver-

1 Auszug aus einer akademischen Abhandlung zur Erlangung des Doktorgrades der Universität Helsingfors.

${ }^{2}$ Joum. Chem. Soe. 77 (1900), 1239. 
teilungssatz von NkrNst zugrunde gelegt. Wird nämlich Chloroform mit $\mathrm{NH}_{3}$-Lösung geschüttelt, so verteilt sich das undissoziierte $\mathrm{NH}_{3}$ in einem konstanten Verhältnis zwischen beiden Lösungsmitteln. Wenn nun durch Komplexbildung ein Teil von dem $\mathrm{NH}_{3}$ gebunden wird, ändert sich die Verteilung, und die Grölse dieser Änderung gibt den Grad der Komplexbildung.

Auch liegen zwei kurze Abhandlungen von Bouzat ${ }^{1}$ vor, in welchen er die Neutralisationswärme des Kupferoxydammoniaks mit einigen Säuren untersucht und bemerkt, dafs die entwickelten Wärmemengen einen konstanten Überschufs gegen die Neutralisationswärme sowohl von Kupferhydroxyd - Säure, wie von $\mathrm{NH}_{3}-$ Säure zeigen. Der Verfasser hat auch die Verbindungswärme von Kupferoxydammoniak untersucht und als Mittel gefunden: CuO gefäll $+28 \mathrm{NH}_{3}$ gel. $(141)=\mathrm{CuO} .28 \mathrm{NH}_{3}$ gel. +4.2 Cal. Bouzat zieht aus den Versuchen den Schlufs, dafs Kupferoxydammoniak eine starke komplexe Base ist. Doch ist diese Schlufsfolgerung auf Grund der Verbindungswärme eine sehr zweifelhafte.

Über Nickel- und Kadmiumhydroxyd ist aus der älteren Literatur $^{2}$ nur zu entnehmen, dafs sie unter Bildung von komplexen $\mathrm{NH}_{3}$-Hydroxyden sich in $\mathrm{NH}_{3}$ lösen. $\nabla$ on $\mathrm{Zn}(\mathrm{OH})_{2}$ glaubte man früher, dafs es beim Lösen in $\mathrm{NH}_{3}$ ein Zinkat bildet. Obwohl diese ältere Ansicht, seitdem $\mathrm{H}_{\mathrm{AnTzSCH}}{ }^{3}$ gezeigt hatte, dafs $\mathrm{Zn}(\mathrm{OH})_{2}$ kaum imstande ist auch mit starken Basen wie $\mathrm{NaOH}$ ein Zinkat zu bilden, bei den physikalischen Chemikern sicherlich nicht viel Anklang fand, waren doch keine direkten Versuche vorhanden, welche das wirkliche Verhalten solcher Lösungen aufklären konnten.

Von Silberoxyd hat man schon lange gewufst, dafs es mit $\mathrm{NH}_{3}$ eine feste Verbindung, das sogenannte Knallsilber, bildet. Doch waren über die Lösungen von $\mathrm{Ag}_{2} \mathrm{O}$ in $\mathrm{NH}_{3}$ bei Beginn meiner Arbeit keine direkten Messungen vorhanden. Meine Absicht war auch die Silberammoniakhydroxyde aufser durch Leitfähigkeits- auch mittelst Potential- und Löslichkeitsmessungen zu studieren. Doch sind unterdessen schon zwei Arbeiten eine von WHItwex und MELCHer ${ }^{4}$ und die andere von EuLER ${ }^{5}$ erschienen, in welchen gezeigt wird, dafs die komplexen Kationen hier ähnlich wie bei Silber-

\footnotetext{
1 Compt. rend. 134, 1216. 1310.

- Vergl. Dammer, Handbuch der Chemie.

s $Z$. anorg. Chem. 30 (1902), 298.

4 Journ. Am. Chem. Soc. 25 (1903), 69; Chem. Centrbl. 1903 I, 620.

${ }^{5}$ Ber. deutseh. chen. Ges. 36 (1903), 1854.
} 
ammoniaksalzen konstituiert sind, also dafs jedes Atom Silber zwei Molekeln $\mathrm{NH}_{3}$ bindet.

Während der zwei Jahre, welche seit Beginn dieser Arbeit verflossen, sind jedoch auch einige andere Arbeiten über die komplexen Metallammoniakhydroxyde in der Literatur erschienen. Die hierüber vorliegenden Untersuchungen sollen später zur Besprechung kommen.

\section{Darstellung der Lösungen.}

Kupferhydroxyd $\mathrm{Cu}(\mathrm{OH})_{2}$.

Wie in der Literatur angegeben ist, kann man diesen Körper auf sehr verschiedenem Wege darstellen. Je nach der Darstellungsweise bekommt man entweder kolloidales oder kristallinisches Kupferhydroxyd. ${ }^{1}$

Das kolloidale Kupferhydroxyd oder Hydrogel enthält in frischem Zustande eine grolse Menge Wasser, nicht chemisch gebunden, sondern als Absorptions- und Imbibitionswasser. ${ }^{2}$ Es ist sehr schwer dasselbe rein zu erhalten, weil es wie alle kolloidalen Substanzen ein grofses Absorptionsvermögen besitzt und infolge dessen immer hartnäckig Alkali zurückhält und leicht Kohlensäure aus der Luft absorbiert. Aufserdem mufs man sehr vorsichtig sein, dafs es bei vielem Waschen sich nicht in Oxyd verwandelt. Das blaue kolloidale Kupferhydroxyd erleidet nämlich auch unter Wasser sehr leicht Veränderungen, verliert allmählich sein Wasser, bis zuletzt ein braunes Oxyd, welches nach Schaffrer und $\mathrm{Rose}^{3}$ der Formel $3 \mathrm{CuO}_{2} \mathrm{H}_{2} \mathrm{O}$ entspricht, resultiert.

Die kristallinischen und amorphen Kupferhydroxyde, welche sich von den Hydrogelen dadurch unterscheiden, dafs sie ein chemisches Hydrat von der Formel $\mathrm{CuO}_{2} \mathrm{H}_{2} \mathrm{O}$ darstellen, sind verhältnismälsig beständig. Man kann sie, wie mehrere Forscher gezeigt haben, frei von Alkali und Kohlensäure ohne Schwierigkeit erhalten.

Das Kupferhydroxyd zu unserem Zwecke wurde aus einer lauwarmen, verdünnten Kupferammoniumsulfat- oder -nitratlösung ${ }^{4}$ durch Fällen mit einer ungefähr äquivalenten Menge reiner, verdünnter Natriumbydratlösung unter Kohlensäure-Abschlufs erhalten.

1 Ann. Chem. u. Pharm. 51 (1844), 179; Arch. Pharm. [2] 89, 35; Z. anorg. Chem. 2 (1892), 195; Compt. rend. 34 (1852), 573; 53 (1861), 209; Arch. Pharm. S9 (1857), 35 .

2 Z. anorg. Chem. 5 (1894), 466.

${ }^{3}$ Journ. soc. chim. 37 (1882), 197.

4 Alle Präparate sind von KaHLbaum bezogen. 
Das zur Anwendung kommende Natriumhydroxyd war aus mit Natrium dargestelltem, festem Natriumhydroxyd bereitet. Weil auch in diesem Präparate Karbonat enthalten ist, wurde davon erst eine gesättigte Lösung bereitet, die klare ron Karbonat freie Schicht abgezogen und mit kohlensäurefreiem Wasser verdünnt. In der so bereiteten Natriumbydroxydlösung waren nur Spuren ron Karbonat nachweisbar.

Aus einer Kupferammoniumsulfat-Lösung scheidet sich ein schöner, blauer, flockiger Niederschlag $a b$, welcher mit der Zeit immer körniger wird. Aus Kupferammoniumnitrat-Lösung bekommt man einen kristallinischen Niederschlag. Kupferhydroxyd, das auf eine dieser beiden Arten erhalten ist, ist leicht $\mathrm{zu}$ waschen. $\mathrm{Zu}$ diesem Zwecke wurde der Niederschlag in geschlossenen Flaschen mit lauwarmem kohlensäurefreiem Wasser so lange dekantiert, bis das Waschwasser eine neutrale Reaktion gab. Wenn dann die Leitfähigkeit des Waschwassers zu einem konstanten Minimalwert gesunken war, wurde die Substanz als rein angesehen.

Das auf diese Weise erhaltene Kupferhydroxyd wurde dann in vorher durch Destillation über Kalk gereinigtem Ammoniak von einem bekannten Titer gelöst, und zwar in feuchtem Zustande, weil bekanntlich die meisten Metallhydroxyde, wenn sie getrocknet werden, sich weniger lösen.

Obwohl es sich zeigte, dafs in einer solchen Lösung weder Kohlensäure noch Schwefel- resp. Salpetersäure nachzuweisen war, wurde zur Kontrolle noch reines Kupferoxyd in Ammoniak gelöst und die Leitfähigkeit einer solchen Lösung mit der Leitfähigkeit einer entsprechenden aus Kupferhydroxyd und Ammoniak bereiteten Lösung verglichen. Wie später gezeigt wird, geben die beiden Lösungen dieselben Werte, was wohl zeigt, dafs sie als identisch zu betrachten sind.

Wenn das feuchte Kupferhydroxyd in Ammoniak von verschiedenen Konzentrationen gelöst wurde, zeigte sich bald, dafs in einer solchen Lösung die $\mathrm{NH}_{3}$-Konzentration erheblich grölser als die Kupferkonzentration war. Für die Messungen war es jedoch wichtig, auch Lösungen zu bekommen, welche in bezug auf Kupfer so konzentriert wie möglich waren.

Um das überschüssige Ammoniak von einer solchen Lösung zu entfernen, wurden verschiedene Methoden geprüft. Erstens wurde durch die Lösung reiner Wasserstoff durchgeleitet und das entweichende $\mathrm{NH}_{3}$ in Schwefelsäure gesammelt. Aber es zeigte sich 
doch, dafs es sehr zeitraubend war, auf diese Weise das überschüssige $\mathrm{NH}_{3}$ wegzutreiben. Nicht bessere Resultate bekam man, wenn kohlensäurefreie Luft durch die Lösung geleitet wurde. Auch habe ich versucht die ammoniakalische Lösung mit Chloroform auszuschütteln. Der Verteilungskoeffizient des $\mathrm{NH}_{3}$ zwischen Chloroform und Wasser ist jedoch zu klein, um diese Methode mit Vorteil anwenden zu können.

Die dritte Methode, das Behandeln der Lösungen in Vakuum über konzentrierter Schwefelsäure, erwies sich als die zweckmälsigste. Die Kupferammoniaklösungen wurden in einen grofsen Exsiklkator gebracht und der Exsikkator zum Vakuum abgesaugt. Die Wirkung ist sehr intensiv. Von einer Lösung, in welcher die ursprüngliche $\mathrm{NH}_{3}$-Konzentration 12 normal war, sind schon nach ungefähr 24 Stunden die ersten Spuren von $\mathrm{Cu}(\mathrm{OH})_{2}$, welches eine kristallinische Struktur zeigt, abgeschieden. Die Ammoniakkonzentration ist dann ungefähr auf ein Drittel der ursprünglichen Konzentration gefallen.

Die $\mathrm{NH}_{3}$-Konzentration einer solchen Lösung ist direkt durch Titration mit Schwefelsäure, Nitrophenol als Indikator, zu bestimmen. Nur ist $z \mathfrak{u}$ bemerken, dals die Lösung erst zu verdünnen ist, um den Farbenumschlag besser konstatieren zu können. Zur Kontrolle wurden die Lösungen auch mit Aluminiumspänen geschüttelt, wobei metallisches Kupfer ausfällt, und die farblos gewordene Lösung titriert. Auf beide Weisen bekam man übereinstimmende Werte.

Die Kupferkonzentrationsbestimmung der Lösungen wurde elektrolytisch nach den Angaben von Luckow ${ }^{1}$ ausgeführt. In die Lösung wurde Schwefelsäure bis zur neutralen Reaktion zugesetzt und bei einem Überschufs von Salpetersäure gewöhnlich über Nacht mit einer Stromstärke von $0.3 \mathrm{Amp}$. elektrolysiert. Das Kupfer scheidet sich sehr schön auf der netzförmigen Platinkatode aus. Immer wurden von einer Lösung zwei Analysen, welche auf Zehntel mmg miteinander übereinstimmten, gemacht.

\section{Nickelhydroxyd $\mathrm{Ni}(\mathrm{OH})_{2}$.}

Nickelhydroxyd wurde erst als voluminöser, apfelgrüner Niederschlag aus einer verdünnten Nickelsulfatlösung durch Fällen mit reiner Natronlauge gewonnen. Es zeigte sich jedoch bald, dafs es unmöglich war, einen sulfatfreien Niederschlag so zu bekommen. Ganz reines Nickelhydroxyd kann man erhalten, wenn zu einer

1 Zeitschr. analyt. Chem. 19 (1880), 1. 
verdünnten Nickelnitratlösung ${ }^{1}$ ein kleiner Überschuf's von Natronlauge zugesetzt wird. Um den Niederschlag schneller waschen zu können, geschah das Fällen in lauwarmer Lösung, wobei der entstandene Niederschlag nicht so voluminös ist, wie der in der Kälte erhaltene. Der Niederschlag wurde erst mit reinem, dann mit $\mathrm{NH}_{3}$ haltigem und zuletzt mit warmem, kohlensäurefreiem Wasser in zugeschlossenen Flaschen dekantiert. Wenn das Waschwasser dann eine konstante Minimalleitfähigkeit erhalten hatte, wurde der Niederschlag in ähnlicher Weise wie Kupferhydroxyd in $\mathrm{NH}_{3}$ gelöst. Die Lösung gab keine Reaktion weder auf Salpeter- noch auf Kohlensäure.

Noch schneller konnte ich ein ganz reines Nickelhydroxyd aus lauwarmer Nickelammoniumnitrat-Lösung mittels Natronlauge bekommen.

Die in bezug auf Nickel konzentriertesten Lösungen wurden auch hier durch Evakuieren einer $\mathrm{NH}_{3}$-reicheren NickelhydroxydLösung über Schwefelsäure gewonnen.

In den den Lösungen, in denen die $\mathrm{NH}_{3}$-Konzentration unbekannt war, wurde direkt auf $\mathrm{NH}_{3}$ mit Nitrophenol als Indikator titriert.

Die Nickelkonzentration wurde elektrolytisch in einer ammonikalischen, Ammoniumsulfat enthaltenden Lösung, gewöhnlich über Nacht bei einer Stromstärke von 0.5 bis 1 Amp. nach den Angaben von NuUmann ${ }^{2}$ bestimmt. Die elektrolytische Nickelbestimmung gab sehr genaue Werte.

\section{Kadmiumbydroxyd $\mathrm{Cd}(\mathrm{OH})_{2}$.}

Kadmiumbydroxyd wurde aus einer verdünnten, lauwarmen Kadmiumnitrat-Lösung mit einer berechneten Menge reiner Natronlauge ausgefällt. ${ }^{3}$ Der Niederschlag wurde in ähnlicher Weise wie beim Kupfer unter Kohlensäure-Abschlufs so lange dekantiert bis weder der Niederschlag noch das Waschwasser eine Nitratreaktion mehr gab. Wenn das Waschwasser eine konstante Minimileitfähigkeit zeigte, wurde das Hydroxyd, wie früher in feuchtem Zustande, in Ammoniak gelöst. In den so erhaltenen $\mathrm{NH}_{3}$-haltigen Lösungen konnte keine Kohlensïure nachgewiesen werden.

1 Vergl. Terchmann, Ann. Chem. u. Pharm. 156 (1870), 17.

2 Die Elektrolyse der Metalle; vergl. Zeitsehr. analyt. Chem. 3 (1864), $334 ; 19$ (1880), 320 .

s Vergl. Ann. Chem. u. Pharm. 51 (1844), 168. 
Die in bezug auf Kadmium konzentriertesten Lösungen wurden wieder durch Evakuieren der $\mathrm{NH}_{3}$-reicheren Lösungen über konzentrierte Sehwefelsäure erhalten.

Das Kadmium wurde als Oxyd bestimmt. Eine abpipetierte Menge der Flüssigkeit wurde zum Trocknen eingedampft, nach Ansäueru mit Salpetersäure geglüht und als Oxyd gewogen. Die Analysen stimmten sehr gut miteinander überein. Auch versuchte ich Kadmium elektrolytisch zu bestimmen, aber es gelang mir nicht auf diese Weise übereinstimmende Resultate zu bekommen.

\section{Zinkhydroxyd $\mathrm{Zn}(\mathrm{OH})_{2}$.}

Das Zinkhydroxyd wurde für unsere Zwecke erst in ähnlicher Weise wie bei $\mathrm{HANTZSOH}^{1}$ aus verdünnter Zinksulfatlösung mit reiner Natronlauge in der Kälte gefällt. Es scheidet sich ein amorpher, ziemlich schwer waschbarer Niederschlag ab, welcher unter Kohlensäure-Abschlufs mit kohlensäurefreiem Wasser, wie bei den anderen Hydroxyden, dekantiert wurde, bis das Waschwasser keine Reaktion auf Schwefelsäure mehr gab und bis die Leitfähigkeit des Waschwassers zu einem Minimum gesunken war.

Zur Kontrolle wurde Zinkhydroxyd auch aus einer verdünnten Sulfatlösung durch Fällen mit Baryt bereitet. $\mathrm{Zu}$ einer bekannten einige Tropfen Phenolphtalein enthaltenden Zinksulfatlösung wurde solange verdünnter Baryt zugesetzt, bis die erste Rosafärbung zu bemerken war. Weil die Operation in der Wärme vorgenommen wurde, setzte sich der Niederschlag, welcher aufser $\mathrm{Zn}(\mathrm{OH})_{2}$ auch $\mathrm{BaSO}_{4}$ enthielt, ziemlich leicht zu Boden. Die Fällung wurde noch mit warmem, kohlensäurefreiem Wasser in zugeschlossenen Flaschen dekantiert, bis das Waschwasser eine konstante Leitfähigkeit gab.

Die auf beide Weisen dargestellten Zinkhydroxyde wurden in feuchtem Zustande in ähnlicher Weise wie die anderen Hydroxyde in $\mathrm{NH}_{3}$ gelöst.

Der Zinkgehalt der Lösungen wurde als $\mathrm{ZnO}$ bestimmt. Eine gewisse Menge wurde abpipetiert, zum Trocknen eingedampft und nach Ansäuren mit Salpetersäure geglüht. Immer wurden zwei Analysen gemacht, welche sehr gut miteinander übereinstimmten.

Wie auch HANTZSCH $^{1}$ und KuRILOFF ${ }^{2}$ gezeigt haben, dürfte es

1 Z. anorg. Chem. 30 (1902), 298.

¿ Chem. Centrbl. 1901 II, 1222. 
ziemlich schwer sein, von Sulfat ganz reines Zinkhydroxyd darzustellen. Hantzsch und Kurilofy geben an, dals, wenn das Hydroxyl durch eine berechnete Menge Alkali aus Zinksulfatlösung gewonnen wird, der Niederschlag auch nach völligem Auswaschen bis zum Ausbleiben der Barytprobe im Filtrat noch eine erhebliche Menge Säure als basisches Sulfat zurückhält.

Später ist eine Arbeit von EdLER ${ }^{1}$ erschienen, in welcher er behauptet, dals von Zinknitratlösung mittels Natronlauge ganz reines Zinkhydroxyd zu bekommen sei. Ich habe deshalb noch einmal das Zinkhydroxyd von Zinknitratlösung mit einer berechneten Menge Natronlauge bereitet, in feuchtem "Zustande in Ammoniak gelöst und mit der so erhaltenen Lösung die Messungen wiederholt.

\section{Silberoxyd $\mathrm{Ag}_{2} \mathbf{0}$.}

$\mathrm{Ag}_{2} \mathrm{O}$ wurde durch Fällen aus einer verdünnten $\mathrm{AgNO}_{3}$-Lösung mit Natronlauge erhalten. Wie bekannt, ist es sehr leicht zu waschen. Um Silberkarbonat in der ammoniakalischen Lösung zu vermeiden, wurde eine gesättigte Lösung von $\mathrm{Ag}_{2} \mathrm{O}$ in $\mathrm{NH}_{3}$ bereitet. Weil nämlich Silberkarbonat viel unlöslicher als Silberoxyd in Ammoniak ist, kann bei einem Überschuls des letzteren das erste nicht mehr in der Lösung vorhanden sein. Die klare Lösung wurde abpipetiert und zu Messungen gebraucht.

Die Ag-Konzentration der Lösung wurde durch Titration mit HCl bestimmt.

\section{Potentialmessungen.}

Um nun erst die Komplextypen bei den Metallammoniakbydroxyden zu bestimmen wurden Konzentrationsketten der ammoniakalischen Lösungen von Kupfer-, Nickel-, Kadmium- und Zinkhydroxyden untersucht, nach der Methode, die BODLÄNDER ${ }^{2}$ bei der Untersuchung der Silberammoniaksalz-Lösungen eingeführt hat.

Die Potentialmessungen wurden nach dem üblichen Kompensationsverfahren von POGGENDORFF und DU BoIs-REYMOND ${ }^{3}$ gemacht.

Die Versuchsanordnung war die übliche. Als Nullinstrument diente ein nach Ostwalds $^{3}$ Angaben dargestelltes Lippuannsches

1 Ber. deutsch. chem. Ges. 36 (1903), 3400.

8 Festschrift zur Feier von Rrar. Dederind, Braunschweig 1901, S. 153; Zeitschr. phys. Chem. 39 (1901), 597; s. auch Z. anorg. Chem. 39 (1904), 197,

3 Ostwaln und Luthen, Physiko-chemische Messungen. 
Kapillarelektrometer mit vertikaler Kapillare. Die Stellung der Quecksilberoberfläche wurde mit einem Mikroskop beobachtet. Hinter dem Kapillarelektrometer war eine Lampe mit kleiner Flamme angebracht. Durch Anwendung eines genauen Frankeschen Kompensationsapparates konnte man sehr gut Millivolt direkt ablesen und zehntel Millivolt schätzen. Als Arbeitselement diente ein Akkumulator, welcher mit einem Normal-Westonelement geaicht wurde.

Die Potentiale wurden gegen eine Normalelektrode $\mathrm{HgHgCl}$ in $n$-KCl-Lösung gemessen.

Die Versuche wurden in einem Thermostaten bei $25^{\circ} \mathrm{C}$. ausgeführt.

\section{Versuche mit Konzentrationsketten von Kupfer- and Nickelhydroxyd in Ammoniak.}

Als Elektroden bei diesen Versuchen wurden sowohl Platinelektroden, welche elektrolytisch mit einem Kupfer- resp. Nickelüberzug belegt waren, als auch elektrolytisch überzogene Kupferresp. Nickelelektroden angewendet. Auch wurde versucht, die so dargestellten Elektroden zu amalgamieren. Es zeigte sich jedoch bald, dafs es unmöglich war, konstante und reproduzierbare Potentiale zu bekommen. Abgesehen davon, dals man mit zwei ähnlich gefertigten Elektroden ganz abweichende Werte erhielt, konnte man auch mit derselben Elektrode in einer bestimmten Lösung keine konstanten Werte bekommen. Meistens zeigte sich, dafs die Potentiale kontinuierlich mit der Zeit abnahmen.

Diese Inkonstanz der Potentiale beruht beim Kupferammoniakhydroxyd jedenfalls darauf, dafs Kupriammoniakhydroxyd sich zu Kuproammoniakhydroxyd reduziert, die Lösung also mit der Elektrode nicht im Gleichgewicht steht. Beim Nickel löst sich wahrscheinlich die Elektrode in überschüssigem Ammoniak, so dals die ursprüngliche Ionen-Konzentration der Lösung verändert wird. Damit stimmt überein, dafs man schon viel konstantere Potentiale erhält, wenn ammoniakalische Nickelhydroxydlösungen von einer relativ grofsen Metallkonzentration gemessen wèrden. Wie wir später sehen werden, ist es jedoch unmöglich, eine Nickelammoniaklösung darzustellen, in welcher nicht ein grofser Überschufs von Ammoniak vorhanden wäre. Aufserdem ist es auch für unsere Untersuchungen nötig bei konstanter Metallkonzentration die Ammoniakmengen variieren zu lassen, also mindestens in einigen Lösungen einen relativ grofsen Überschufs von $\mathrm{NH}_{3}$ zu brauchen. 


\section{Versuche mit Konzentrationsketten von Kadmiumhydroxyd in Ammoniak.}

Bei den Messungen wurden mit einem elektrolytisch dargestellten Kadmiumüberzug versehene Platinelektroden angewendet. Man erhält sehr schöne konstante Elektroden, wenn nur darauf geachtet wird, dafs die Elektroden mit schwachem Strom elektroplattiert werden. Konstante Elektroden bekommt man auch, wenn die so dargestellten amalgamiert werden. Die amalgamierten Elektroden geben ein höheres Potential als die unamalgamierten. Bei unseren Messungen, bei denen es sich um relative Potentialunterschiede handelt, war es natürlich nur wichtig immer gleich dargestellte Elektroden anzuwenden. Um eine Oxydation der Elektroden zu vermeiden, wurden sie vor jeder Messung eine Zeitlang mit Kadmium elektrolytisch überzogen.

Die Messungen mit variierenden Ammoniak-Konzentrationen und konstanter Kadmium-Konzentration sind in der Tabelle $1 \mathrm{zu}-$ sammengestellt.

Tabelle 1.

Konzentrationsketten von Kadmiumbydroxyd in Ammoniak bei gleichem Kadmium- und wechselndem Ammoniakgehalt.

\begin{tabular}{|c|c|c|c|c|c|c|c|c|}
\hline \multirow{2}{*}{$\begin{array}{l}\text { Ver- } \\
\text { such }\end{array}$} & \multirow{2}{*}{$\begin{array}{l}\text { Tempe- } \\
\text { ratur } \\
\text { in } 0\end{array}$} & \multirow{2}{*}{$\begin{array}{l}\text { Konzentrat. } \\
\text { des Kad- } \\
\text { miums äqn.* }\end{array}$} & \multicolumn{2}{|c|}{$\begin{array}{c}\text { Konzentrat. d. } \\
\text { Ammoniaks }\end{array}$} & \multicolumn{2}{|c|}{$\begin{array}{l}\text { Aktive Masse } \\
\text { des Ammoniaks }\end{array}$} & \multirow[t]{2}{*}{$E$ Volt } & \multirow[t]{2}{*}{$n / m$} \\
\hline & & & I & II & I & II & & \\
\hline 1 & 25 & 0.0167 & 6.454 & 3.227 & 9.72 & 4.01 & 0.0470 & 4.24 \\
\hline 2 & 25 & 0.00835 & 6.454 & 2 & 9.75 & 2.30 & 0.0780 & 4.21 \\
\hline 3 & 25 & 0.0167 & 5 & 3.227 & 6.95 & 4.01 & 0.0298 & 4.24 \\
\hline 4 & 25 & 0.0167 & 6.454 & 5 & 9.72 & 6.96 & 0.0172 & 4.02 \\
\hline 5 & 25 & 0.0167 & 6.454 & 4 & 9.72 & 5.22 & 0.0330 & 4.15 \\
\hline 6 & 25 & 0.0167 & 4 & 3.227 & 5.22 & 4.01 & 0.0140 & 4.09 \\
\hline 7 & 25 & 0.0167 & 5 & 4 & 6.95 & 5.22 & 0.0158 & 4.31 \\
\hline 8 & 25 & 0.00835 & 6.454 & 3 & 9.75 & 3.69 & 0.0525 & 4.22 \\
\hline 9 & 25 & 0.00835 & 3 & 2 & 3.69 & 2.30 & 0.0265 & 4.34 \\
\hline 10 & 25 & 0.0167 & 6.454 & 2 & 9.72 & 2.30 & 0.0740 & 4.06 \\
\hline
\end{tabular}

Wie man sicht, stimmen die erhaltenen Resultate sehr gut miteinander überein. Dem komplexen Kation kommt also die Formel $\mathrm{Cd}_{m}\left(\mathrm{NH}_{3}\right)_{n} \mathrm{zu}$, wo $n 4 \mathrm{mal}$ so grofs ist wie $m$.

Um den Wert von $m$ zu bestimmen, wurden weitere Versuche mit konstantem $\mathrm{NH}_{3}$-Gehalt und variierendem Metallgehalt gemacht. 
Obwohl man konstante Potentiale bekam, war bei der Berechnung der Messungen kein konstanter Wert für $m$ zu erhalten. Die Potentialunterschiede zwischen zwei Lösungen mit demselben Ammoniak und variierendem Metallgehalt sind zu klein, um die erhaltenen Werte zur Berechnung von $m$ sicher verwerten zu können. Manchmal bekam ich Werte, aus welchen $m$ sich zu 1 berechnen läfst. Nach den Messungen ist es also nicht sicher, ob dem komplexen Kation die Formel $\mathrm{Cd}\left(\mathrm{NH}_{3}\right)_{4}$ oder $\mathrm{Cd}_{2}\left(\mathrm{NH}_{3}\right)_{8}$ u. s. w. zukommt. Es liegt jedoch kein Grund vor, anzunehmen, dals die Formel nicht $\mathrm{Cd}\left(\mathrm{NH}_{3}\right)_{4}$ wäre.

Mittels Tensionsmessung von ammoniakilischen Kadmiumnitratlösungen hat KoNowaLOFF ${ }^{1}$ gefunden, dafs jedes A tom Kadmium wahrscheinlich vier Molekeln Ammoniak zur Komplexbildung aufnimmt. DAwson und $\mathrm{MC} \mathrm{C}_{\mathrm{RAE}}{ }^{2}$ sind wieder durch Bestimmungen von der Verteilung des $\mathrm{NH}_{3}$ zwischen ammoniakalischen Kadmiumjodidlösungen und Chloroform zu einem ähnlichen Resultat gekommen. Auch lärst sich aus den von $\mathrm{G}_{\mathrm{AUS}}{ }^{3}$ ausgeführten $\mathrm{NH}_{3}$-Partialdruckbestimmungen von ammoniakalischen Kadmiumsulfatlösungen für $\mathrm{NH}_{3}$ ein Wert berechnen, welcher nahe 4 ist. Danach würde also das komplexe Kadmiumammoniakhydroxyd ähnlich, wie die davon sich ableitenden komplexen Kadmiumammoniaksalze gebaut sein.

Nachdem meine Messungen ausgeführt waren, ist eine Arbeit von EULER ${ }^{4}$ erschienen, in welcher er durch Untersuchungen der Konzentrationsketten nach der BODLändeRschen Methode sowohl in Kadmiumammoniaksulfat wie in dem freien Hydroxyd für das komplexe Kation die Formel $\mathrm{Cd}_{m}\left(\mathrm{NH}_{3}\right)_{\mathbf{s}_{m}}$ findet.

Die von EuLER erhaltenen Werte stimmen also überein mit den meinigen.

Überführungs- und Potentialuntersuchungen von Zinkhydroxyd in Ammoniak.

Zinkhydroxyd ist wie bekannt ein amphoterer Elektrolyt, welcher unter Salzbildung sowohl in Säuren als in Basen sich löst. Auf Grund von Leitfähigkeitsmessungen und von Bestimmungen der Verseifungsgeschwindigkeit des Äthylacetats hat $\mathrm{HANTZSCH}^{5}$ zeigen können, dals Zinkhydroxyd eine sehr schwache Säure ist, die auch bei einem

\footnotetext{
'Journ. russ. phys.-chem. Ges. 31 (1819), 910; Chem. Centrbl. 1900 I, 646.

2 Journ. Chem. Soe. 77 (1900), 1239.

${ }^{3} Z$. anorg. Ohem. 25 (1900), 236; s. auch LockE.

4 Ber. deutsch. chem. Oes. 36 (1903), 3400.

${ }^{5} Z$. anarg. Chem. 30 (1902), 289.
} 
Überschufs von Alkali nur sehr geringe Mengen Zinkat bildet und wahrscheinlich vorwiegend kolloidal gelöst ist. Daís in einer Alkalilösung von Zinkhydroxyd nur geringe Mengen von Zinkat vorhanden sind, hat auch $\mathrm{HERz}^{1}$ durch Dialysatorversuche bewiesen.

Wenn also Zinkhydroxyd mit so starken Basen wie KOH und $\mathrm{NaOH}$ kaum ein Zinkat bildet, war zu erwarten, dafs es auch nicht mehr imstande wäre, mit Ammoniak ein Zinkat zu bilden. Da, soviel mir bekannt, keine direkten Versuche darüber in der literatur zu finden waren, habe ich einige Überführungsversuche mit Zinkammoniaklösungen ausgefübrt.

Der Apparat dazu war ganz einfach, wie die nebenstehende Fig. 1 zeigt. Der eine Schenkel $a$ wurde mit Zinkammoniaklösung bis zum Glashahn $c$ gefüllt. Der andere Schenkel $b$ samt der sehr weiten Durchbohrung des Hahns war mit einer Ammoniaklösung von entsprechendem Gehalt gefüllt. Wenn man sich überzeugt hatte, dals die Oberfläche in beiden Röhren genau auf demselben Niveau stand, wurde der Hahn e geöffnet und ein Strom mit 120 Volt durch die Lösung geschickt. War nun die in dem rechten Schenkel befindliche Elektrode Kathode, so zeigte es sich, wenn nach einigen

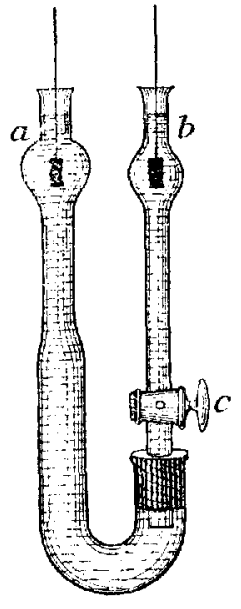

Fig. 1. Stunden derGlashahn zugeschlossen und derStrom unterbrochen wurde, dals hier eine beträchtliche Menge von Zink nachzuweisen war. Um sicher zu sein, dafs keine Diffusion in der Richtung der Kathode während des Versuches stattgefunden hatte, wurde noch ein zweiter Versuch gemacht, bei dem die Flüssigkeitsoberfläche in dem rechten Schenkel absichtlich etwas böher als in dem linken war. Das Resultat war dasselbe.

Der Gegenversuch, bei dem der Strom in entgegengesetzter Richtung geschickt wurde, zeigte, dafs nach der Anode keine Spur Zink gewandert war. Nachdem nun bewiesen war, dafs ein Zinkat in melsbarer Menge nicht vorliegt, wurden die Potentialmessungen ausgeführt.

Bei den Zinkammoniakmessungen war es sehr schwer, konstante Elektroden zu bekommen. Es wurde versucht Platinelektroden in gewöhnlicher Weise elektrolytisch mit Zink zu überziehen, aber die so gewonnenen Elektroden gaben keine konstanten Werte. Durch

${ }^{1}$ Z. anorg. Chem. 31 (1902), 454. 
schwaches Amalgamieren der Elektroden konnte ich ebenfalls keine konstanten Werte erhalten. Es gelang mir jedoch auf einem anderen Wege, brauchbare Elektroden darzustellen. Die Platinelektroden wurden in einer verdünnten, einen Tropfen reinen Quecksilbers enthaltenden Zinkcyankaliumlösung bei schwachem Strom mit Zink überzogen. Die Lösung wurde bei der Elektrolyse bis ungefähr $60^{\circ}$ erwärmt. Wahrscheinlich wurde hier durch die kleine Löslichkeit des Quecksilbers eine schwache Amalgamierung der Elektroden herbeigeführt.

Die brauchbaren Elektroden waren also nur unter ganz bestimmten Verhältnissen zu erhalten. Besonders ist zu bemerken, dafs nicht zu lange elektrolysiert werden darf. Doch konnte ich niemals mit zwei auf ganz ähnliche Weise dargestellten Elektroden dieselben Potentiale in ein und derselben Lösung bekommen, obwohl die beiden Elektroden für sich konstante und reproduzierbare Potentiale gaben. Es war deshalb nötig, die verschiedenen Lösungen mit ein und derselben Elektrode zu messen. Um zu kontrollieren, ob die Elektrode bei dem Versuche unverändert geblieben war, wurde die zuerst gemessene, schon eine Zeitlang konstant gebliebene Lösung wieder mit derselben Elektrode gemessen, wobei derselbe Wert herauskam.

Die auf diese Weise ausgeführten Potentialmessungen von Zinkhydroxydammoniaklösungen sind in der Tabelle 2 angegeben.

\section{Tabelle 2.}

Konzentrationsketten ron Zinkhydroxyd in Ammoniak bei gleichem Zink- und wechselndem Ammoniakgehalt.

\begin{tabular}{c|c|c|c|c|c|c|c|c}
\hline $\begin{array}{c}\text { Ver- } \\
\text { such }\end{array}$ & $\begin{array}{c}\text { Tempe- } \\
\text { ratur } \\
\text { in }\end{array}$ & $\begin{array}{c}\text { Konzentrat. } \\
\text { des Zinks } \\
\text { äqn. }\end{array}$ & \multicolumn{2}{|c|}{$\begin{array}{c}\text { Konzentrat. d. } \\
\text { Ammoniaks }\end{array}$} & \multicolumn{2}{|c|}{$\begin{array}{c}\text { Aktive Masse } \\
\text { des Ammoniaks }\end{array}$} & $E$ Volt & $n / m$ \\
\hline & & I & II & I & II & & \\
1 & 25 & 0.0330 & 4 & 2 & 5.20 & 2.26 & 0.0335 & 3.13 \\
2 & 25 & 0.0330 & 6 & 2 & 8.78 & 2.26 & 0.0547 & 3.14 \\
3 & 25 & 0.0330 & 6 & 4 & 8.78 & 5.20 & 0.0212 & 3.16 \\
4 & 25 & 0.0165 & 4 & 2 & 5.24 & 2.29 & 0.0320 & 3.01 \\
5 & 25 & 0.0165 & 6 & 2 & 8.81 & 2.29 & 0.0520 & 3.33 \\
6 & 25 & 0.0165 & 6 & 4 & 8.81 & 5.24 & 0.0200 & 2.99 \\
7 & 25 & 0.0648 & 4 & 2 & 5.12 & 2.19 & 0.0330 & 3.03 \\
8 & 25 & 0.0648 & 6 & 4 & 8.69 & 5.12 & 0.0205 & 3.03 \\
9 & 25 & 0.0643 & 4 & 2 & 8.69 & 2.19 & 0.0535 & 3.03
\end{tabular}


Wie man sieht, stimmen die aus den verschiedenen Messungen berechneten Werte ausgezeichnet miteinander überein. Nach diesen Messungen hat das komplexe Kation also die Formel $\mathrm{Zn}_{m}\left(\mathrm{NH}_{3}\right)_{3 m}$.

Damit ist natürlich nicht entschieden, ob dem Kation die Formel $\mathrm{Zn}\left(\mathrm{NH}_{3}\right)_{3}$ oder $\mathrm{Zn}_{2}\left(\mathrm{NH}_{3}\right)_{6}$ u. s. w. zukommt. Erst die Messungen mit konstantem Ammoniak- und wechselndem Zinkgehalt könnten hierüber Aufschlufs geben. Leider haben wir jedoch, ebensowenig wie beim Kadmium, konstante Werte für $m$ aus den beobachteten Potentialunterschieden bekommen, so dals die Frage auch hier noch offen bleibt. Es liegt jedoch kein Grund vor, anzunehmen, dals die Formel des Kations nicht $\mathrm{Zn}\left(\mathrm{NH}_{3}\right)_{3}$ wäre.

In der bereits erwähnten Arbeit von KonowaLOFF ${ }^{1}$ bat der Verfasser durch Untersuchungen über die Tension der ammoniakalischen Zinknitratlösungen gefunden, dals jedes Atom Zink wahrscheinlich vier Molekeln $\mathrm{NH}_{3}$ zum komplexen Kation bindet. Dasselbe Resultat für ammoniakalische Zinksulfatlösungen haben auch die Untersuchungen von Dawson und Mc CRAE ${ }^{1}$ gegeben. Und aus Dampfdruckbestimmungen der ammoniakalischen Zinksulfatlösungen von GADS ${ }^{1}$ lälst sich für das pro Atom Zink gebundenen $\mathrm{NH}_{3}$ ein Wert, welcher ¿wischen drei und vier ist, berechnen. Es war deshalb auffällig, dafs, obwohl in den Zinkammoniaksalzen das komplexe Kation wahrscheinlich die Formel $\mathrm{Zn}\left(\mathrm{NH}_{3}\right)_{4}$ hat, in dem freien Hydroxyd nur $3 \mathrm{NH}_{3}$ an $1 \mathrm{Zn}$ gebunden sein sollten.

In der früher erwähnten Abhandlung von EuLER ${ }^{1}$ hat der Verfasser Konzentrationsketten von Zinkammoniaksulfat- resp. -hydroxyd

\section{Tabelle 3.}

Konzentrationsketten von Zinkhydroxyd in Ammoniak bei gleichem Zink- und wechselndem Ammoniakgehalt.

\begin{tabular}{l|c|c|c|c|c|c|c|c}
\hline $\begin{array}{l}\text { Ver- } \\
\text { such }\end{array}$ & $\begin{array}{c}\text { Tempe- } \\
\text { ratur } \\
\text { in }\end{array}$ & $\begin{array}{c}\text { Konzentrat. } \\
\text { des Zinks } \\
\text { äqn. }\end{array}$ & \multicolumn{2}{|c|}{$\begin{array}{c}\text { Konzentrat. d. } \\
\text { Ammoniaks }\end{array}$} & \multicolumn{2}{|c|}{$\begin{array}{c}\text { Aktive Masse } \\
\text { des Ammoniaks }\end{array}$} & $E$ Volt & $n / m$ \\
& & & II & I & II & & \\
\hline & & & & & & & & \\
10 & 25 & 0.05 & 3 & 1.5 & 3.53 & 1.59 & 0.0340 & 3.32 \\
11 & 25 & 0.05 & 5 & 1.5 & 6.86 & 1.59 & 0.0550 & 2.93 \\
13 & 25 & 0.25 & 2.5 & 1.5 & 2.94 & 1.63 & 0.0238 & 3.14 \\
13 & 25 & 0.25 & 6 & 2.5 & 8.80 & 2.94 & 0.0446 & 3.18 \\
14 & 25 & 0.25 & 6 & 1.5 & 8.80 & 1.63 & 0.0684 & 3.17
\end{tabular}

1 1. c.

2. anorg. Chem. Bd. 41 . 
nach demselben Schema wie bei Kadmium hergestellt und gelangt zu dem Schlufs, dafs sowohl in Zinkammoniaksulfat als in Zinkammoniakhydroxyd das komplexe Kation die Formel $\mathrm{Zn}_{m}\left(\mathrm{NH}_{3}\right)_{4 m}$ hat.

Ich habe deshalb meine Versuche mit neuen Lösungen und Elektroden ganz unabhängig von den früheren wiederholt, finde aber wieder für $n / m$ denselben Wert wie früher, wie die vorstehende Tabelle 3 zeigt.

\section{Leitfähigkeitsmessungen.}

Um einen Aufschlufs über den Dissoziationsgrad der komplexen Kupfer-, Nickel-, Kadmium-, Zink- und Silberammoniakbasen zu bekommen, wurden Leitfähigkeitsmessungen von den ammoniakalischen Hydroxydlösungen der genannten Metalle ausgeführt. Des Vergleiches wegen habe ich ähnliche Messungen auch von ammoniakalischen Baryumhydroxyd- und Kupfersulfatlösungen gemacht.

Die Leitfähigkeiten wurden nach der üblichen KoHLRAdschschen Wechselstrom-Methode gemessen. Die zur Untersuchung kommenden Lösungen wurden in Stöpselflaschen gebracht und wenn die Flascheninhalte die Temperatur des Bades angenommen hatten, konnten die Messungen begimen. So war es möglich, die Leitfähigkeitsmessungen rasch durchzuführen. Dies war auch sehr wichtig, weil trotz zugeschlossener Elektrodengefäfse besonders die konzentrierteren Lösungen Kohlensäure aus der Luft anziehen konnten und von den stärkeren Ammoniaklösungen vielleicht während der Versuche etwas $\mathrm{NH}_{3}$ entwich, was jedoch in Anbetracht der kleinen Leitfähigkeit des $\mathrm{NH}_{3}$ nur einen sehr geringen Einfluls haben konnte. Jeder einzelne Leitfähigkeitswert ist ein Mittelwert dreier Messungen. Gewöhnlich habe ich erst eine Messung gemacht und dann, als die erforderlichen Widerstände bekannt waren, eine neue Portion der Lösung gemessen. Die Leitfähigkeit des kohlensäurefreien reinen Wassers betrug 2 bis $3 \cdot 10^{-6}$. Dieser Wert wurde nicht von den beobachteten Leitfähigkeiten der Lösungen abgezogen.

Die Messungen wurden bei $18^{\circ}$ ausgeführt.

\section{Leitfähigkeitsmessungen von Kupferhydroxyd in Ammoniak.}

Da ich zuerst mit Kupferammoniaklösungen gearbeitet habe, sollen die Leitfähigkeiten derselben hier an erster Stelle angegeben werden.

Um nun zu konstatieren, in welcher Richtung die Leitfähigkeiten der Lösungen gehen, wurde das Leitvermögen von Lösungen 
sowohl mit konstantem $\mathrm{NH}_{3}-$, als mit konstantem Kupfergehalt ausgeführt. geben.

In folgenden Tabellen sind die so erhaltenen Zahlen ange-

Leitfähigkeitsmessungen von Kupferoxyd resp. -hydroxyd in Ammoniak bei konstantem $\mathrm{NH}_{3}$-Gehalt.

Tabelle 4.

\begin{tabular}{c|c|c|c}
\hline $\begin{array}{c}\mathrm{CuO} \\
\ddot{a ̈ q n} .\end{array}$ & $\begin{array}{c}\mathrm{NH}_{3} \\
\text { norm. }\end{array}$ & $\begin{array}{c}\text { Leitfähigkeit von } \\
\mathrm{NH}_{3} 10^{4} \cdot x\end{array}$ & $\begin{array}{c}\text { Leitfähigkeit von } \\
\mathrm{CuO}+\mathrm{NH}_{3} 1^{4} \cdot x\end{array}$ \\
\hline 0.0445 & 8 & 7.6 & 38.4 \\
0.0223 & 8 & 7.6 & 23.7 \\
0.0148 & 8 & 7.6 & 18.5 \\
0.0111 & 8 & 7.6 & 15.3 \\
0.0056 & 8 & 7.6 & 11.1 \\
0.0028 & 8 & 7.6 & 9.1
\end{tabular}

Tabelle 5 .

\begin{tabular}{c|c|c|c}
\hline $\begin{array}{c}\mathrm{Cu}(\mathrm{OH})_{2} \\
\text { äqu. }\end{array}$ & $\begin{array}{c}\mathrm{NH}_{3} \\
\text { norm. }\end{array}$ & $\begin{array}{c}\text { Leitfähigkeit von } \\
\mathrm{NH}_{\mathbf{3}} 10^{4} \cdot x\end{array}$ & $\begin{array}{c}\text { Leitfähigkeit von } \\
\mathrm{Cu}(\mathrm{OH})_{2}+\mathrm{NH}_{2} \mathbf{1 0}^{4} \cdot x\end{array}$ \\
\hline & 8 & 7.6 & 48.6 \\
0.0639 & 8 & 7.6 & 30.3 \\
0.0312 & 8 & 7.6 & 23.1 \\
0.0213 & 8 & 7.6 & 19.0 \\
0.0160 & 8 & 7.6 & 13.0 \\
0.0799 & 8 & 7.6 & 10.1 \\
0.0040 & & &
\end{tabular}

Tabelle 6.

\begin{tabular}{c|c|c|c}
\hline $\begin{array}{c}\mathrm{Cu}(\mathrm{OH})_{2} \\
\text { äqn. }\end{array}$ & $\begin{array}{c}\mathrm{NH}_{\mathrm{s}} \\
\text { norm. }\end{array}$ & $\begin{array}{c}\text { Leitfähigkeit von } \\
\mathrm{NH}_{3} \mathbf{1 0}^{4} \cdot \boldsymbol{x}\end{array}$ & $\begin{array}{c}\text { Leitfähigkeit von } \\
\mathrm{Cu}(\mathrm{OH})_{2}+\mathrm{NH}_{3} 1^{4} \cdot x\end{array}$ \\
\hline 0.0400 & 4 & 10.8 & 40.8 \\
0.0307 & 4 & 10.8 & 34.5 \\
0.0154 & 4 & 10.8 & 23.2 \\
0.0102 & 4 & 10.8 & 18.9 \\
0.0077 & 4 & 10.8 & 16.7 \\
0.0038 & 4 & 10.8 & 13.8 \\
0.0019 & 4 & 10.8 & 123 \\
& & & $10^{*}$
\end{tabular}


Tabelle 7.

\begin{tabular}{c|c|c|c}
\hline $\begin{array}{c}\mathrm{Cu}(\mathrm{OH})_{2} \\
\ddot{a q n} .\end{array}$ & $\begin{array}{c}\mathrm{NH}_{3} \\
\text { norm. }\end{array}$ & $\begin{array}{c}\text { Leitfähigkeit von } \\
\mathrm{NH}_{8} 10^{4} \cdot x\end{array}$ & $\begin{array}{c}\text { Leitfähigkeit von } \\
\mathrm{Cu}(\mathrm{OH})_{2}+\mathrm{NH}_{3} 10^{4} \cdot x\end{array}$ \\
\hdashline & 2.5 & 10.9 & 70.6 \\
0.1077 & 2.5 & 10.9 & 56.9 \\
0.0776 & 2.5 & 10.9 & 36.9 \\
0.0388 & 2.5 & 10.9 & 24.9 \\
0.0194 & 2.5 & 10.9 & 17.8 \\
0.0097 & 2.5 & 10.9 & 14.5 \\
0.0049 & & &
\end{tabular}

Tabelle 8.

\begin{tabular}{c|c|c|c}
\hline $\begin{array}{c}\mathrm{Cu}(\mathrm{OH})_{2} \\
\mathrm{aqu}\end{array}$ & $\begin{array}{c}\mathrm{NH}_{3} \\
\text { norm. }\end{array}$ & $\begin{array}{c}\text { Leitfähigkeit von } \\
\mathrm{NH}_{3} 10^{4} \cdot x\end{array}$ & $\begin{array}{c}\text { Leitfähigkeit von } \\
\mathrm{Cu}(\mathrm{OH})_{2}+\mathrm{NH}_{3} 1^{4} \cdot x\end{array}$ \\
\hline & & 9.7 & $\mathbf{3 2 . 9}$ \\
0.0299 & 5.2 & 9.7 & 21.0 \\
0.0150 & 5.2 & 9.7 & 15.5 \\
0.0075 & 5.2 & 9.7 & 13.5 \\
0.0037 & 5.2 & 9.7 & 11.2
\end{tabular}

Tabelle 9.

\begin{tabular}{c|c|c|c}
\hline $\begin{array}{c}\mathrm{Cu}(\mathrm{OH})_{2} \\
\ddot{a} q \mathrm{n} .\end{array}$ & $\begin{array}{c}\mathrm{NH}_{3} \\
\text { norm. }\end{array}$ & $\begin{array}{c}\text { Leitfähigkeit von } \\
\mathrm{NH}_{8} 10^{4} \cdot x\end{array}$ & $\begin{array}{c}\text { Leitfähigkeit von } \\
\mathrm{Cu}(\mathrm{OH})_{2}+\mathrm{NH}_{\mathrm{a}} 1^{*} \cdot x\end{array}$ \\
\hline & & 8.4 & 38.5 \\
0.0410 & 6.7 & 8.4 & 24.6 \\
0.0205 & 6.7 & 8.4 & 19.4 \\
0.0137 & 6.7 & 8.4 & 16.4 \\
0.0103 & 6.7 & 8.4 & 12.8
\end{tabular}

Die Lösungen sind alle durch Lösen von $\mathrm{Cu}(\mathrm{OH})_{2}$ in Ammoniak bereitet, ausgenommen die in der Tabelle 4, welche zur Kontrolle durch Lösen von $\mathrm{CuO}$ in $\mathrm{NH}_{3}$ dargestellt wurden.

(S. Tabelle 10, S. 149.)

Um den Gang der Leitfähigkeiten ersichtlich zu machen, habe ich auf Grund der erhaltenen Zahlen Kurven gezeichnet sowohl für Lösungen mit konstantem $\mathrm{NH}_{3}$ - wie für solche mit konstantem Metall-Gehalt. Im ersten Falle (Fig. 2) sind die Metall-Konzen- 
Tabelle 10.

Leitfähigkeiten von Kupferhydroxyd in Ammoniak bei variablen Gehalt beider Komponenten.

\begin{tabular}{|c|c|c|c|c|c|c|}
\hline \multirow[b]{2}{*}{$\begin{array}{r}\mathrm{NH}_{3} \\
\text { norm. }\end{array}$} & \multicolumn{6}{|c|}{ Leitfähigkeiten $10^{4} \cdot x$} \\
\hline & $\begin{array}{c}\mathrm{Cu}(\mathrm{OH})_{2} \\
\text { äqn. }= \\
0\end{array}$ & $\begin{array}{c}\mathrm{Cu}(\mathrm{OH})_{2} \\
\text { äqn. }= \\
0.005\end{array}$ & $\begin{array}{c}\mathrm{Cu}(\mathrm{OH})_{2} \\
\ddot{a q n} .= \\
0.01\end{array}$ & $\begin{array}{c}\mathrm{Cu}(\mathrm{OH})_{2} \\
\text { äqn. }= \\
0.02\end{array}$ & $\begin{array}{c}\mathrm{Cu}(\mathrm{OH})_{2} \\
\text { äqn. }= \\
0.03\end{array}$ & $\begin{array}{c}\mathrm{Cu}(\mathrm{OH})_{2} \\
\text { äqn. }= \\
0.04\end{array}$ \\
\hline 0.25 & 5.1 & 6.8 & 8.2 & - & - & - \\
\hline 0.5 & 6.8 & 9.0 & 11.5 & 16.0 & 19.1 & - \\
\hline 0.75 & 8.0 & 10.4 & 13.4 & 18.5 & 22.4 & $\begin{array}{c}25.2 \\
\left(\mathrm{NH}_{3}=\right. \\
0.7 \mathrm{n})\end{array}$ \\
\hline 1 & 8.9 & 11.7 & 14.8 & 20.5 & 25.2 & 29.2 \\
\hline 1.5 & 9.9 & 13.5 & 16.6 & 23.5 & 28.6 & 34.0 \\
\hline$\simeq$ & 10.6 & 14.6 & 17.7 & 25.0 & 31.0 & 36.8 \\
\hline 2.5 & 10.9 & 15.0 & 18.3 & 26.0 & 32.5 & 38.5 \\
\hline 3 & 10.9 & 15.2 & 18.7 & 26.6 & 33.5 & 39.8 \\
\hline 3.5 & 10.8 & 15.2 & 18.7 & 26.8 & - & 40.5 \\
\hline 4 & 10.8 & 15.0 & 18.5 & 26.7 & 34.1 & 40.7 \\
\hline 5 & 10.1 & - & 17.9 & 26.0 & 33.1 & 40.2 \\
\hline 6 & 9.1 & 13.5 & 16.9 & 25.2 & - & - \\
\hline 7 & 8.1 & 12.4 & - & 24.0 & 33.7 & 37.3 \\
\hline 8 & 7.6 & - & 14.2 & 22.4 & 28.8 & - \\
\hline 10 & 5.4 & 8.8 & 12.0 & 19.4 & 25.0 & 31.0 \\
\hline
\end{tabular}

trationen, im zweiten (Fig 3) die $\mathrm{NH}_{3}$-Konzentrationen als Abszissen aufgetragen.

Aus diesen Kurven ist sofort $\mathrm{zu}$ sehen, welchen bedeutenden Einflufs die Ammoniak-Konzentration auf die Leitfähigkeitswerte ausübt. Die Leitfähigkeitszahlen von Lösungen mit denselben Kupferund verschiedenen Ammoniakkonzentrationen sind nicht dieselben, vielmehr zeigt die Kurve 4 norm. $\mathrm{NH}_{3}$ die grölste Leitfähigkeit, während die Leitfähigkeitskurven für kleineren wie für gröfseren $\mathrm{NH}_{3}$-Gehalt niedriger laufen.

Ein sehr klares Bild über den Gang der Leitfäligkeiten bei wachsendem $\mathrm{NH}_{3}$-Gehalt gibt Fig. 3 .

Betrachten wir nun zuerst die Leitfähigkeitskurve des reinen $\mathrm{NH}_{3}$.

Wie schon KoHLRauscr ${ }^{1}$ gefunden hat, steigt die Leitfähigkeit des Ammoniaks anfangs, bis die Lösung ungefähr 3 normal ist. Hier ist das Maximum erreicht, und mit zunehmendem $\mathrm{NH}_{3}$-Gehalt sinkt die Leitfähigkeit allmählich. Die Abnahme der Leitfähigkeit scheint durch die Anreicherung der Lösung an Nichtelektrolyt und

${ }^{1}$ Kohlrausch und Holborn, Leitvermögen der Elektrolyte, S. 160 


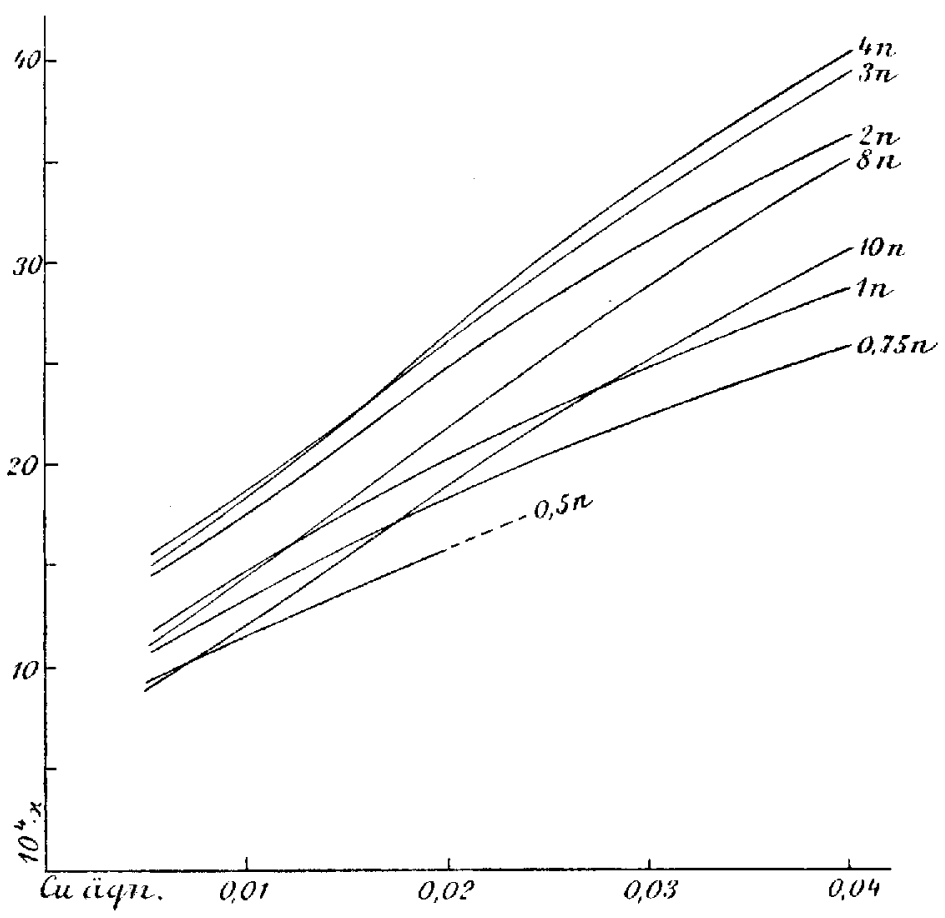

Fig. 2.

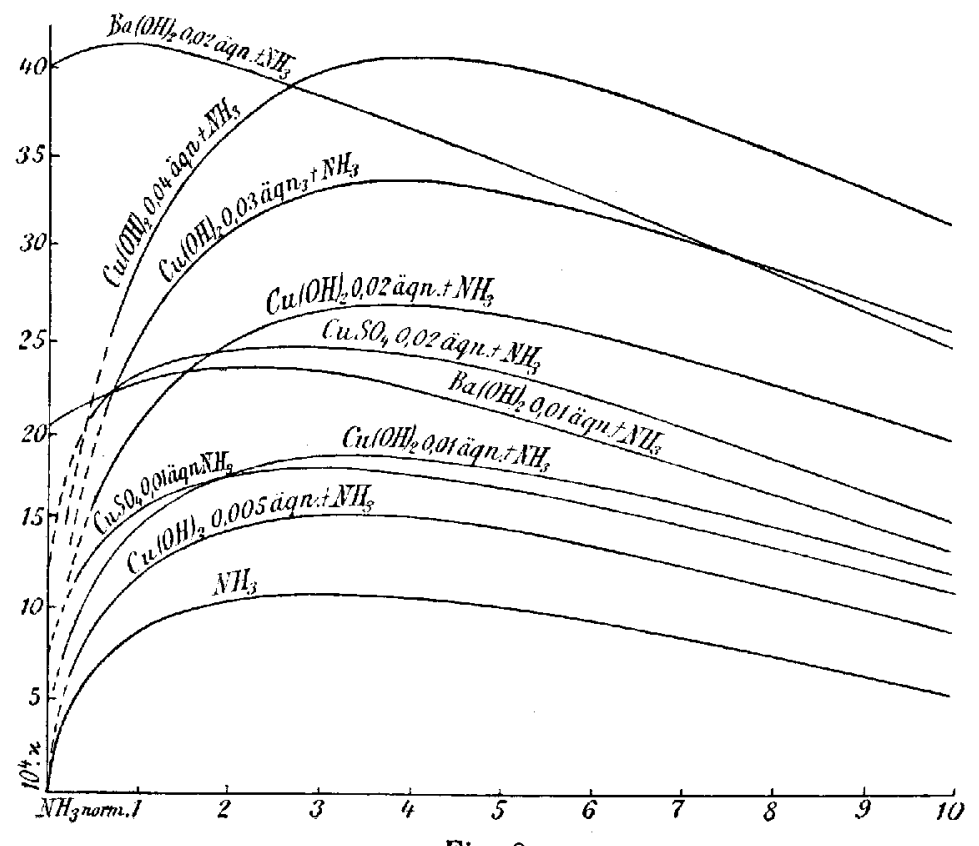

Fig. 3. 
die daraus folgende Verminderung der Wanderungsgeschwindigkeit der Ionen bedingt zu sein. Der Punkt der maximalen Leitfähigkeit bei Ammoniak wäre also nach Gonoschmmot ${ }^{1}$ so zu erklären, dals bis dahin das begünstigende Moment der absoluten Zunahme der Ionen-Konzentration dem hemmenden Moment einer Abnahme der Wanderungsgeschwindigkeit entgegenwirkt; von da ab aber mit weiterem Zurückgehen der Dissoziation das letztere überwiegt.

Wenn wir nun die Kupferammoniak-Kurven mit der Leitfähigkeitskurve von reinem $\mathrm{NH}_{3}$ (Fig. 3) vergleichen, so bemerken wir, dafs alle diese Kurven mit verschiedenen Kupferkonzentrationen ein Maximum der Leitfähigkeit zeigen, und zwur ist dieses Maximum ungefähr in demselben Punkte, wie bei reinem $\mathrm{NH}_{3}$. Doch ist leicht zu sehen, dafs das Maximum der Leitfähigkeit, ein wenig nach rechts verschoben wird und zwar desto mehr, je gröfser die Kupferkonzentration ist.

Weil nun die Kupferammoniak-Kurven ähnlich wie die Kurve von reinem $\mathrm{NH}_{3}$ verlaufen, besonders aber, da die Punkte der maximalen Leitfähigkeit ungefähr bei derselben $\mathrm{NH}_{3}$-Konzentration liegen, lag es nahe, anzunehmen, dafs die Leitfähigkeitswerte in einem bestimmten Punkte sich aus den Leitfähigkeiten der beiden Komponenten, des Ammoniaks und des gebildeten komplexen Kupferammoniakhydroxyds addieren. Wenn es jedoch so wäre, müfste bei allen $\mathrm{NH}_{3}$-Konzentrationen derselbe Wert herauskommen, wenn man von den Leitfähigkeitswerten der Lösungen die des ungebundenen reinen $\mathrm{NH}_{3}$ abzieht.

Das ist jedoch nicht der Fall, was auch ganz leicht zu ersehen ist. Denn in der Lösung haben wir wenigstens zwei Komponenten, nämlich: Kupferammoniakhydroxyd und Ammoniak, welche aufeinander einen beträchtlichen Einflul's ausüben. Die in der Lösung befindlichen Basen enthalten alle ein gemeinsames Ion, nämlich das Hydroxylion. Sicher ist deshalb, dals die OH-Ionen der schwächeren Base durch die OH-Ionen der stärkeren Base zurückgedrängt werden und zwar umsomehr, in je gröfserer Konzentration die letztgenannte Base vorhanden ist. Wenn die stärkere Base in sehr kleinen Konzentrationen vorhanden ist, von denen sehr wenig $\mathrm{OH}$-Ionen in der Lösung erzeugt werden, kann der umgekehrte Fall eintreten, so dals die kleine Menge der OH-Ionen der stärkeren Base durch die OH-Ionen der schwächeren Base zurückgedrängt wird. Das Zurück-

${ }^{1}$ Z. anorg. Chem. 28 (1901), 97. 
gehen der Hydroxylionen-Konzentration ist also die erste Störung, welche in erheblichem Malse die Lösung unseres Problems erschwert.

Aber aufserdem wird, wie viele Verfasser, besonders ARrhentus, gezeigt haben, in einer Lösung irgend eines Elektrolyten die innere Reibung durch Zusatz von schlechten Elektrolyten erheblich vergrölsert. Ebenso wird die Beweglichkeit der Ionen herabgesetzt, weshalb die Leitfähigkeitszahlen einer solchen Lösung keinen exakten Mafsstab mehr für den wirklichen Dissoziationszustand der Lösung geben. Sicherlich wird auch deshalb die Leitfähigkeit der Kupferammoniak-Lösung durch die vom Ammoniak bedingte Vergrölserung der inneren Reibung herabgesetzt.

Die Leitfähigkeitszahlen, welche wir für eine Kupferhydroxydlösung in Ammoniak bekommen, repräsentieren also in keinem Falle eine Summe der Leitfähigkeiten der reinen komplexen Kupferammoniakbasen und des reinen Ammoniaks. Sicher ist, dals die erbaltenen Zahlen immer kleiner sind, als die Summe aus den Leitfähigkeiten der reinen Komponenten. Ja, sie können sogar kleiner ausfallen, als die Leitfähigkeit der stärkeren Komponenten allein.

Es besteht also die Frage, ob wir die störenden Einflüsse irgendwie eliminieren and die wirkliche Leitfähigkeit der Kupferammoniakbase bestimmen können, wodurch die letztere definiert wäre. Mit den Hilfsmitteln, welche wir bisher besitzen, ist es wahrscheinlich unmöglich, diese Frage zu beantworten. Denn zu den zwei störenden Faktoren, welche wir eben erwähnt haben, kommt noch ein dritter hinzu, welcher die Sache noch komplizierter macht, indem die Leitfähigkeitsversuche andeuten, dafs wir in der Lösung nicht allein zwei, sondern mehrere Komponenten vor uns haben.

Betrachten wir nämlich die Leitfähigkeitskurven mit konstantem Kupfer- und zunehmendem Ammoniakgehalt (Fig. 3), so bemerken wir, dals sie bis 3-4 normal $\mathrm{NH}_{3}$ erheblich wachsen. Man könnte vielleicht vermuten, dals diese Erhöhung durch die zunehmende Konzentration der Hydroxylionen des $\mathrm{NH}_{3}$ bedingt wäre. So ist das Verhalten jedoch nicht zu erklären. Denn wenn wirklich dasselbe Kupferammoniakhydroxyd bei allen $\mathrm{NH}_{3}$-Konzentrationen in der Lösung vorhanden wäre, sollte man, wenn man von den Leitfähigkeitszahlen der Lösungen die des Ammoniaks abzieht, bei wachsendem $\mathrm{NH}_{3}$-Gehalt wegen der wachsenden Reibung abnehmende $x$-Werte erwarten. Wenn wir dies aber tun und diese $x$-Kurven 
zeichnen, sieht man, dafs sie bis zu einer Konzentration von 3 norm. $\mathrm{NH}_{3}$ erheblich steigen.

Wir können deshalb den Verlauf der Kurven kaum anders erklären als dadurch, dafs bei kleineren $\mathrm{NH}_{3}$-Konzentrationen eine resp. mehrere Kupferammoniakbasen in der Lösung vorhanden sind, welche schwächer sind, als die bei grölseren $\mathrm{NH}_{3}$-Konzentrationen vorherrschende Kupferammoniakbase.

Folgen wir nämlich unseren Kurren weiter, so bemerken wir, dals sie ron $3-4$ norm. $\mathrm{NH}_{3}$ ab immer sinken. Um das zu erklären, brauchen wir mehrere Kupferammoniakhydroxyde bei den grölseren $\mathrm{NH}_{3}$-Konzentrationen nicht anzunehmen. Denn wenn auch nur zwei Hydroxyde nämlich ein Kupferammoniakhydroxyd und Ammoniak hiẹr vorhanden sind, ist der Verlauf der Kurven ganz normal. Bei so grolsen $\mathrm{NH}_{3}$-Konzentrationen wird durch die Vergrölserung der inneren Reibung die Leitfähigkeit kontinuierlich vermindert. Es ist deshalb sehr wahrscheinlich, dals bei grölserem $\mathrm{NH}_{3}$ Überschufs zum grölsten Teil nur eine und zwar eine stärkere Kupferammoniakbase vorhanden ist.

Es ist auch anzunehmen, dafs die bei den grölseren $\mathrm{NH}_{3}$-Konzentrationen vorherrschende Kupferammoniakbase mehr $\mathrm{NH}_{3}$ in dem komplexen Kation, als die bei kleineren $\mathrm{NH}_{3}$ - Konzentrationen existierenden schwächeren Basen enthält. Nach dem Massenwirkungsgesetz scheint es nämlich notwendig, dals bei grolsem Überschufs von $\mathrm{NH}_{3}$ eine $\mathrm{NH}_{3}$-reichere aus einer $\mathrm{NH}_{3}$-ärmeren Base gebildet wird. Dafs die $\mathrm{NH}_{3}$-reichere Base stärker ist, steht auch mit anderen Erfahrungen ${ }^{1}$ im Einklang.

Ich hatte gehofft, der Lösung des Problems mit Hilfe der ARrhenrusschen Theorie der isohydrischen Lösungen ${ }^{2}$ näher zu kommen. Wenn wir nämlich zwei oder mehrere Elektrolyte mit einem gemeinsamen Ion in solchem Verhältnis in Wasser gelöst haben, dal's die Konzentrationen des gemeinsamen Ions bei allen gelösten Elektrolyten dieselben sind, ist die Leitfähigkeit des Gemisches, wenn keine anderen Beeinflussungen rorhanden sind, ebensogrols, wie die Summe aus den Leitfähigkeiten der einzelnen Komponenten.

Wenn wir also in unseren Lösungen nur zwei Basen hätten, nämlich ein bestimmtes Kupferammoniakhydroxyd und Ammoniak,

1 Vergl. F. Augraach, Z. anorg. Chem. 37 (1903), 353. Der Verfasser hat bewiesen, dars die Polyborsäure bedeutend stärker als die Borsäure ist.

2 Zeitschr. phys. Chem. 2 (1888), 284 
so sollten wir, vorausgesetzt, dals wir genügend kleine Kupferkonzentrationen nehmen, bei einem gewissen $\mathrm{NH}_{3}$-Gehalt zu isohydrischen Punkten kommen, also zu einem Punkt, wo die OH-Ionenkonzentration der Kupferammoniakbase ebensogrols wäre wie die $\mathrm{OH}$-Ionenkonzentration des $\mathrm{NH}_{3}$. Aber in diesem Falle sollten, wenn wir die Form der $\mathrm{NH}_{3}$-Leitfähigkeitskurve in Betracht ziehen, nicht allein ein, sondern zwei solche Punkte und zwar auf beiden Seiten des Maximums der $\mathrm{NH}_{3}$-Leitfähigkeit vorhanden sein. Diese isohydrischen Punkte würden nicht die Summe der Leitfähigkeiten der beiden reinen Komponenten ausmachen, weil infolge der durch $\mathrm{NH}_{3}$ bedingten inneren Reibung die Leitfähigkeit herabgesetzt wird, weshalb auch der Punkt bei grölserer $\mathrm{NH}_{3}$-Konzentration nicht auf derselben Höhe wie bei niedrigerer $\mathrm{NH}_{3}$ Konzentration sein würde.

Beim Eintreten solcher Punkte könnte man mit ziemlicher Sicherheit den Dissoziationsgrad der Kupferammoniakbase bestimmen. Denn die wegen der inneren Reibung bedingte Leitfähigkeitserniedrigung pro $\mathrm{Mol} \mathrm{NH}_{3}$ dürfte annähernd dieselbe, wie bei anderen Elektrolyten und somit eliminierbar sein.

Solche isohydrischen Punkte haben wir jedoch nicht gefunden, was auch erklärlich ist, wenn mehrere Hydroxyde vorhanden sind; denn in diesem Falle wäre es schwer, sich gerade einen solchen Punkt zu denken, wo die Hydroxylionen-Konzentrationen der vorhandenen Basen dieselben wären. Aufserdem würde man auf diese Weise nur die Summe der Leitfähigkeiten der beiden Basen ermitteln können.

\section{Leitfähigkeitsversuche mit $\mathrm{Ba}(\mathrm{OH})_{2}+\mathrm{NH}_{8}$.}

Om nun mindestens einen qualitativen Aufschlufs über die Gröfsenordnung der beiden störenden Einflüsse auf die Leitfähigkeit der Mischung zu bekommen, habe ich die Leitfähigkeiten von $\mathrm{Ba}(\mathrm{OH})_{2}+\mathrm{NH}_{3}$, wo die einzelnen Komponentleitfähigkeiten bekannt sind, untersucht.

Wie wir später sehen werden, ist es sehr wahrscheinlich, dafs $\mathrm{NH}_{3}$ in geringem Grade mit $\mathrm{Ba}(\mathrm{OH})_{2}$ ein Komplexhydroxyd bildet. ${ }^{1}$ Dieses Verhalten kann jedoch nur einen unbedeutenden Einfluls auf den Gang der Leitfähigkeiten ausüben.

Die erhaltenen Leitfähigkeitszahlen von $\mathrm{Ba}(\mathrm{OH})_{2}$, sowie die des Gemisches $\mathrm{Ba}(\mathrm{OH})_{2}+\mathrm{NH}_{3}$ sind in folgenden Tabellen angegeben.

1 Vergl. GAUs, l. c. 
Leitfähigkeitsmessungen ron $\mathrm{Ba}(\mathrm{OH})_{2}$ und ron $\mathrm{Ba}(\mathrm{OH})_{2}+\mathrm{NH}_{3}$.

Tabelle 11.

\begin{tabular}{c|c|c|c|c}
\hline \hline $\begin{array}{c}3 \mathrm{a}(\mathrm{OH})_{2} \\
\text { äqn. }\end{array}$ & $\begin{array}{c}\text { Leitfähigkeit v. } \\
\mathrm{Ba}(\mathrm{OH})_{2} \\
10^{4} \cdot r\end{array}$ & $\begin{array}{c}\mathrm{NH}_{3} \\
\text { norm. }\end{array}$ & $\begin{array}{c}\text { Leitfähigkeit v. } \\
\mathrm{NH}_{3} \\
10^{4} \cdot \%\end{array}$ & $\begin{array}{c}\text { Leitfähigkeit von } \\
\mathrm{Ba}(\mathrm{OH})_{2}+\mathrm{NH}_{3} \\
10^{4} \cdot \varkappa\end{array}$ \\
\hline 0.1108 & 199.8 & 3.4 & 10.9 & 168.0 \\
0.0554 & 105.4 & 3.4 & 10.9 & 90.6 \\
0.0277 & 55.0 & 3.4 & 10.9 & 49.3 \\
0.01385 & 28.2 & 3.4 & 10.9 & 28.6 \\
0.00693 & 14.3 & 3.4 & 10.9 & 18.8 \\
0.00346 & 7.2 & 3.4 & 10.9 & 14.9 \\
0.00138 & 3.6 & 3.4 & 10.9 & 12.3
\end{tabular}

Tabelle 12.

\begin{tabular}{c|c|c|c|c}
\hline $\begin{array}{c}\mathrm{Ba}(\mathrm{OH})_{2} \\
\mathrm{aqn}\end{array}$ & $\begin{array}{c}\text { Leitfähigkeit v. } \\
\mathrm{Ba}(\mathrm{OH})_{2} \\
10^{4} \cdot x\end{array}$ & $\begin{array}{c}\mathrm{NH}_{8} \\
\text { norm. }\end{array}$ & $\begin{array}{c}\text { Leitfähigkeit v. } \\
\mathrm{NH}_{8} \\
10^{4} \cdot x\end{array}$ & $\begin{array}{c}\text { Leitfähigkeit von } \\
\mathrm{Ba}(\mathrm{OH})_{2}+\mathrm{NH}_{3} \\
10^{4} \cdot x\end{array}$ \\
\hline \hline 0.0277 & 55.0 & 5.2 & 9.6 & 44.1 \\
0.01385 & 28.2 & 5.2 & 9.6 & 25.3
\end{tabular}

Tabelle 13.

\begin{tabular}{l|c|c|c|c}
\hline $\begin{array}{c}\mathrm{Ba}(\mathrm{OH})_{2} \\
\text { aqn. }\end{array}$ & $\begin{array}{c}\text { Leitfähigkeit v. } \\
\mathrm{Ba}(\mathrm{OH})_{2} \\
10^{4} \cdot x\end{array}$ & $\begin{array}{c}\mathrm{NH}_{3} \\
\text { norm. }\end{array}$ & $\begin{array}{c}\text { Leitfähigkeit v. } \\
\mathrm{NH}_{3} \\
10^{4} \cdot x\end{array}$ & $\begin{array}{c}\text { Leitfähigkeit von } \\
\mathrm{Ba}(\mathrm{OH})_{2}+\mathrm{NH}_{\mathrm{s}} \\
10^{4} \cdot x\end{array}$ \\
\hline & 105.40 & 6.7 & 8.4 & 74.9 \\
0.0554 & 28.20 & 6.7 & 8.4 & 23.4 \\
0.01385 & 7.20 & 6.7 & 8.4 & 11.3 \\
0.00346 & 1.60 & 6.7 & 8.4 & 10.0
\end{tabular}

Tabelle 14.

\begin{tabular}{c|c|c|c|c}
\hline $\begin{array}{c}\mathrm{Ba}(\mathrm{OH})_{2} \\
\mathrm{aqn}\end{array}$ & $\begin{array}{c}\text { Leitfähigkeit v. } \\
\mathrm{Ba}(\mathrm{OH})_{2} \\
10^{4} \cdot \%\end{array}$ & $\begin{array}{c}\mathrm{NH}_{3} \\
\text { norm. }\end{array}$ & $\begin{array}{c}\text { Leitfähigkeit v. } \\
\mathrm{NH}_{3} \\
10^{4} \cdot \varkappa\end{array}$ & $\begin{array}{c}\text { Leitfähigkeit von } \\
\mathrm{Ba}(\mathrm{OH})_{2}+\mathrm{NH}_{2} \\
\mathbf{1 0 ^ { 4 } \cdot \varkappa}\end{array}$ \\
\hline & & & 7.6 & 67.9 \\
0.0554 & 105.4 & 8 & 7.6 & $\mathbf{2 0 . 1}$ \\
0.01385 & 28.2 & 8 & 7.6 & $\mathbf{9 . 6}$ \\
0.00346 & $\mathbf{7 . 2}$ & 8 & $\mathbf{7 . 6}$ & $\mathbf{7 . 5}$
\end{tabular}


Tabelle 15.

\begin{tabular}{c|c|c|c|c}
\hline $\begin{array}{l}\mathrm{Ba}(\mathrm{OH})_{2} \\
\text { aqn. }\end{array}$ & $\begin{array}{c}\text { Leitfähigkeit } \\
\mathrm{Ba}(\mathrm{OH})_{2} \\
10^{4} \cdot x\end{array}$ & $\begin{array}{c}\mathrm{NH}_{3} \\
\text { norm. }\end{array}$ & $\begin{array}{c}\text { Leitfähigkeit v. } \\
\mathrm{NH}_{3} \\
10^{4} \cdot *\end{array}$ & $\begin{array}{c}\text { Leitfähigkeit von } \\
\mathrm{Ba}(\mathrm{OH})_{2}+\mathrm{NH}_{3} \\
10^{4} \cdot \pi\end{array}$ \\
\hline \hline & & & 3.1 & \\
0.0554 & 105.4 & 13.4 & 3.1 & 55.5 \\
0.01385 & 28.2 & 13.4 & 3.1 & 14.2 \\
0.00346 & 7.2 & 13.4 & 3.1 & 3.4
\end{tabular}

Wenn wir die von mir erhaltenen, mit den aus den KoHLRACSCHSchen Tabellen ${ }^{1}$ berechneten und interpolierten Leitfähigkeiten des reinen $\mathrm{Ba}(\mathrm{OH})_{2}$ vergleichen, ist zu bemerken, dals, trotzdem wir möglichst Kohlensäure zu vermeiden versuchten, die unseren ungefähr $4 \%$ kleiner sind. Weil jedoch die Leitfähigkeiten sowohl von reinem $\mathrm{Ba}(\mathrm{OH})_{2}$ als von $\mathrm{Ba}(\mathrm{OH})_{2}+\mathrm{NH}_{3}$ mit demselben Fehler behaftet sind, so dürfte die Vergleichbarkeit der Leitfähigkeiten beide Lösungen nicht darunter leiden.

Wir haben wieder die Leitfähigkeitskurven gezeichnet, wobei die $\mathrm{Ba}(\mathrm{OH})_{2}$-Konzentrationen als Abszissen, die Leitfähigkeiten als Ordinaten dienen. (Fig. 4.)

Beim Vergleich der Leitfähigkeitskurven der Mischung $\mathrm{Ba}(\mathrm{OH})_{2}+$ $\mathrm{NH}_{3}$ mit der Leitfähigkeitskurve von reinem $\mathrm{Ba}(\mathrm{OH})_{2}$, ist zu bemerken, dafs trotz der Eigenleitfähigkeit des $\mathrm{NH}_{3}$, die Leitfähigkeit des Gemisches sehr bald kleiner wird als die des $\mathrm{Ba}(\mathrm{OH})_{2}$ allein. Und je grölser der $\mathrm{NH}_{3}$-Gehalt ist, bei um so kleineren $\mathrm{Ba}(\mathrm{OH})_{2}$-Konzentrationen sinkt die Leitfähigkeit des Gemisches auf den Leitfähigkeitswert des reinen $\mathrm{Ba}(\mathrm{OH})_{2}$, um dann kontinuierlich weiter abzunehmen.

Wie bei den Kupferammoniaklösungen, machen sich auch hier wieder dieselben beiden Einflüsse zur Verminderung der Iseitfähigkeit des Gemisches von $\mathrm{Ba}(\mathrm{OH})_{2}+\mathrm{NH}_{3}$ geltend, nämlich das Zurückdrängen der $\mathrm{OH}-$ Ionen und die durch $\mathrm{NH}_{3}$ vergrölserte innere Reibung der Lösung.

Aus den Kurven ist zu sehen, dals zur Leitfähigkeitserniedrigung der Gemische die Vergröfserung der inneren Reibung einen viel grölseren Einflufs, als das Zurückgehen der OH-Ionen ausübt. Der erste Einflufs überwiegt bald ganz den zweiten. Das ist auch natür-

${ }^{1}$ Kohlradsom und Holbons, Leitvermögen der Elektrolyte, S. 200. 
lich, wenn wir bedenken, dafs $\mathrm{NH}_{3}$ eine sehr schwache Base ist. $\mathrm{Da}$ dagegen $\mathrm{Ba}(\mathrm{OH})_{2}$ eine sehr starke ist, erzeugt sie schon in kleineren Konzentrationen die Menge OH-Ionen, welche zur vollständigen Zurückdrängung der $\mathrm{OH}-$ Ionen des $\mathrm{NH}_{3}$ nötig sind. Bei

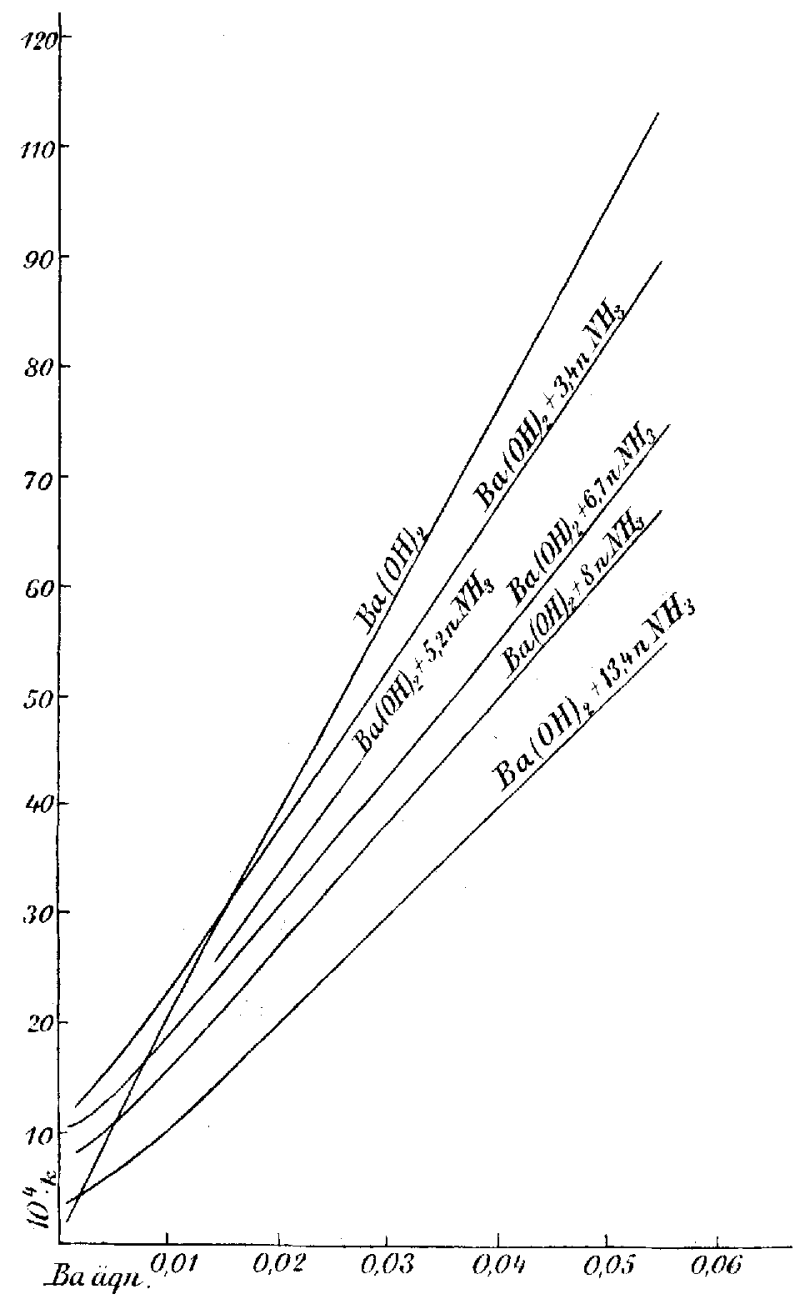

Fig. 4.

ganz kleinen $\mathrm{Ba}(\mathrm{OH})_{2}$-Konzentrationen ist die Leitfähigkeit des Gemisches grölser, als die des $\mathrm{Ba}(\mathrm{OH})_{2}$, weil hier die $\mathrm{OH}-I$ Konzentration des $\mathrm{Ba}(\mathrm{OH})_{2}$ noch sehr gering ist.

Weil wir nun in der Mischung $\mathrm{Ba}(\mathrm{OH})_{2}+\mathrm{NH}_{3}$ vorwiegend zwei Komponenten mit bekannten Leitfähigkeiten haben, können 
wir durch theoretische Überlegung ${ }^{1}$ den anderen Einflufs, nämlich das Zurückgehen der OH-Ionen, berechnen, wodurch die VergröIserung der inneren Reibung in der Mischung ermittelt werden kann.

Wir haben die Massenwirkungsgleichung

$$
\mathrm{NH}_{4} \cdot \mathrm{OH}=k(G-\mathrm{OH}),
$$

wo $k$ die Dissoziationskonstante des $\mathrm{NH}_{3}$ und $G$ die durch Titration gefundene Gesamtkonzentration der Lösung ist.

Wenn nun weiter $c_{1}$ die Ionenkonzentration, $C$ die Konzentration des nicht ionisierten Ammoniaks ist, so lautet die Glejcbung:

$$
e_{1} \cdot c_{1}=k\left(G-e_{1}\right)=k C \text {. }
$$

Wenn wir $c_{2} \mathrm{OH}-\mathrm{Ionen}$ von $\mathrm{Ba}(\mathrm{OH})_{2}$ zusetzen, so rerschwinden durch Rückgang der Dissoziation des Ammoniaks $x . \mathrm{NH}_{4}$ - und $x . \mathrm{OH}$ Ionen.

Die Gleichung ist dann

$$
\left(c_{1}-x+c_{2}\right)\left(c_{1}-x\right)=k\left[G-\left(c_{1}-x\right)\right]
$$

Setzen wir $\left(c_{1}-x\right)=y$, so ist

$$
\begin{gathered}
\left(c_{2}+y\right) y=k(G-y) \\
y^{2}+\left(c_{2}+k\right) y-k G=0 \\
y=c_{1}-x=-\frac{\left(c_{2}+k\right)}{2}+\sqrt{\left(\frac{c_{2}+k}{2}\right)^{2}+k G}
\end{gathered}
$$

Die Leitfähigkeit des Ammoniaks $L$ verhält sich vor der isohydrischen Beeinflussung $\mathrm{zu}$ der nach erfolgter Beinflussung $l$, wie $c_{1}$ zu $\left(e_{1}-x\right)$.

Die berechnete Leitfähigkeit des Ammoniaks, welche wir von der des Ammoniakgemisches subtrahieren müssen, um die Leitfähigkeit des $\mathrm{Ba}(\mathrm{OH})_{2}$ zu bekommen, ist also

$$
l=L \cdot \frac{c_{1}-x}{c_{1}} .
$$

Aus der Gleichung

$$
y^{2}+\left(c_{2}+k\right) y-k G=0
$$

1 Vergl. Goldschmidr, Z. anorg. Chem. 28 (1901), 97. 
findet man, dals, wenn $c_{2}$ um einen Betrag $\alpha$ zunimmt, $y$ um einen Betrag, der kleiner als $\frac{G k}{c_{2}^{2}} \cdot \alpha$ ist, abnimmt. Wir sehen also, dals ein Fehler von $c_{2}$ sehr wenig auf den Wert von $y$ einwirkt.

In den folgenden Tabellen sind einige Versuchsserien angegeben. Ich habe die Leitfähigkeit, welche in dem Gemisch $\mathrm{Ba}(\mathrm{OH})_{2}+\mathrm{NH}_{3}$ nach erfolgter isohydrischer Beeinflussung dem $\mathrm{NH}_{3}$ zukommt, berechnet. Diese korrigierten Leitfähigkeitswerte sind von denen des Gemisches subtrahiert, und alsdann berechnet, um wieviel die für $\mathrm{Ba}(\mathrm{OH})_{2}$ erhaltenen Leitfähigkeitswerte niedriger sind, als die ursprünglichen.

\section{(S. Tabellen 16 u. 17, S. 160.)}

Wenn wir die Tabellen betrachten, so ist zu bemerken, dafs in beiden die berechneten Leitfähigkeitsverminderungen per Mol $\mathrm{NH}_{3}$ gut miteinander übereinstimmen. Doch geht aus ihnen hervor, dafs, während die Leitfähigkeitserniedrigung des $\mathrm{Ba}(\mathrm{OH})_{2}$ in der ersten Tabelle, also in einer Ba-Konzentration von 0.1108 bis 0.0277 pro $\mathrm{Mol} \mathrm{NH}_{3}$, ungefähr $4.4 \%$ ist, sie in der zweiten, also bei einer $0.01385 \mathrm{Ba}-$ Konzentration, nur $3.7 \%$ pro $\mathrm{Mol} \mathrm{NH}$ beträgt.

GoLDsChмidT $^{1}$ hat gezeigt, dals die Leitfähigkeit der $\mathrm{NaCl}$, $\mathrm{KNO}_{3}, \mathrm{Na}_{2} \mathrm{SO}$ und LiCl-Lösungen je nach der Natur des Elektrolyten um 2 bis $3 \%$ pro $\mathrm{Mol} \mathrm{NH}$ herabgesetzt wird. Die Prozentzahlen sind also hier gröfser, als die von GoLDschmпт bei den erwähnten Alkalisalzlösungen gefundenen. Weil nun mehrwertige Kationen als schwächere Ionen überhaupt mehr oder weniger zu $\mathrm{NH}_{3}$ - Komplexbildung neigen ${ }^{2}$, ist es wahrscheinlich, dals $\mathrm{Ba}(\mathrm{OH})_{2}$ zum Teil mit $\mathrm{NH}_{3}$ ein komplexes Hydroxyd bildet. Da das komplexe Baryumammoniak-Ion komplizierter als das Baryum-Ion ist, könnte ersteres vielleicht eine kleine Wanderungsgeschwindigkeit haben, weshalb die durch $\mathrm{NH}_{3}$ bedingte innere Reibung der Lösung vergröfsert wird.

Bei geringeren Ba-Konzentrationen ist die Komplexbildung kleiner, als bei höheren, weshalb wir hier auch eine kleinere Prozentzahl bekommen. Bei konstanter Ba-Konzentration und wachsender $\mathrm{NH}_{3}$-Konzentration ist die innere Reibung pro $\mathrm{Mol} \mathrm{NH}_{3}$ ziemlich konstant. Es scheint folglich, als ob für die Komplexbildung nur die Ba-Konzentration malsgebend wäre. Doch sieht man, dafs die

\footnotetext{
1 l. c.

2 Vergl. Gaus l. c.
} 


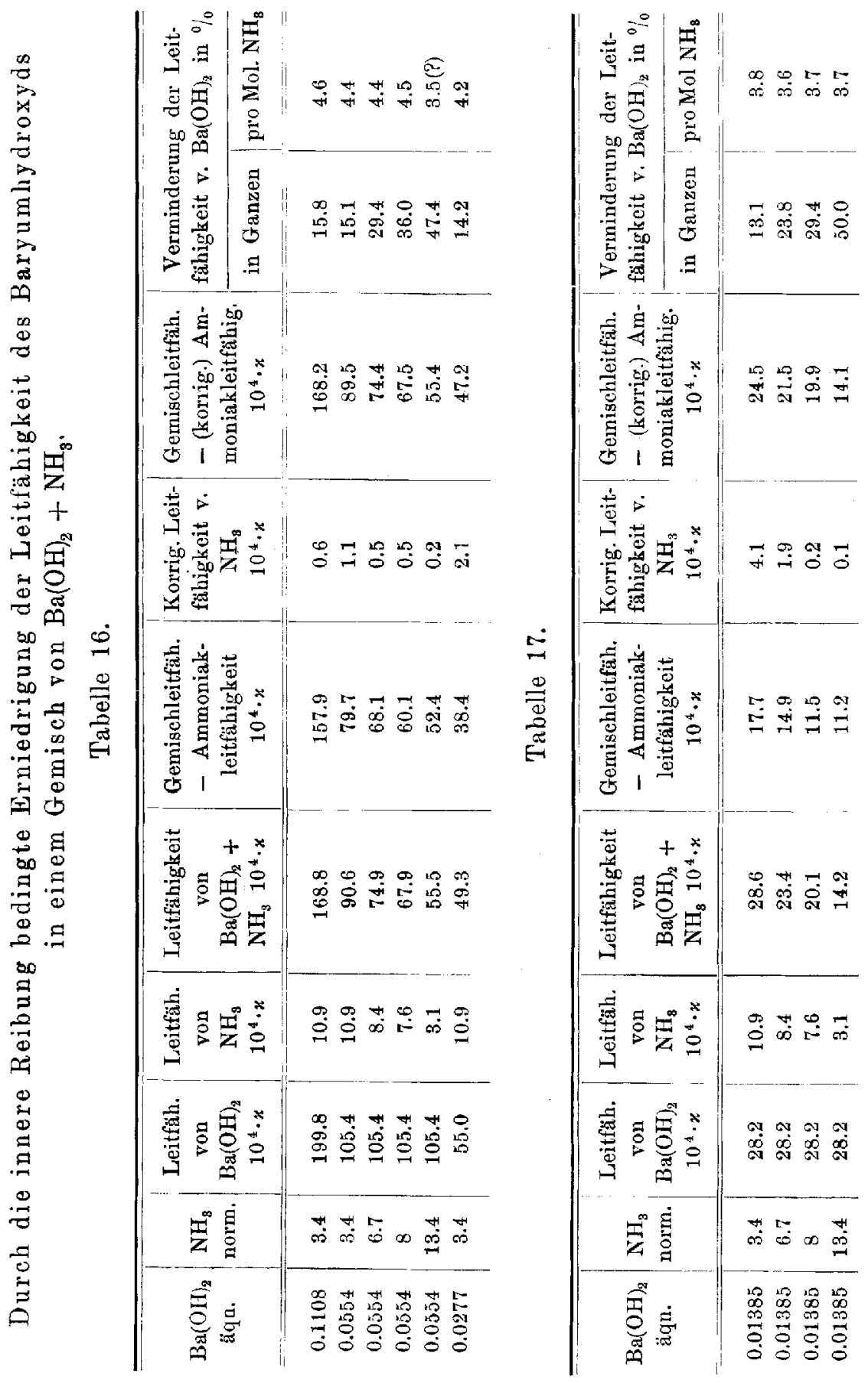


Komplexbildung in sehr geringem Grade vor sich geht. Denn ohne dies würde man erwarten, dals auch bei konstantem Ba- und steigendem $\mathrm{NH}_{3}$-Gehalt die Komplexbilduug zunehmen müfste.

Wir haben also bemerkt, dafs in einem Gemisch $\mathrm{Ba}(\mathrm{OH})_{2}+\mathrm{NH}_{3}$ die Erniedrigung der Leitfähigkeit des $\mathrm{Ba}(\mathrm{OH})_{2}$ durch Vergrölserung der inneren Reibung eine erhebliche ist. Wenn wir nun in Betracht ziehen, dafs in einer Kupferammoniaklösung nur komplizierte Kationen vorhanden sind, ist der durch $\mathrm{NH}_{3}$ bedingte Einflufs wahrscheinlich hier noch grölser.

Weil dagegen auch die stärksten Kupferammoniakbasen, wie die Leitfähigkeitskurven zeigen, viel schwächere als $\mathrm{Ba}(\mathrm{OH})_{2}$ sind, werden die $\mathrm{OH}-I$ nenen des $\mathrm{NH}_{3}$ durch die genannten Basen nicht so stark zurückgedrängt, wie durch $\mathrm{Ba}(\mathrm{OH})_{2}$, so dafs die Leitfähigkeitsverminderung im ganzen hier wohl kleiner ist als beim $\mathrm{Ba}(\mathrm{OH})_{2}$. Natürlich ist aufserdem auch in Betracht zu ziehen, ob wir verdünntere oder stärkere $\mathrm{NH}_{3}$-Lösungen haben. Denn wie schon früher erwähnt, sind die in wenig $\mathrm{NH}_{3}$ enthaltenden KupferhydroxydLösungen vorhandenen Basen allem Anschein nach schwach. (Vergl. Fig. 2).

Um noch die Leitfähigkeitskurven von $\mathrm{Cu}(\mathrm{OH})_{2}+1$ norm. $\mathrm{NH}_{3}$ mit konstantem Kupfer und wachsendem $\mathrm{NH}_{3}$-Gehalt mit denen des $\mathrm{Ba}(\mathrm{OH})_{2}+\mathrm{NH}_{3}$ vergleichen zu können, habe ich einige Messungen mit den letzteren ausgeführt.

Tabelle 18.

Leitfähigkeit von $\mathrm{Ba}(\mathrm{OH})_{2}+\mathrm{NH}_{3}$.

\begin{tabular}{|c|c|c|c|}
\hline $\begin{array}{l}\mathrm{NH}_{3} \\
\text { norm. }\end{array}$ & $\begin{array}{l}\text { Leitfähigkeit } \\
\text { von } \mathrm{NH}_{\mathrm{B}} \\
10^{4} \cdot x\end{array}$ & $\begin{array}{l}\text { Leitfähigkeit von } \\
\qquad \mathrm{Ba}(\mathrm{OH})_{2} \\
\text { äqn. }=0.01\end{array}$ & $\begin{array}{c}\mathrm{Ba}(\mathrm{OH})_{2}+\mathrm{NH}_{3} 10^{4} \cdot x \\
\mathrm{Ba}(\mathrm{OH})_{2} \\
\ddot{\mathrm{aqn}}=0.02\end{array}$ \\
\hline 0 & - & 20.6 & 40.2 \\
\hline 0.5 & 6.8 & 22.1 & - \\
\hline 1 & 8.9 & 23.0 & 41.0 \\
\hline 1.5 & 9.9 & - & 40.5 \\
\hline 2 & 10.6 & 23.5 & 39.9 \\
\hline 2.5 & 10.9 & 23.5 & - \\
\hline 3 & 10.9 & 23.4 & 38.4 \\
\hline 4 & 10.8 & 22.3 & 36.5 \\
\hline 5 & 10.1 & 20.8 & 34.5 \\
\hline 7 & 8.1 & - & 30.8 \\
\hline 10 & 5.4 & 13.5 & 24.0 \\
\hline
\end{tabular}


Aus den Leitfähigkeitszahlen ist zu sehen, dals bei kleineren $\mathrm{NH}_{3}$-Konzentrationen der Leitfähigkeit erst ein wenig steigt und zwar bis zu desto gröfsere $\mathrm{NH}_{3}$-Konzentrationen, je kleiner das $\mathrm{Ba}(\mathrm{OH})_{2}-$ Gehalt ist. Die $\mathrm{OH}$-Ionenkonzentrationen des $\mathrm{Ba}(\mathrm{OH})_{2}$ sind noch zu klein, um die $\mathrm{OH}$-Ionen des $\mathrm{NH}_{3}$ zurückzudrängen. Bei gröfseren $\mathrm{NH}_{3}$-Konzentrationen hingegen wird die innere Reibung der Lösung so grofs, dafs die Leitfähigkeit kontinuierlich abnimmt.

Beim Vergleich dieser Leitfähigkeitskurven Fig. 3 mit den entsprechenden Kupferammoniak-Kurven, sieht man, dals beide von ungefähr 4-5 norm. $\mathrm{NH}_{3}$ an ziemlich parallel laufen. In kleineren $\mathrm{NH}_{3}$-Konzentrationen ist der Kurvenverlauf aber ganz verschieden. Während die Leitfähigkeitswerte bei $\mathrm{Cu}(\mathrm{OH})_{2}+\mathrm{NH}_{3}$ bis ungefähr 3-4 norm. $\mathrm{NH}_{3}$ rasch steigen, nehmen die Leitfähigkeitswerte des $\mathrm{Ba}(\mathrm{OH})_{2}+\mathrm{NH}_{3}$ sehr wenig zu.

Dieses Verhalten der Leitfähigkeitskurven deutet wieder an, dals bei grölseren $\mathrm{NH}_{3}$-Konzentrationen eine stärkere Kupferammoniakbase in der Lösung vorherrscht, während bei kleineren $\mathrm{NH}_{3}$ - Konzentrationen wahrscheinlich schwächere Kupferammoniakbasen existieren. ${ }^{1}$

\section{Leitfähigkeitsversuche mit Kupfersulfat-Ammoniaklösungen.}

Es war noch interessant zu sehen, wie sich die Leitfähigkeitszahlen einer Lösung von Kupfersulfat-Ammoniak zu denen von Kupferhydroxyd-Ammoniak verhalten. Zu diesem Zwecke habe ich die Leitfähigkeiten von zwei Kupfersulfatkonzentrationen, nämlich 0.01 und 0.02 äq. norm., mit wachsenden $\mathrm{NH}_{3}$-Konzentrationen untersucht. In folgender Tabelle gebe ich die erhaltenen Zahlen.

In einer solchen Lösung von $\mathrm{CuSO}_{4}+\mathrm{NH}_{3}$ gibt es keine gemeinsamen Ionen der beiden Komponenten, Kupferammoniaksulfat und Ammoniak. Es ist dehalb sicher, dals die Leitfähigkeit des Ammoniaks durch isohydrischen Einflufs nicht in der Weise herabgesetzt wird, wie die des Ammoniaks durch OH-Ionen des Kupferammoniakhydroxyds. Jedoch wird die innere Reibung der Lösung auch in diesem Falle durch $\mathrm{NH}_{3}$ vergröfsert und infolgedessen die

1 Denkbar, wenn auch kein Anhalt dafür vorliegt, wäre vielleicht noch, dafs das $\mathrm{Cu}(\mathrm{OH})_{2}$ zu einem kleineren oder gröfseren Teil im $\mathbf{N H}_{3}$ nicht ehemisch, sondern kolloidal grelöst ist. Dann müfste man annehmen, dafs bei wachsender $\mathrm{NH}_{\mathrm{g}}$-Konzentration kolloidal gelöstes in chemisch gelöstes (komplexes) Hydroxyd übergeht, um die beobachteten Daten zu erklären. 
Tabelle 19.

Leitfähigkeitsmessungen von $\mathrm{CuSO}_{4}+\mathrm{NH}_{3}$.

\begin{tabular}{|c|c|c|c|c|}
\hline \multirow[b]{2}{*}{$\begin{array}{c}\mathrm{NH}_{3} \\
\text { norm. }\end{array}$} & $a$ & \multirow{2}{*}{$\begin{array}{c}\text { a-Leitfähigk. v. } \\
\text { ungebundener } \\
\text { Menge des } \mathrm{NH}_{3} \\
10^{4} \cdot \%\end{array}$} & b & \multirow{2}{*}{$\begin{array}{l}\text { b-Teitfähigkeit } \\
\text { v. ungebund. } \\
\text { Menge d. } \mathrm{NH}_{3} \\
10^{4} \cdot x\end{array}$} \\
\hline & $\begin{array}{l}\text { Lcitfähigkeit v. } \\
0.01 \text { äqn. } \mathrm{CuSO}_{4} \\
+\mathrm{NH}_{3} 10^{4} \cdot x\end{array}$ & & $\begin{array}{l}\text { Leitfähigkeit v. } \\
0.02 \mathrm{äqn} \text {. CuSO } \\
+\mathrm{NH}_{\mathrm{g}} 10^{4} \cdot x\end{array}$ & \\
\hline 0 & $7.2^{*}$ & - & $12.6^{*}$ & - \\
\hline 0.25 & 13.8 & 6.9 & - & - \\
\hline 0.5 & 13.5 & 6.9 & 21.0 & 14.4 \\
\hline 1 & 15.7 & 6.9 & 23.3 & 14.5 \\
\hline 2 & 17.6 & 7.1 & 24.3 & 13.7 \\
\hline 3 & 17.9 & 7.0 & 24.6 & 13.6 \\
\hline 4 & 17.6 & 6.8 & 24.3 & 13.5 \\
\hline 5 & 16.8 & 6.6 & - & - \\
\hline 7 & 14.6 & 6.5 & 19.3 & 11.8 \\
\hline 10 & 11.1 & 5.7 & 14.8 & 9.4 \\
\hline
\end{tabular}

* Nach Kohlrausoh und Holborn, Leitvermögen der Elektrolyte, S. 160.

Leitfähigkeit der Lösung herabgesetzt und zwar desto mehr, in je grölserer Menge $\mathrm{NH}_{3}$ vorhanden ist.

Konowalofi ${ }^{1}$, Dawson und Mc CraF ${ }^{1}$ haben gezeigt, dals mindestens bei einem $\mathrm{NH}_{3}$-Überschufs dem Kupferammoniaksulfat wahrscheinlich die Formel $\mathrm{Cu}\left(\mathrm{NH}_{3}\right)_{5} \mathrm{SO}_{4}$ zukommt. Wenn wir nun in allen $\mathrm{NH}_{3}$-Konzentrationen dasselbe Kupferammoniaksulfat haben, und wir von den Leitfähigkeitswerten der Lösungen die der ungebundenen Menge des Ammoniaks abziehen, so sollten wir mit zunehmendem $\mathrm{NH}_{3}$-Gehalt abnehmende Werte bekommen. Betrachten wir die erhaltenen Zahlen, so ist zu bemerken, dals kein Grund vorliegt, verschieden starke und verschieden konstituierte Kupferammoniaksulfate in nennenswerter Menge in der Lösung anzunehmen. Bei den niedrigeren Kupferkonzentrationen 0.01 äqn. ist jedoch zu bemerken, dafs die erhaltenen Werte bis 3 norm. $\mathrm{NH}_{3}$ konstant sind, um dann erst abzunehmen. Es würde also darauf deuten, dal's wir auch hier bei kleineren $\mathrm{NH}_{3}$-Konzentrationen schwächere Kupferammoniaksulfate in der Lösung hätten. Wahrscheinlich hingegen ist jedoch, dals die erhaltenen zu kleinen Werte auf anderen Ursachen beruhen.

Um nun die beiden Leitfähigkeitskurven von $\mathrm{CuSO}_{4}+\mathrm{NH}_{3}$ mit

1. c.; vergl. Gsus, l. c. 
den entsprechenden $\mathrm{Cu}(\mathrm{OH})_{2}+\mathrm{NH}_{3}$ Kurven vergleichen zu können, habe ich sie beide nebeneinander gezeichnet. (Fig. 3). Wir sehen, dafs von ungefähr 3 norm. $\mathrm{NH}_{3} \mathrm{ab}$, die Leitfähigkeitskurven von $\mathrm{Cu}(\mathrm{OH})_{2}+\mathrm{NH}_{3}$ höher laufen, als die von $\mathrm{CuSO}_{4}+\mathrm{NH}_{3}$. Man kann also den Schlul's ziehen, dals mindestens die in höheren $\mathrm{NH}_{3}$. Konzentrationen befindliche Kupferammoniakbase besser als das entsprechende Kupferammoniumsulfat leitet, während in kleinen $\mathrm{NH}_{3}$ Konzentrationen die Lösung $\mathrm{Cu}(\mathrm{OH})_{2}+\mathrm{NH}_{3}$ eine bedeutend kleinere Leitfähigkeit, als $\mathrm{CuSO}_{4}+\mathrm{NH}_{3}$, besitzt.

Wie wir später sehen werden, bindet jedes Atom Kupfer zwei Molekel $\mathrm{NH}_{3}$ bei den in kleinen $\mathrm{NH}_{3}$-Konzentrationen existierenden schwächeren Kupferammoniakbasen. Früher haben wir die Annahme ausgesprochen, dals die stärkeren Kupferammoniakbasen auch $\mathrm{NH}_{3}$ reichere wären. Wenn nun angenommen wird, dafs das komplexe $\mathrm{NH}_{3}$-reichere Kation hier ähnlich als beim Kupferammoniumsulfat konstituiert ist, und infolgedessen auch gleich schnell wandert, so entspricht der Kurvenverlauf den zu erwartenden Verhältnissen bei etwa gleichstarker Dissoziation von Kupferammonium-sulfat und -hydroxyd, wegen der grölseren Beweglichkeit von OH-Ionen gegen $\mathrm{SO}_{4}$-Ionen.

\section{Leitfähigkeitsmessungen von Nickelhydroxyd-Ammoniaklösungen.}

Weil die Leitfähigkeiten sowohl von Kupferammoniak-Lösungen, wie von $\mathrm{Ba}(\mathrm{OH})_{2}+\mathrm{NH}_{3}$ schon so eingehend besprochen sind, ist zur Erörterung der Leitfähigkeiten von den anderen Metallammoniakhydroxyden nicht mehr viel zu sagen.

Die Leitfähigkeitsmessungen von $\mathrm{Ni}(\mathrm{OH})_{2}+\mathrm{NH}_{3}$ sind in zwei Verdünnungsreiben in ähnlicher Weise, wie beim Kupfer ausgeführt. Die erhaltenen Zahlen sollen in Tabellen hier folgen:

Leitfähigkeitsmessungen von Nickelhydroxyd in Ammoniak.

Tabelle 20.

\begin{tabular}{c|c|c|c}
\hline \hline $\begin{array}{c}\mathrm{Ni}(\mathrm{OH})_{2} \\
\text { äqn. }\end{array}$ & $\begin{array}{c}\mathrm{NH}_{3} \\
\text { norm. }\end{array}$ & $\begin{array}{c}\text { Leitfähigkeit von } \mathrm{NH}_{3} \\
10^{4} \cdot x\end{array}$ & $\begin{array}{c}\text { Leitfähigkeit von } \mathrm{Ni}(\mathrm{OH})_{9} \\
+\mathrm{NH}_{3} 10^{4} \cdot x\end{array}$ \\
\hline \hline & & 9.1 & 80.0 \\
0.0540 & 6 & 9.1 & $\mathbf{4 3 . 1}$ \\
0.0270 & 6 & 9.1 & 24.4 \\
0.0135 & 6 & 9.1 & 16.1 \\
0.0068 & 6 & 9.1 & 14.6
\end{tabular}


Tabelle 21.

\begin{tabular}{|c|c|c|c|c|c|}
\hline \multirow[b]{2}{*}{$\begin{array}{l}\mathrm{NH}_{3} \\
\text { norm. }\end{array}$} & \multicolumn{5}{|c|}{ Leitfähigkeit $10^{4} \cdot x$} \\
\hline & $\begin{array}{l}\mathrm{Ni}(\mathrm{OH})_{2} \\
\quad=0\end{array}$ & $\begin{aligned} & \mathrm{Ni}(\mathrm{OH})_{2} \\
= & 0.0505 \ddot{a} q \mathrm{n} .\end{aligned}$ & $\begin{array}{c}\mathrm{Ni}(\mathrm{OH})_{2}= \\
0.0101 \text { äqn. }\end{array}$ & $\begin{array}{c}\mathrm{Ni}(\mathrm{OH})_{2}= \\
0.0202 \text { äqn. }\end{array}$ & $\begin{array}{l}\mathrm{Ni}(\mathrm{OH})_{2}= \\
0.0404 \text { äqn. }\end{array}$ \\
\hline 0.545 & 7 & 12.7 & - & - & - \\
\hline 0.75 & 8.0 & 13.9 & - & - & - \\
\hline 1 & 8.9 & 14.7 & $\begin{array}{c}22.7 \\
\left(\mathrm{NH}_{\mathrm{g}}=1.1 \mathrm{n} .\right)\end{array}$ & - & - \\
\hline 2 & 10.6 & 16.1 & 23.4 & $\begin{array}{c}22.7 \\
\left(\mathrm{NH}_{3}=2.18\right)\end{array}$ & - \\
\hline 3 & 10.9 & 16.0 & 23.0 & 38.5 & - \\
\hline 4 & 10.8 & 15.5 & 22.1 & 36.9 & 62.5 \\
\hline 5 & 10.1 & 14.7 & 20.8 & 35.1 & - \\
\hline 7 & 8.1 & 12.6 & - & 一 & - \\
\hline 8 & 7.6 & - & 16.4 & 30.0 & - \\
\hline 10 & 1.4 & 9.6 & - & 26.6 & - \\
\hline
\end{tabular}

Vergleichen wir nun zunächst die Leitfähigkeitszahlen mit konstantem $\mathrm{NH}_{3}$ - und wechselndem Metallgehalt mit denen von Kupferammoniaklösungen, so bemerken wir sofort, wie viel rascher die ersteren mit wachsendem Metallgehalt zunehmen. Wenn wir die den Zahlen entnommene Leitfähigkeitskurve mit der entsprechenden des $\mathrm{Ba}(\mathrm{OH})_{2}+\mathrm{NH}_{3}$ vergleichen, so ist zu sehen, dafs sie ziemlich zusammenfallen. Die Zahlen deuten also an, dals $\mathrm{Ni}(\mathrm{OH})_{2}$ mit $\mathrm{NH}_{3}$ sehr starke Basen bildet.

In Übereinstimmung damit stehen auch die Leitfähigkeitskurven (Fig. 5) mit konstantem Nickel- und wachsendem $\mathrm{NH}_{3}$-Gehalt. Beim Vergleich mit den entsprechenden $\mathrm{Ba}(\mathrm{OH})_{2}+\mathrm{NH}_{3}$. Kurven (Fig. 3) sehen wir, dals sie nicht allein denselben Verlauf haben, sondern auch ziemlich zusammenfallen. Daher kann zur Erklärung des Verlaufes der Ni-Kurven die nämliche Erklärung dienen wie für den Verlauf der entsprechenden Kurven von $\mathrm{Ba}(\mathrm{OH})_{2}+\mathrm{NH}_{3}$. Während beim $\mathrm{Cu}(\mathrm{OH})_{2}+\mathrm{NH}_{3}$ die Leitfähigkeitskurven von $3-4$ norm. $\mathrm{NH}_{3}$ mit abnehmendem Ammoniakgehalt rasch fallen, ist ein solches Verhalten hier nicht zu konstatieren.

1 Wie früher gesagt, wurde das zur Anwendung kommende Nickelhydroxyd aus einer Nickelnitratlösung mittels Natronlauge gefällt, da nur auf solche Weise ein reines Hydroxyd zu erhalten ist. Weil das Nickelhydroxyd ans Sulfat dargestellt und infolgedessen wahrseheinlich basisches Sulfat enthielt, sind die Leitfähigkeitsmessungen in der vorläufigen Mitteilung Ber. deutsch. chem. Ges. 36 (1903), 2324 zu klein ausgefallen. 
Es ist deshalb auch nicht nötig, hier, wie es beim Kupfer geschah, bei kleineren $\mathrm{NH}_{3}$-Konzentrationen schwächere und $\mathrm{NH}_{3}$ ärmere Nickelammoniakbasen mindestens in nennenswerter Menge anzunehmen. Vielmehr deuten die Leitfähigkeiten an, dafs nur eine Nickelammoniakbase in allen $\mathrm{NH}_{3}$-Konzentrationen vorliegt.

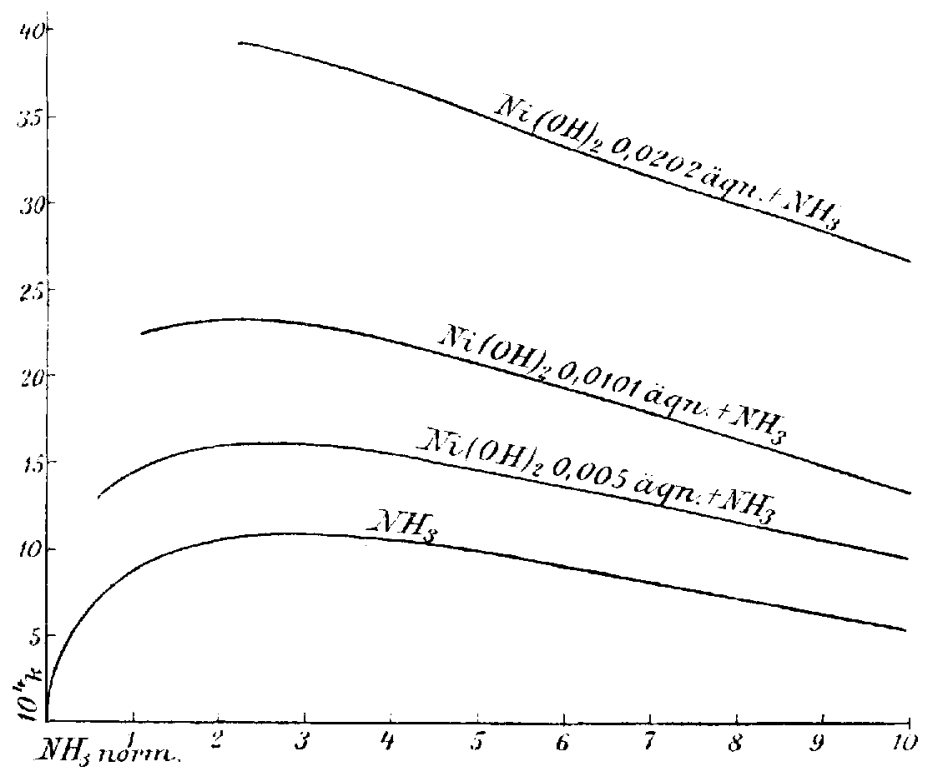

Fig. 5.

Weil $\mathrm{Ni}(\mathrm{OH})_{2}$ noch weniger als $\mathrm{Cu}(\mathrm{OH})_{2}$ sich in $\mathrm{NH}_{3}$ löst, ist es nicht möglich eine Nickelammoniak-Lösung darzustellen, in welcher nicht $\mathrm{NH}_{3}$ in einen relativ grolsen Überschufs vorhanden wäre. Wegen derselben störenden Einflüsse, wie beim Kupfer, dürfte es hier auch schwer sein, die Dissoziation der reinen Nickelammoniakbasen genau zu bestimmen.

\section{Leitfähigkeitsmessungen von Kadmiumhydroxyd in Ammoniak.}

Die Versuche sind in ähnlicher Weise wie bei den anderen Metallen ausgeführt und in folgenden Tabellen angegeben:

(S. Tabellen 22-24, S. 167.)

Von den Leitfähigkeiten des Kadmiumhydroxyds in Ammoniak ist nicht viel anderes zu sagen, als von denen der entsprechenden 
Leitfähigkeitsmessungen von Kadmiumhydroxyd in Ammoniak.

Tabelle 22.

\begin{tabular}{c|c|c|c}
\hline \hline $\begin{array}{c}\mathrm{Cd}(\mathrm{OH})_{2} \\
\text { aqn. }\end{array}$ & $\begin{array}{c}\mathrm{NH}_{\mathrm{g}} \\
\text { norm. }\end{array}$ & $\begin{array}{c}\text { Leitfähigkeit von } \\
\mathrm{NH}_{\mathrm{g}} 10^{4} \cdot \boldsymbol{x}\end{array}$ & $\begin{array}{c}\text { Leitfähigkeit von } \\
\mathrm{Cd}(\mathrm{OH})_{2}+\mathrm{NH}_{\mathbf{3}} \mathbf{1 0}^{4} \cdot \boldsymbol{x}\end{array}$ \\
\hline \hline & 5 & 10.1 & 62.3 \\
0.04385 & 5 & 10.1 & 35.5 \\
0.02195 & 5 & 10.1 & 21.5 \\
0.01095 & 5 & 10.1 & 15.0 \\
0.00548 & 5 & 10.1 & 12.0 \\
0.00274 & 5 & &
\end{tabular}

Tabelle 23.

\begin{tabular}{c|c|c|c}
\hline \hline $\begin{array}{c}\mathrm{Cd}(\mathrm{OH})_{2} \\
\mathrm{a} q \mathrm{qn} .\end{array}$ & $\begin{array}{c}\mathrm{NH}_{8} \\
\text { norm. }\end{array}$ & $\begin{array}{c}\text { Leitfähigkeit von } \\
\mathrm{NH}_{3} 10^{4} \cdot x\end{array}$ & $\begin{array}{c}\text { Leitfähigkeit von } \\
\mathrm{Cd}(\mathrm{OH})_{2}+\mathrm{NH}_{\mathbf{3}} \mathbf{1 0}^{4} \cdot x\end{array}$ \\
\hline \hline & & 10.1 & 62.3 \\
0.4385 & 5 & 10.9 & 38.1 \\
0.02195 & 2.5 & 9.5 & 22.5 \\
0.01095 & 1.25 & 7.4 & 13.5 \\
0.00548 & 0.63 & 5.6 & 7.8 \\
0.00247 & 0.31 & &
\end{tabular}

Tabelle 24.

\begin{tabular}{|c|c|c|c|c|c|}
\hline \multirow[b]{2}{*}{$\begin{array}{l}\mathrm{NH}_{3} \\
\text { norm. }\end{array}$} & \multicolumn{5}{|c|}{ Leitfähigkeit $10^{4} \cdot x$} \\
\hline & $\begin{array}{l}\mathrm{Cd}(\mathrm{OH})_{2} \\
\quad=0\end{array}$ & $\begin{array}{l}\mathrm{Cd}(\mathrm{OH})_{2}= \\
0.0104 \mathrm{aqn} .\end{array}$ & $\begin{array}{l}\mathrm{Cd}(\mathrm{OH})_{2}= \\
0.0208 \text { äqn. }\end{array}$ & $\begin{array}{c}\mathrm{Cd}(\mathrm{OH})_{2}= \\
0.0312 \text { äqn. }\end{array}$ & $\begin{array}{c}\mathrm{Cd}(\mathrm{OH})_{2}= \\
0.0416 \text { äqn. }\end{array}$ \\
\hline 1 & 8.9 & $\begin{array}{c}17.7^{*} \\
\left(\mathrm{NH}_{8}=0.93 \mathrm{n}\right)\end{array}$ & 一 & - & - \\
\hline 1.5 & 9.9 & 21.5 & $\begin{array}{c}29.7^{*} \\
\left(\mathrm{NH}_{3}=1.31 \mathrm{n}\right)\end{array}$ & - & 一 \\
\hline 2 & 10.6 & 22.5 & $\begin{array}{c}34.9 \\
\left(\mathrm{NH}_{3}=1.8 \mathrm{n}\right)\end{array}$ & - & - \\
\hline 2.5 & 10.9 & 22.8 & 35.5 & - & - \\
\hline 3 & 10.9 & 22.9 & 35.5 & 48.0 & $\left(\begin{array}{c}60.0 \\
\left(\mathrm{NH}_{8}=3.6 \mathrm{n} .\right)\end{array}\right.$ \\
\hline 4 & 10.8 & 22.3 & 34.9 & 47.2 & 59.5 \\
\hline 5 & 10.1 & 21.0 & 33.2 & 45.5 & 57.5 \\
\hline 7 & 8.1 & 18.4 & 33.0 & 41.2 & 52.4 \\
\hline 10 & 5.4 & 14.6 & 25.2 & 34.8 & 43.5 \\
\hline
\end{tabular}


Nickelammoniak-Lösungen. Wir bemerken, dals die Leitfähigkeitskurven sowohl mit konstantem $\mathrm{NH}_{3}$ - und steigendem Metall-, als auch die mit konstantem Metall- und wachsendem $\mathrm{NH}_{3}$-Gehalt (Fig. 6) ziemlich denselben Verlauf wie die entsprechenden Nickelammoniak-Kurven haben. Jedoch ist zu sehen, dafs die Kadmiumammoniak-Kurven etwas niedriger laufen, als die entsprechenden

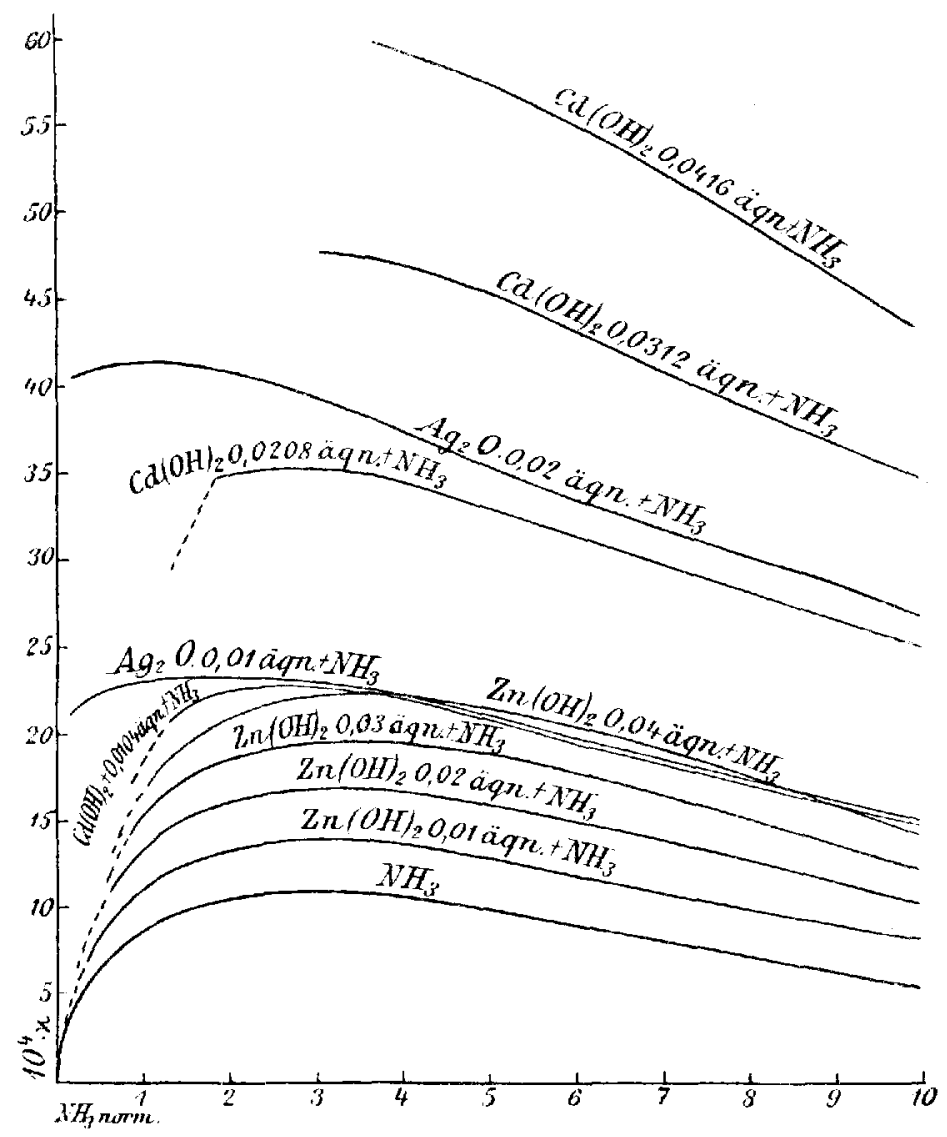

Fig. 6.

des Nickels. Kadmiumbydroxyd bildet also, danach zu urteilen, mit $\mathrm{NH}_{3}$ eine etwas schwächere Base als Nickelhydroxyd.

Der Verlauf der Leitfähigkeitskurven mit konstantem Kadmiumund wachsendem $\mathrm{NH}_{3}$-Gehalt gibt ebensowenig wie beim Nickel Anlals anzunehmen, dafs in kleineren $\mathrm{NH}_{3}$-Konzentrationen schwächere, und zwar $\mathrm{NH}_{3}$-ärmere Basen, als bei grölserem $\mathrm{NH}_{3}$-Gehalt in der Lösung wären. Sehr wahrscheinlich ist deshalb, dals in allen $\mathrm{NH}_{3}$ - 
Konzentrationen nur eine Kadmiumammoniakbase vorherrscht und zwar von dem Typus $\mathrm{Cd}_{m}\left(\mathrm{NH}_{3}\right)_{4 m}(\mathrm{OH})_{2 m}$, wie die Potentialmessungen gezeigt haben.

In einer Arbeit: Über Ammoniak und Metallammoniak. basen $^{1}$ hat Euler die Leitfähigkeiten von zwei mit Kadmiumhydroxyd gesättigten $\mathrm{NH}_{3}$-Lösungen angegeben. Obwohl ich keine Leitfähigkeitsmessungen habe, welche mit denselben Kadmiumkon. zentrationen ausgeführt wären, sieht man jedoch beim Vergleich der EuLErschen Zahlen mit den meinigen, dals die ersteren viel kleinere Leitfähigkeiten zeigen. Ich glaube jedoch, dals die relativ kleinen Zahlen von EuLER darauf beruhen, dals bei Ausführung der Messungen $\mathrm{Cd}(\mathrm{OH})_{2}$ ausgefallen ist. Ich babe nämlich versucht, Leitfähigkeitsmessungen ebenfalls mit $\mathrm{Cd}(\mathrm{OH})_{2}$ gesättigten $\mathrm{NH}_{3}$ Lösungen zu machen, aber immer ist dabei $\mathrm{Cd}(\mathrm{OH})_{2}$ ausgefallen.

Die in der Tabelle 24 befindlichen $\mathrm{NH}_{3}$-ärmeren Lösungen sind von einer sowohl in bezug auf Kadmium als in bezug auf $\mathrm{NH}_{3}$ konzentrierteren Lösung durch Verdünnen mit Wasser gewonnen. Ein Vergleich der EuLErschen Lösungen zeigt, dafs obwohl der $\mathrm{NH}_{3}$-Überschufs hier bedeutend grölser als bei ihm ist, dennoch $\mathrm{Cd}(\mathrm{OH})_{2}$ ausgefallen ist.

\section{Leitfähigkeitsmessungen von Zinkhydroxyd in Ammoniak.}

Die Leitfähigkeitsversuche wurden auch hier ebenso wie bei den anderen Metallen ausgeführt. Das Zinkhydroxyd wurde erst aus Zinksulfatlösung und zwar sowohl mit Natronlauge als mit Baryumhydrat ausgefällt und in $\mathrm{NH}_{3}$ gelöst, wie früher beschrieben ist.

In folgender Tabelle sind die so erhaltenen Leitfähigkeitswerte zusammengestellt:

$$
\text { (S. Tabelle 25, S. 170.) }
$$

Die mit II bezeichneten Werte beziehen sich auf Lösungen, welche aus mittelst $\mathrm{Ba}(\mathrm{OH})_{2}$ ausgefälltem Zinkhydroxyd bereitet sind. Wir sehen, dals die Leitfähigkeitszahlen der beiden Lösungen ziemlich gut miteinander übereinstimmen.

Weil, wie früher erwähnt, die aus Zinksulfat ausgefällten Zinkhydroxydpräparate etwas basisches Sulfat enthielten, wurden noch Versuche mit Lösungen gemacht, in welchen das Zinkhydroxyd aus Nitrat gewonnen und also als rein anzusehen war.

1 Chem. Centrbl. 1903 II. 1104 ; vergl. Arkiv för Kemi, Mineralogi och Geologi 1 (1903), 77. 
Tabelle 25.

Leitfähigkeitsmessungen von Zinkhydroxyd in Ammoniak bei steigendem Ammoniakgehalt.

$\mathrm{Zn}(\mathrm{OH})_{2}$ aus $\mathrm{ZnSO}_{4}$.

\begin{tabular}{|c|c|c|c|c|c|c|c|}
\hline \multirow{3}{*}{$\begin{array}{l}\mathrm{NH}_{\mathrm{s}} \\
\text { norm. }\end{array}$} & \multicolumn{7}{|c|}{ Leitfähigkeit von $\mathrm{Zn}(\mathrm{OH})_{2}+\mathrm{NH}_{3} 10^{4} \cdot x$} \\
\hline & \multirow{2}{*}{$\begin{array}{c}\mathrm{Zn}(\mathrm{OH})_{2} \\
\quad=0\end{array}$} & \multicolumn{2}{|c|}{$\begin{array}{c}\mathrm{Zn}(\mathrm{OH})_{2}= \\
0.01 \text { äqn. }\end{array}$} & \multirow{2}{*}{$\begin{array}{c}\mathrm{Zn}(\mathrm{OH})_{2}= \\
0.02 \text { äqn. }\end{array}$} & \multirow{2}{*}{$\begin{array}{l}\mathrm{Zn}(\mathrm{OH})_{2}= \\
0.03 \text { äqn. }\end{array}$} & \multicolumn{2}{|c|}{$\begin{array}{c}\mathrm{Zn}(\mathrm{OH})_{2}= \\
0.04 \text { äqn. }\end{array}$} \\
\hline & & $\mathbf{I}$ & II & & & I & II \\
\hline 0.5 & 6.8 & 8.4 & 8.3 & 10.3 & 13.2 & $\begin{array}{c}14.0 \\
\mathrm{NH}_{3}= \\
0.642)\end{array}$ & - \\
\hline 1 & 8.9 & 10.8 & 10.7 & 13.1 & 15.4 & 17.6 & - \\
\hline 1.5 & 9.9 & - & - & 14.6 & 17.1 & - & - \\
\hline 2 & 10.6 & 13.1 & 12.9 & 15.6 & 18.5 & 21.5 & 21.1 \\
\hline 2.5 & 10.9 & - & - & 16.1 & - & - & - \\
\hline 3 & 10.9 & 13.8 & 13.7 & 16.3 & 19.2 & 22.7 & 22.9 \\
\hline 4 & 10.8 & 13.6 & 13.4 & 16.2 & 19.1 & 22.6 & 22.8 \\
\hline 5 & 10.1 & - & - & 15.6 & - & - & - \\
\hline 7 & 8.1 & 11.2 & 11.1 & 13.5 & 16.5 & 19.0 & 19.1 \\
\hline 10 & 5.4 & 8.2 & 8.1 & 10.2 & 12.3 & 14.3 & - \\
\hline
\end{tabular}

Die erhaltenen Zahlen sind in folgenden Tabellen angegeben:

Leitfähigkeitsmessungen von Zinkhydroxyd in Ammoniak. $\mathrm{Zn}(\mathrm{OH})_{2}$ aus $\mathrm{Zn}\left(\mathrm{NO}_{3}\right)_{2}$.

Tabelle 26.

\begin{tabular}{|c|c|c|c|c|c|}
\hline \multirow[b]{2}{*}{$\begin{array}{l}\mathrm{NH}_{\mathrm{s}} \\
\text { norm. }\end{array}$} & \multicolumn{5}{|c|}{ Leitfahigkeit von $\mathrm{Zn}(\mathrm{OH})_{2}+\mathrm{NH}_{3} 10^{4} \cdot x$} \\
\hline & $\begin{array}{c}\mathrm{Zn}(\mathrm{OH})_{2}= \\
0\end{array}$ & $\begin{array}{r}\mathrm{Zn}(\mathrm{OH})_{2}= \\
0.01 \text { äqn. }\end{array}$ & $\begin{array}{c}\mathrm{Zn}(\mathrm{OH})_{2}= \\
0.02 \text { äqn. }\end{array}$ & $\begin{array}{c}\mathrm{Zn}(\mathrm{OH})_{2}= \\
0.03 \text { äqn. }\end{array}$ & $\begin{array}{r}\mathrm{Zn}(\mathrm{OH})_{2}= \\
0.04 \text { äqn. }\end{array}$ \\
\hline 0.25 & 5.6 & 6.4 & - & - & - \\
\hline 0.5 & 6.8 & 8.6 & 10.2 & - & - \\
\hline 1 & 8.9 & 11.1 & 13.5 & 15.6 & 17.0 \\
\hline 1.5 & 9.9 & 12.6 & 15.2 & 17.5 & 19.5 \\
\hline 2 & 10.6 & 13.4 & 16.2 & 18.8 & 21.1 \\
\hline 2.5 & 10.9 & 13.8 & - & - & - \\
\hline 3 & 10.9 & 14.0 & 17.0 & 19.6 & 22.3 \\
\hline 4 & 10.8 & 13.7 & 16.8 & 19.5 & 22.3 \\
\hline 5 & 10.1 & - & 16.0 & 19.0 & 21.5 \\
\hline 7 & 8.1 & 10.8 & 13.9 & 16.5 & 19.2 \\
\hline 10 & 5.4 & 8.1 & 10.2 & 12.1 & 14.2 \\
\hline
\end{tabular}


Tabelle 27.

\begin{tabular}{c|c|c|c}
\hline $\begin{array}{c}\mathrm{Zn}(\mathrm{OH})_{2} \\
\text { aqn. }\end{array}$ & $\begin{array}{c}\mathrm{NH}_{3} \\
\text { norm. }\end{array}$ & $\begin{array}{c}\text { Leitfähigkeit von } \\
\mathrm{NH}_{3} 10^{4} \cdot x\end{array}$ & $\begin{array}{c}\text { Leitfähigkeit v. } \mathrm{Zn}(\mathrm{OH})_{2} \\
+\mathrm{NH}_{3} 10^{4} \cdot x\end{array}$ \\
\hline 0.1 & - & - & 32.7 \\
0.05 & 2.5 & 10.9 & 24.3 \\
0.025 & 2.5 & 10.9 & 18.3 \\
0.0125 & 2.5 & 10.9 & 14.5 \\
0.0063 & 2.5 & 10.9 & 11.2
\end{tabular}

Ein Vergleich der Leitfähigkeitszahlen in der Tabelle 26 mit denjenigen der Tabelle 25 zeigt, dafs sie nicht viel voneinander abweichen.

Wir sehen also, dafs die in den ersten Lösungen noch befindlichen $\mathrm{SO}_{4}$-Ionen sehr geringen Einflufs auf die Leitfähigkeit haben.

Betrachten wir die Leitfähigkeitszahlen ion ZinkhydroxydAmmoniaklösungen, so bemerken wir, dafs sie viel niedriger sind, als bei allen den bisher besprochenen Metallammoniaklösungen. Ein Vergleich der Leitfähigkeitskurven mit konstantem Zink- und wachsendem $\mathrm{NH}_{3}$-Gehalt zeigt, dafs die 0.01 äq. Kadmiumammoniaklösung ungefähr ebensogut leitet wie eine Zinkammoniak-Lösung von viermal so starker Metallnormalität und gleichem $\mathrm{NH}_{3}$-Gehalt. (Fig. 6.)

Wir sehen also, dafs Zinkhydroxyd mit $\mathrm{NH}_{3}$ viel schwächere Basen als Kadmiumhydroxyd bildet, obwohl die beiden Metalle in anderen Beziehungen sich ziemlich ähnlich verhalten. Es ist jedoch bemerkenswert, daỉs $\mathrm{Cd}(\mathrm{OH})_{2}$ eine viel stärkere Base als $\mathrm{Zn}(\mathrm{OH})_{2}$ ist. Bekanntlich bildet $\mathrm{Zn}(\mathrm{OH})_{2}$ mit starken Alkalien wie $\mathrm{KOH}$ und $\mathrm{NaOH}$ mindestens zum Teil Zinkate, während kein anderes von uns studiertes Hydroxyd imstande ist, solche zu bilden. Es spricht also im selben Sinne, wenn $\mathrm{Zn}(\mathrm{OH})_{3}$ auch mit $\mathrm{NH}_{3}$ komplexes AmmoniakHydroxyd von schwächerer Basizität bildet.

In der eben erwähnten Arbeit von EULER ${ }^{1}$ sind auch einige Leitfähigkeitsmessungen von ammoniakalischen Zinkhydroxydlösungen angegeben. Weil die Messungen sowohl in anderen Zink- als in anderen $\mathrm{NH}_{3}$-Konzentrationen ausgeführt sind, ist es schwer, diese Werte mit den meinigen zu vergleichen. Doch kann man sehen, dals die Euterschen Werte ziemlich mit den von mir gefundenen übereinstimmen.

1. c. 
Auch hier bleibt übrigens die Möglichkeit zu prüfen, dals ein erheblicher Teil des Zinkhydroxyds kolloidal gelöst sei, was für die Schwäche der Base verantwortlich gemacht werden könnte.

\section{Leitfähigkeitsmessungen von Silberoxyd in Ammoniak.}

Des Vergleiches wegen babe ich noch einige Leitfähigkeitsmessungen mit konstantem Silber- und wachsendem $\mathrm{NH}_{3}$-Gehalt ausgeführt. Die erhaltenen Werte sind in der folgender Tabelle angegeben:

Tabelle 28.

Leitfähigkeitsmessungen von Silberoxyd in Ammoniak bei wachsendem Ammoniakgehalt.

\begin{tabular}{l|c|c|c}
\hline \hline \multirow{2}{*}{\begin{tabular}{c|c}
$\mathrm{NH}_{3}$ \\
norm.
\end{tabular}} & $\begin{array}{c}\mathrm{Ag}_{2} \mathrm{O} \\
=0\end{array}$ & $\begin{array}{c}\text { Leitfühigkeit von } \mathrm{Ag}_{2} \mathrm{O}+\mathrm{NH}_{3} 10^{4} \cdot x \\
\mathrm{Ag}_{2} \mathrm{O}=0.01\end{array}$ & $\begin{array}{c}\mathrm{Ag}_{2} \mathrm{O}=0.02 \\
\text { äqn. }\end{array}$ \\
\hline 0.068 & 1.5 & 20.8 & - \\
0.126 & 3.5 & - & 40.5 \\
0.25 & 5.1 & 21.9 & 41.0 \\
0.5 & 6.8 & 22.7 & 41.3 \\
0.75 & 8.0 & - & 41.5 \\
1 & 8.9 & 23.1 & 41.8 \\
1.5 & 9.9 & 23.4 & 41.4 \\
2 & 10.6 & 23.5 & 40.3 \\
3 & 10.9 & 23.2 & 39.6 \\
4 & 10.8 & 22.4 & 37.8 \\
5 & 10.1 & 21.1 & 35.5 \\
7 & 8.1 & 18.6 & 32.1 \\
10 & 5.4 & 14.8 & 27.0
\end{tabular}

Zeichnen wir nun wieder die Leitfähigkeitskurven (Fig. 6) und vergleichen wir sie mit denjenigen anderer MetallhydroxydammoniakLösungen, so sehen wir, dafs die beiden Kurven ziemlich, sowie die entsprechenden $\mathrm{Ba}(\mathrm{OH})_{2}+\mathrm{NH}_{3}$ Leitfähigkeitskurven (Fig. 3) verlaufen. Erst steigt die Leitfähigkeit mit wachsendem $\mathrm{NH}_{3}$-Gehalt um so mehr, je kleiner die Ag-Konzentration ist, um dann ganz kontinuierlich mit wachsendem $\mathrm{NH}_{3}$-Gehalt $\mathrm{zu}$ fallen. Die Erklärung darüber ist wohl dieselbe wie bei $\mathrm{Ba}(\mathrm{OH})^{2}+\mathrm{NH}_{3}$. Es ist noch zu bemerken, dals die beiden Leitfähigkeitskurven von $\mathrm{AgO}_{2}+\mathrm{NH}_{3}$ noch höher laufen als die entsprechenden von $\mathrm{Ba}(\mathrm{OH})_{2}+\mathrm{NH}_{3}$. Wir sehen also, dafs $\mathrm{Ag}_{2} \mathrm{O}$ mit $\mathrm{NH}_{3}$ eine sehr starke Base bildet. Die 
Leitfähigkeitskurven geben keinen Anlals anzunehmen, dals mehrere verschieden starke Silberammoniakbasen in der Lösung vorhanden wären, sondern es ist sehr wahrscheinlich, dafs vorwiegend nur eine Base und zwar von der Formel $\mathrm{Ag}\left(\mathrm{NH}_{3}\right)_{2} . \mathrm{OH}$ in allen $\mathrm{NH}_{3}$-Konzentrationen in der Lösung existiert. ${ }^{1}$

\section{Hydroxylionenmessungen.}

Um unserem Problem näher zu treten, war es von grofsem Interesse, die OH-Ionenkonzentration, über welche die Leitfähigkeitsmessungen wegen der inneren Reibung kein genaues Mafs zu geben vermögen, in einer gegebenen Lösung von Metallhydroxyd in Ammoniak direkt bestimmen zu können.

$\mathrm{Zu}$ diesem Zwecke wurden Hydroxylionenmessungen nach der Methode von KoELICHEN ${ }^{2}$ angestellt. Bekanntlich beruht diese darauf, dafs Diacetonalkohol katalytisch durch die vorhandenen Hydroxylionen in Aceton verwandelt wird, ein Vorgang, der zeitlich zu verfolgen ist.

Kokuchen hat durch seine Versuche beweisen können, dals in verdünnteren wässerigen Lösungen die Spaltung des Diacetonalkohols als eine Reaktion erster Ordnung anzusehen ist.

Die Dilatometergefälse, welche bei den Versuchen gebraucht wurden, sind nach den Angaben von KozLichen gefertigt. ${ }^{3}$ Die Kapillarröhre habe ich selbst nach sorgfältiger Kalibrierung ausgewählt. Um genauere Resultate zu bekommen, war der Durchmesser der Kapillarröhre etwas kleiner, als in den von KonLICHen benutzten Dilatometern. Die Dilatometerskale war eine willkiirliche. Der zur Anwendung kommende Diacetonalkohol wurde von mir selbst nach den Angaben von Koblichen dargestellt.

1 Als ich diese Messungen bereits ausgeführt hatte, erschien eine Arbeit von H. Euter, Ber. deutsch. chem. Ges. 36 (1903), 1854; vergl. WHITNEY und Melcher, 1. c. S. 5, wo er zwei Leitfähigkeitswerte angibt, welche in Übereinstimmung mit meinen Messungen zeigen, dals Silberammoniakhydroxyd eine sehr starke Base ist. $\mathrm{Er}$ fand auch, dafs die Leitfähigkeit einer 0.1 norm. $\mathrm{AgNO}_{3}$-Lösung mit einer in bezug auf $\mathrm{AgNO}_{3}$ ebenfalls 0.1 , in bezug auf $\mathrm{NH}_{3} \quad 0.2$ normalen, ganz übereinstimmte. Daraus ist zu schlielsen, dals die Wanderungsgeschwindigkeit des $\mathrm{Ag}\left(\mathrm{NH}_{3}\right)_{2}$-Ions dieselbe ist wie die des $\mathrm{Ag}$-Ions, d. h. 55. Wenn die Beweglichkeit des OH-Ions bei $18^{\circ}$ zu 174 angenommen wird, berechnet sich die äquivalente Leitfähigkeit des $\mathrm{Ag}\left(\mathrm{NH}_{8}\right)_{2} \mathrm{OH}$ zu $\boldsymbol{A}=\mathbf{2 2 9}$.

${ }_{2}^{2}$ Zeitschr. phys. Chem. 33 (1900), 129.

${ }^{3}$ von Glasbläser Schmot, Breslau. 
Nach der Füllung des Dilatometers mit der Versuchsflüssigkeit wurde der Apparat in den Thermostaten, bestehend aus einem grolsen Glasgefäls, gebracht. Die Messungen wurden bei $25^{\circ} \mathrm{C}$. ausgefübrt. Die Dilatationen sind mit Hilfe eines Mikroskops beobachtet. Die erste Ablesung geschah nach 10 Minuten, gerechnet von dem Moment an, in dem das Dilatometer in den Thermostaten gebracht und dann alle 5 oder 10 Minuten je nach der Konzentration der $\mathrm{OH}-\mathrm{Ionen}$ der Versuchsflüssigkeit.

Bei der Berechnung der Resultate wurden direkt die vom Meniskus durchwanderten Strecken nach einem beliebigen Mafs gemessen, in die Formel eingesetzt, was zulässig ist, weil die Geschwindigkeitskonstante für Reaktionen erster Ordnung nur von der Mafseinheit der Zeit abhängig ist. ${ }^{1}$

Die Ausführung der Versuche erfordert eine längere Übung. Besonders schwierig ist es, den Quecksilbertropfen, welcher als schützende Hülle der Versuchsflüssigkeit dienen soll, in die rechte Lage zu bringen. Es ist wichtig, dals er so dicht wie möglich an die Oberfläche der Versuchsflüssigkeit anschlielst, so dafs die oft unvermeidliche Luftblase zwischen dem Flüssigkeitsniveau und Quecksilber so klein wie möglich ist.

Obwohl der Quecksilbertropfen im Anfang der Versuche in die rechte Lage gebracht war, gingen doch sehr viele Messungen dadurch verloren, dals er während des Versuches in der Kapillare etwas gesunken war und Versuchstlüssigkeit über das Quecksilber drang.

Bei stark ammoniakalischen Lösungen ist es ziemlich schwer, konstante Geschwindigkeitskoeffizienten zu bekommen, weil sich während der Versuche leicht Gas zwischen dem Flüssigkeitsniveau und dem Quecksilber entwickelt.

Bei grölseren OH-Ionenkonzentrationen geht die Spaltung des Diacetonalkohols schnell vor sich. Bei kleineren OH-Ionenkonzentrationen wird das Gleichgewicht zwischen Aceton und Diacetonalkohol erst nach längerer Zeit erreicht, weshalb die Versuche gewöhnlich über Nacht im Gange waren.

Bei allen meinen Versuchen wurden immer $1.13 \mathrm{ccm}$ Diacetonalkohol mit $10 \mathrm{ccm}$ der Versuchsflüssigkeit versetzt.

Ehe wir zur Besprechung unserer Resultate gehen, müssen die Resultate von KoELICHEN erst näher betrachtet werden. Er trennt

1 Ostwald, Lehrbuch der allgem. Chemie 2 II, 231. 
seine Versuchsergebnisse in zwei Teile, nämlich in solche, die sich auf starke, und solche, die sich auf schwache Basen beziehen. Von den ersten hat er $\mathrm{Ba}(\mathrm{OH})_{2}$ und $\mathrm{NaOH}$, von den letzteren Ammoniak und einige Ammoniakbasen in verschiedenen Konzentrationen untersucht. Aus den Leitfähigkeitsmessungen von OsTwaLd hat er die $\mathrm{OH}-\mathrm{Tonenkonzentration} \mathrm{für} 0.0942$ norm. NaOH berechnet und auf Grund einer Proportionalitätsannahme zwischen Geschwindigkeitskonstanten und OH-Ionenkonzentrationen die Hydroxylionenkonzentrationen bei allen anderen Lösungen erhalten.

Dabei hat er gefunden, dafs bei den starken Basen die Geschwindigkeitskonstanten sich proportional den Hydroxylionenkonzentrationen der betreffenden Basen ändern, so dals zwei Basen mit derselben OH-Ionenkonzentration dieselbe Konstante geben. Die Basen aus der Gruppe der Ammoniakderivate dagegen gaben kleinere Geschwindigkeitskonstanten, als sie auf Grund ihrer AffinitätsgröIsen zeigen sollten, und zwar war die Abweichung von den berechneten Geschwindigkeitskonstanten desto grölser, je schwächer die Base war.

Um zu erfahren, worauf diese Abweichungen beruhen, hat der Verfasser die Leitfähigkeiten der genannten Ammoniakbasen erst in wässerigen Lösungen, dann in Reaktionsgemischen untersucht und die erhaltenen Zahlen mit denen von entsprechenden Natriumhydratlösungen verglichen. Er gelangt zu der Annahme, dafs die zu kleinen Geschwindigkeitskonstanten darauf beruhen: „dafs zwischen Diacetonalkohol, resp. Aceton und den Ammoniakderivaten irgend welche Vorgänge stattfinden, die das einfache Bild der katalytischen Spaltung des Diacetonalkohols in Gegenwart von OH-Ionen undeutlicher gestalten, und zwar ist es wahrscheinlich, dafs Aceton mit Ammoniak und dessen Derivaten zu verschiedenen Aminen sich verbindet."

Unter diesen Umständen war es nicht zu erwarten, dals aus den dilatometrischen Messungen sichere quantitative Schlüsse in bezug auf die $\mathrm{OH}$-Ionenkonzentration der Metallammoniaklösungen zu ziehen wären. Deshalb habe ich auch solche Messungen nur mit Kupferammoniaklösungen ausgeführt. Hier können wir nämlich jedoch beim Vergleich der Geschwindigkeitskonstanten zweier Kupferammoniak-Lösungen mit konstantem Kupfer- und verschiedenem $\mathrm{NH}_{3}$-Gehalt mit denen von zwei entsprechenden reinen $\mathrm{NH}_{3}$-Lösungen Resultate bekommen, welche mindestens qualitativ die bei Leitfähigkeitsmessungen ausgesprochenen Vermutungen bestätigen. 
Die Messungen mit ammoniakalischen KupferammoniakhydroxydLösungen sind in folgenden Tabellen angegeben.

Dilatometrische Versuche mit ammoniakalischen Kupferhydroxydlösungen.

Tabelle 29.

\begin{tabular}{|c|c|c|c|c|c|}
\hline \multicolumn{3}{|c|}{$\begin{array}{c}\text { Versuch } 1 . \\
\mathrm{Cu}(\mathrm{OH})_{2}=0.01 \ddot{a q n} . ; \mathrm{NH}_{\mathrm{s}}=1 \text { norm. }\end{array}$} & \multicolumn{3}{|c|}{$\begin{array}{c}\text { Versuch } 2 . \\
\mathrm{Cu}(\mathrm{OH})_{2}=0.01 \text { äqn.; } \mathrm{NH}_{3}=2 \text { norm. }\end{array}$} \\
\hline in Min. & $\begin{array}{l}\text { Zahl der } \\
\text { Teilstriche }\end{array}$ & $k$ & in Min. & $\begin{array}{l}\text { Zahl der } \\
\text { Teilstriche }\end{array}$ & $k$ \\
\hline 10 & 50 & 0.001513 & 10 & 42 & 0.001903 \\
\hline 20 & 98 & 0.001507 & 20 & 82 & 0.001900 \\
\hline 30 & 150 & 0.001568 & 30 & 121 & 0.001908 \\
\hline 40 & 190 & 0.001512 & 40 & 156 & 0.001882 \\
\hline 50 & 232 & 0.001501 & 50 & 193 & 0.001905 \\
\hline 60 & 278 & 0.001527 & 60 & 225 & 0.001888 \\
\hline 70 & 314 & 0.001500 & 70 & 260 & 0.001913 \\
\hline 80 & 369 & 0.001579 & 80 & 290 & 0.001905 \\
\hline 95 & 422 & 0.001557 & 95 & 335 & 0.001912 \\
\hline \multirow[t]{3}{*}{$\infty$} & 1462 & & 105 & 361 & 0.001900 \\
\hline & & 0.001529 & $\infty$ & 980 & \\
\hline & & & & & 0.001902 \\
\hline
\end{tabular}

Tabelle 30.

\begin{tabular}{|c|c|c|c|c|c|}
\hline \multicolumn{3}{|c|}{$\begin{array}{c}\text { Versuch } 3 . \\
\mathrm{Cu}(\mathrm{OH})_{2}=0.04 \text { äqn. } ; \mathrm{NH}_{3}=1 \text { norm. }\end{array}$} & \multicolumn{3}{|c|}{$\begin{array}{c}\text { Versuch } 4 . \\
\mathrm{Cu}(\mathrm{OH})_{2}=0.01 \text { äqn.; } \mathrm{NH}_{\mathbf{3}}=2 \text { norm. }\end{array}$} \\
\hline in $\stackrel{t}{\mathrm{Min}}$. & $\begin{array}{l}\text { Zahl der } \\
\text { Teilstriche }\end{array}$ & $k$ & in $\stackrel{t}{\text { Min. }}$ & $\begin{array}{l}\text { Zahl der } \\
\text { Teilstriche }\end{array}$ & $k$ \\
\hline 5 & 30 & 0.002598 & 5 & 90 & 0.004070 \\
\hline 10 & 60 & 0.002638 & 10 & 175 & 0.004051 \\
\hline 20 & 117 & 0.002654 & 20 & 335 & 0.004059 \\
\hline 30 & 170 & 0.002645 & 30 & 485 & 0.004103 \\
\hline 40 & 217 & 0.002603 & 45 & 675 & 0.004062 \\
\hline 50 & 264 & 0.002608 & 50 & 725 & 0.004000 \\
\hline 60 & 310 & 0.002629 & 55 & 785 & 0.004027 \\
\hline 70 & 347 & 0.002582 & 60 & 835 & 0.004005 \\
\hline \multirow[t]{2}{*}{$\infty$} & 1018 & & $\infty$ & 1965 & \\
\hline & & 0.002620 & & & 0.004047 \\
\hline
\end{tabular}


Tabelle 31 .

\begin{tabular}{|c|c|c|c|c|c|}
\hline \multicolumn{3}{|c|}{$\begin{array}{c}\text { Versuch } 5 . \\
\mathrm{Cu}(\mathrm{OH})_{2}=0.01756 \text { äqn.; } \mathrm{NH}_{\mathbf{s}}=1 \mathrm{n} .\end{array}$} & \multicolumn{3}{|c|}{$\begin{array}{c}\text { Versuch } 6 . \\
\mathrm{Cu}(\mathrm{OH})_{2}=0.049 \text { äqn.; } \mathrm{NH}_{3}=0.52 \mathrm{n} .\end{array}$} \\
\hline in $\stackrel{t}{\mathrm{Min}}$. & $\begin{array}{l}\text { Zahl der } \\
\text { Teilstriche }\end{array}$ & $k$ & in $\stackrel{t}{\mathrm{Min} .}$ & $\begin{array}{l}\text { Zahl der } \\
\text { Teilstriche }\end{array}$ & $k$ \\
\hline 10 & 43 & 0.002067 & 5 & 11 & 0001036 \\
\hline 20 & 83 & 0.002041 & 10 & 22 & 0.001042 \\
\hline 30 & 123 & 0.002083 & 20 & 42 & 0.001006 \\
\hline 40 & 160 & 0.002062 & 30 & 63 & 0.001018 \\
\hline 50 & 195 & 0.002056 & $3 \tilde{~}$ & 73 & 0.001018 \\
\hline 60 & 230 & 0.002069 & 40 & 84 & 0.001030 \\
\hline 70 & 260 & 0.002047 & 50 & 102 & 0.001011 \\
\hline 80 & 293 & 0.002068 & 60 & 123 & 0.001029 \\
\hline$\infty$ & 925 & & 70 & 141 & 0.001022 \\
\hline & & 0.002062 & $\infty$ & 928 & \\
\hline & & & & & 0.001023 \\
\hline
\end{tabular}

Tabelle 32.

\begin{tabular}{|c|c|c|c|c|c|}
\hline \multicolumn{3}{|c|}{$\begin{array}{c}\text { Versuch } 7 . \\
\mathrm{Cu}(\mathrm{OH})_{2}=0.07743 \text { äqn.; } \mathrm{NH}_{3}=2.36 \mathrm{n} .\end{array}$} & \multicolumn{3}{|c|}{$\begin{array}{c}\text { Versuch 8. } \\
\mathrm{Cu}(\mathrm{OH})_{2}=0.153 \text { äqn.; } \mathrm{NH}_{\mathrm{s}}=2.21 \mathrm{n} \text {. }\end{array}$} \\
\hline in $\stackrel{t}{\mathrm{Min} .}$ & $\begin{array}{l}\text { Zahl der } \\
\text { Teilstriche }\end{array}$ & $k$ & in $\stackrel{t}{\mathrm{Min} .}$ & $\begin{array}{l}\text { Zahl der } \\
\text { Teilstriche }\end{array}$ & $k$ \\
\hline 10 & 21 & 0.006236 & 5 & 88 & 0.00719 \\
\hline 20 & 39 & 0.006201 & 10 & 172 & 0.00730 \\
\hline 30 & 55 & 0.006265 & 15 & 241 & 0.00710 \\
\hline 40 & 69 & 0.006285 & 25 & 377 & 0.00727 \\
\hline 50 & 80.5 & 0.006245 & 30 & 432 & 0.00715 \\
\hline 60 & 90.5 & 0.006215 & 35 & 487 & 0.00718 \\
\hline 70 & 99.5 & 0.006232 & 40 & 533 & 0.00712 \\
\hline 80 & 107 & 0.006216 & $4 \overline{5}$ & 583 & 0.00721 \\
\hline 120 & 129 & 0.006233 & 50 & 624 & 0.00718 \\
\hline \multirow[t]{2}{*}{$\infty$} & 151 & & $\infty$ & 1108 & \\
\hline & & 0.006236 & & & 0.00719 \\
\hline
\end{tabular}

Der besseren Übersicht wegen habe ich die gewonnenen Resultate in der Tabelle 33 zusammengestellt. In der fünften Kolumne sind die nach den Geschwindigkeitskonstanten berechneten OH-Ionenkonzentrationen der Kupferammoniaklösungen angegeben. Als Ausgangswert ist der von KowLichen benutzte Wert $k=0.02181$ für 0.0942 norm. NaOH genommen. Koedichen hat von den LeitZ. anorg. Chem. Bd. 41. 
fähigkeitszahlen von OsTwaLd für 0.0942 norm. $\mathrm{NaOH}$ die $\mathrm{OH}$ Ionenkonzentration 0.08762 berechnet. Seitdem ist jedoch die Beweglichkeit des $\mathrm{OH}-$ Ions von KoHLRAUsCH ${ }^{3}$ neu bestimmt worden. Legt man diesen für $18^{\circ}$ angegebenen Wert zugrunde, so berechnet sich die $\mathrm{OH}-I$ nenkonzentration für 0.0942 norm. $\mathrm{NaOH}$ bei $25^{\circ}$ zu 0.08261 , welchen Wert wir benutzt haben. In sechster Kolumne sind die spezifischen Leitfähigkeiten der Kupferammoniaklösungen bei $18^{\circ}$. In der siebenten Kolumne sind die nach den Leitfähigkeitsmessungen von GoLDsCHмIDT ${ }^{2}$ berechneten OH-Tonenkonzentrationen von $\mathrm{NH}_{3}$ und in der achten die entsprechenden Geschwindigkeitskonstanten.

Tabelle 33.

\begin{tabular}{l|l|l|l|c|c|c|c}
\hline \hline $\begin{array}{l}\text { Ver- } \\
\text { such }\end{array}$ & $\begin{array}{c}\mathrm{Cu}(\mathrm{OH})_{2} \\
\mathrm{dqn} .\end{array}$ & $\begin{array}{c}\mathrm{NH}_{3} \\
\text { norm. }\end{array}$ & $\begin{array}{c}k \\
\text { bei } 25^{\circ}\end{array}$ & $\begin{array}{c}\text { OH- } \\
\text { Ionen- } \\
\text { konz. }\end{array}$ & $\begin{array}{c}\text { Spez. } \\
\text { Leitfäh. } \\
\text { bei 18 }\end{array}$ & $\begin{array}{c}\text { OH-Ionen- } \\
\text { konz. von } \\
\mathrm{NH}_{3} \text { ber. }\end{array}$ & $\begin{array}{c}k \text { von } \\
\mathrm{NH}_{2} \text { ber. } \\
\text { bei 25 }\end{array}$ \\
\hline 1 & 0.01 & 1 & 0.001529 & 0.005787 & 0.001476 & 0.00377 & 0.000990 \\
2 & 0.01 & 2 & 0.001902 & 0.007204 & 0.001768 & 0.00459 & 0.001214 \\
3 & 0.04 & 1 & 0.002620 & 0.009924 & 0.002921 & 0.00377 & 0.000996 \\
4 & 0.04 & 2 & 0.004047 & 0.015330 & 0.003675 & 0.00459 & 0.001214 \\
5 & 0.01756 & 1.1 & 0.002062 & 0.007811 & 0.001890 & 0.00392 & 0.001034 \\
6 & 0.049 & 0.52 & 0.001023 & 0.003875 & 0.001211 & 0.00283 & 0.000751 \\
7 & 0.07743 & 2.36 & 0.006236 & 0.023621 & 0.005680 & 0.00471 & 0.001243 \\
8 & 0.0153 & 2.21 & 0.007190 & 0.027340 & 0.008370 & 0.00469 & 0.001238
\end{tabular}

Betrachten wir erst die Versuche 1 und 2, in denen die Lösungen in bezug auf Kupferhydroxyd 0.01 äq. und in bezug auf Ammoniak 1 resp. 2 normal sind, und zwar soll die erste Lösung I, die zweite II bezeichnet sein. Wenn wir nun annehmen, dals dieselbe Kupferammoniakbase sowohl bei 1 norm., als auch bei 2 norm. $\mathrm{NH}_{3}$ in der Lösung vorhanden wäre, so sollte der Unterschied der Geschwindigkeitskonstanten der Lösungen II und I höchstens ebensogrols sein, wie der von 2 norm. und 1 norm. Ammoniaklösungen. Die in der Lösung befindlichen Basen müssen aber sich noch isohydrisch beeinflussen und zwar wahrscheinlich in der Richtung, dals die $\mathrm{OH}$-Ionen der $\mathrm{NH}_{3}$ durch die Kupferammoniakbasen zurückgedrängt werden. Also wird die $\mathrm{OH}-I$ onenkonzentration in den beiden Lösungen I und II herabgesetzt und infolgedessen sollte $k$ (Lösung

1 Vergl. Konlrausch and Holborn, Leitvermögen der Elektrolyte, S. 200.

* 1. c. 
II) $-k$ (Lösung I) kleiner sein, als der Unterschied der Geschwindigkeitskonstanten für 2 norm. und 1 norm. $\mathrm{NH}_{3}$.

Nun ist aber im Gegenteil $k$ (Lösung II) $-k$ (Lösung I) grölser, als der Unterschied der Gewichtskonstanten für 2 norm. und 1 norm. $\mathrm{NH}_{3}$. Dabei ist noch zu bemerken, dafs die berechneten Geschwindigkeitskonstanten von $\mathrm{NH}_{3}$ erheblich gröfser sind als die beobachteten ${ }^{1}$, so dafs der Unterschied der Geschwindigkeitskonstanten für 2 norm. and 1 norm. $\mathrm{NH}_{3}$ in Wirklichkeit noch kleiner wäre.

Wir sehen also, dafs mit zunehmendem $\mathrm{NH}_{3}$-Gehalt die Hydroxylionen-Konzentration erheblich gewachsen ist. Dieses Verhalten bestätigt die bei den Leitfähigkeitsmessungen ausgesprochene Annahme, dafs die rasche Zunahme der Leitfähigkeit bei zunehmendem $\mathrm{NH}_{3}-$ Gehalt, trotz der Vergrölserung der inneren Reibung darauf beruhen mufs, dals eine oder einige stärker dissozierte $\mathrm{NH}_{\mathbf{3}}$-Basen gebildet werden. Betrachten wir die Leitfähigkeiten in den Versuchen 1 und 2, so sehen wir, dals sie mit zunehmendem $\mathrm{NH}_{3}-$ Gehalt nicht ganz so rasch wachsen wie die Geschwindigkeitskonstanten. Dieses Verbalten hat wohl seinen Grund in der inneren Reibung der Lösung.

Ganz dasselbe Verhalten, wie die Versuche 1 und 2, zeigen auch die Versuche 3 und 4. Wir haben schon früher bemerkt, dafs die Zunahme der Leitfühigkeit ron 1 bis 2 normal $\mathrm{NH}_{3}$ in einer Kupferhydroxyd-Ammoniaklösung von 0.04 äq. Kupfer viel grölser ist, als in einer 0.01 äq. Kupferlösung. Es war deshalb auch zu erwarten, dals die OH-Ionenkonzentration, also auch die Geschwindigkeitskonstante, im ersten Falle viel rascher steigt, als im zweiten. Wenn wir die Tabelle betrachten, so bemerken wir, dals es wirklich so ist. Doch dürfte wohl die Geschwindigkeitskonstante für $(0.04$ äq. $\mathrm{Cu}+1 \mathbf{n} \cdot \mathrm{NH}_{3}$ ) zu klein ausgefallen sein.

Es ist vielleicht auffallend, das in den Versuchen 5, 6 und 7 die erhaltenen Geschwindigkeitskonstanten so klein sind, obwohl die Konzentration des $\mathrm{Cu}(\mathrm{OH})_{2}$ relativ grofs ist; doch ist zu bemerken, dafs alle diese Lösungen ziemlich konzentriert in bezug auf Kupfer sind, also $\mathrm{NH}_{3}$ in ihnen nur in kleinem Überschuls vorhanden ist. Wenn wir die Leitfähigkeitskurven mit konstantem Kupfer und zunehmendem $\mathrm{NH}_{\mathbf{s}}$-Gehalt betrachten, so bemerken wir in Übereinstimmung mit den erhaltenen kleinen $\mathrm{OH}$-Ionenkonzentrationen, dafs die Leitfähigkeiten in diesen Punkten relativ sehr klein sind, um

1 Vergl. Kondichen. 
dann mit zunehmendem $\mathrm{NH}_{3}$-Gehalt mindestens im Anfang sehr rasch $\mathrm{zu}$ steigen.

Da somit die dilatometrischen Messungen im ammoniakalischen Lösungen nur einen qualitativen, aber keinen quantitativen Malsstab für die Konzentration der OH-Ionen geben, habe ich solche Messungen mit den anderen Metallammoniakbasen nicht ausgeführt.

Nur ein Versuch mit $\mathrm{Zn}(\mathrm{OH})_{2}+\mathrm{NH}_{3}$ ist noch gemacht worden und folgt hierunter:

Tabelle 34.

$$
\mathrm{Zn}(\mathrm{OH})_{3}=0.234 \text { äqn.; } \mathrm{NH}_{3}=2.36 \text { norm. }
$$

\begin{tabular}{c|c|c}
\hline$t$ in Minuten & Zahl der Teilstriche & $k$ \\
\hline 5 & 50 & 0.00352 \\
10 & 98 & 0.00352 \\
20 & 189 & 0.00353 \\
30 & 266 & 0.00343 \\
40 & 337 & 0.00338 \\
50 & 405 & 0.00337 \\
62 & 478 & 0.00335 \\
70 & 524 & 0.00334 \\
81 & 579 & 0.00330 \\
$\infty$ & 1259 & \\
& & 0.00342
\end{tabular}

Der kleine Wert der Geschwindigkeitskonstanten zeigt wie wenig $\mathrm{OH}-$ Ionen in der Lösung vorhanden sind, wie schwach also die gebildete Zinkammoniakbase ist, in Bestätigung dessen, was wir auch schon bei den Leitfäbigkeitsmessungen gesehen haben.

\section{Löslichkeitsversuche.}

Um weiteren Aufschluls über die Konstitution der Metallammoniakbasen zu bekommen, habe ich Löslichkeitsversuche mit den Hydroxyden von Kupfer, Nickel, Kadmium und Zink in Ammoniak ausgeführt.

\section{Löslichkeitsversuche von Kupferhydroxyd in Ammoniak.}

Zuerst wurde aus einer Kupferammoniumsulfatösung gefälltes reines Kupferhydroxyd in feuchtem Zustande in eine bekannte Ammoniaklösung gebracht und bei $25^{\circ}$ geschüttelt. Sobald das 
überschüssige Hydroxyd am Boden sich abgesetzt hatte, wurde eine bestimmte Menge von der klaren Lösung abpipettiert und das Kupfer elektrolytisch nach der üblichen Weise bestimmt. Es zeigte sich jedoch bald, dals zwei auf ganz ähnliche Weise bereitete Kupferhydroxydpräparate eine verschiedene Löslichkeit in Ammoniak hatten, was sicherlich so zu deuten ist, dafs die Niederschläge wechselnde Mischungen von mehreren Modifikationen mit verschiedener Löslichkeit sind.

In folgender Tabelle sind einige Löslichkeitszahlen von einem so dargestellten Kupferhydroxydpräparat in Ammoniak angegeben.

Löslichkeitsversuche von Kupferhydroxyd in Ammoniak.

Tabelle 35.

\begin{tabular}{c|c|c|c}
\hline Temperatur in & $\mathrm{NH}_{3}$ norm. & Cu g pro & Cu(OH) \\
\hline & $=$ & 3.05 & \\
\hline 25 & 2.63 & 2.12 & 0.096 \\
25 & 2 & 1.08 & 0.067 \\
25 & 1.32 & 0.034
\end{tabular}

Versuchen wir nun mit Hilfe dieser Zahlen die Konstanten, welche einen Aufschlufs über die Konstitution der komplexen Kationen geben könnten, zu berechnen, so sehen wir bald, dafs keine solchen zu erhalten sind. Dies beruht sicherlich darauf, dafs wir in den Lösungen keinen einheitlichen Bodenkörper haben, also in der Gleichung

$$
(\mathrm{Cu} \cdot) \cdot(\mathrm{OH})^{2}=L
$$

das Löslichkeitsprodukt $L$ nicht konstant ist.

Um verschiedene Kupferhydroxyd-Modifikationen in dem Bodenkörper zu vermeiden, habe ich weitere Löslichkeitsversuche durch Austreiben des Ammoniaks aus einer Kupferammoniaklösung ausgeführt. Die Kupferammoniaklösung wurde in einen konzentrierte Schwefelsäure enthaltenden Exsikkator gebracht und evakuiert. Der Exsikkator befand sich in einem Thermostaten von $25^{\circ} \mathrm{C}$. Sobald Kupferhydroxyd ausgefallen war, wurde die Lösung, um eventuelle Konzentrationsveränderungen zu vermeiden, noch umgerührt. Wenn nach kurzer Zeit der Niederschlag sich abgesetzt hatte, wurde eine bestimmte Meuge von der Lösung zur Analyse genommen. Dann wurde weiter evakuiert und nach einiger Zeit dieselbe Operation 
wiederbolt. Die Ammoniakkonzentration der Lösung wurde nach Verdünnen mit Wasser in einer Probe direkt titriert, in einer zweiten Probe erst, nachdem das Kupfer durch Aluminiumspähne ausgeschieden und die Lösung farblos geworden war.

Da das auf diese Weise ausgeschiedene Kupferhydroxyd ganz kristallinisch ist, war anzunehmen, dals mindestens der aus derselben Lösung ausgefallene Niederschlag nur eine Modifikation darstelle. In folgenden Tabellen sind zwei so ausgeführte Löslichkeitsversuchsreihen zusammengestellt:

Löslichkeitsversuche von Kupferhydroxyd in Ammoniak.

Tabelle 36.

\begin{tabular}{c|c|c|c|c}
\hline Temperatur & $\mathrm{NH}_{3}$ norm. & $\mathrm{Cu} \mathrm{g}$ pro 1 & $\mathrm{Cu}(\mathrm{OH})_{2}$ äqn. & $100 \mathrm{~K}$ \\
\hline $25^{0}$ & 2.540 & 6.26 & 0.197 & 11.2 \\
25 & 1.965 & 6.28 & 0.166 & 11.2 \\
25 & 1.280 & 4.13 & 0.129 & 11.8 \\
25 & 0.973 & 3.36 & 0.106 & 11.6 \\
25 & 0.870 & 3.08 & 0.097 & 11.5 \\
25 & 0.540 & 2.36 & 0.074 & 12.3 \\
25 & 0.391 & 2.04 & 0.064 & 13.5
\end{tabular}

Tabelle 37.

\begin{tabular}{c|c|c|c|c}
\hline Temperatur & $\mathrm{NH}_{3}$ norm. & $\mathrm{Cu}$ g pro $\mathrm{l}$ & $\mathrm{Cu}(\mathrm{OH})_{2}$ äqn. & $100 \mathrm{~K}$ \\
\hline $25^{\circ}$ & 3.176 & 8.06 & 0.253 & 12.4 \\
25 & 2.070 & 5.72 & 0.180 & 11.8 \\
25 & 1.272 & 4.75 & 0.149 & 13.8 \\
25 & 0.451 & 2.54 & 0.080 & 15.4 \\
25 & 0.320 & 2.13 & 0.067 & 16.6
\end{tabular}

Wenn wir die aus diesen Zahlen entnommenen Löslichkeitskurven (Fig. 7) betrachten, so bemerken wir, dals die beiden Kurven nicht zusammenfallen, was wohl, darauf beruht, dals nicht dieselben Hydroxydmodifikationen in den beiden Lösungen ausgefallen sind. Doch zeigen die beiden Kurven II und III, welche viel höher laufen als die löslichkeitskurve I, einen übereinstimmenden Verlauf.

Wenn wir in einer Kupferhydroxydammoniaklösung einen ein- 
heitlichen Bodenkörper haben, bekommen wir nach dem Massenwirkungsgesetz:

$$
\begin{aligned}
& \mathrm{Cu} \cdot\left(\mathrm{OH}^{\prime}\right)^{2}=L \\
& \mathrm{Cu}^{*} \cdot\left(\mathrm{NH}_{3}\right)^{n}=k e
\end{aligned} \text { also } \frac{\left(\mathrm{OH}^{\prime}\right)^{2}}{\left(\mathrm{NH}_{3}\right)^{n}}=\frac{L}{k e},
$$

wo $L$ das Löslichkeitsprodukt, $e$ die Kupferkonzentration und $k$ eine Konstante ist.

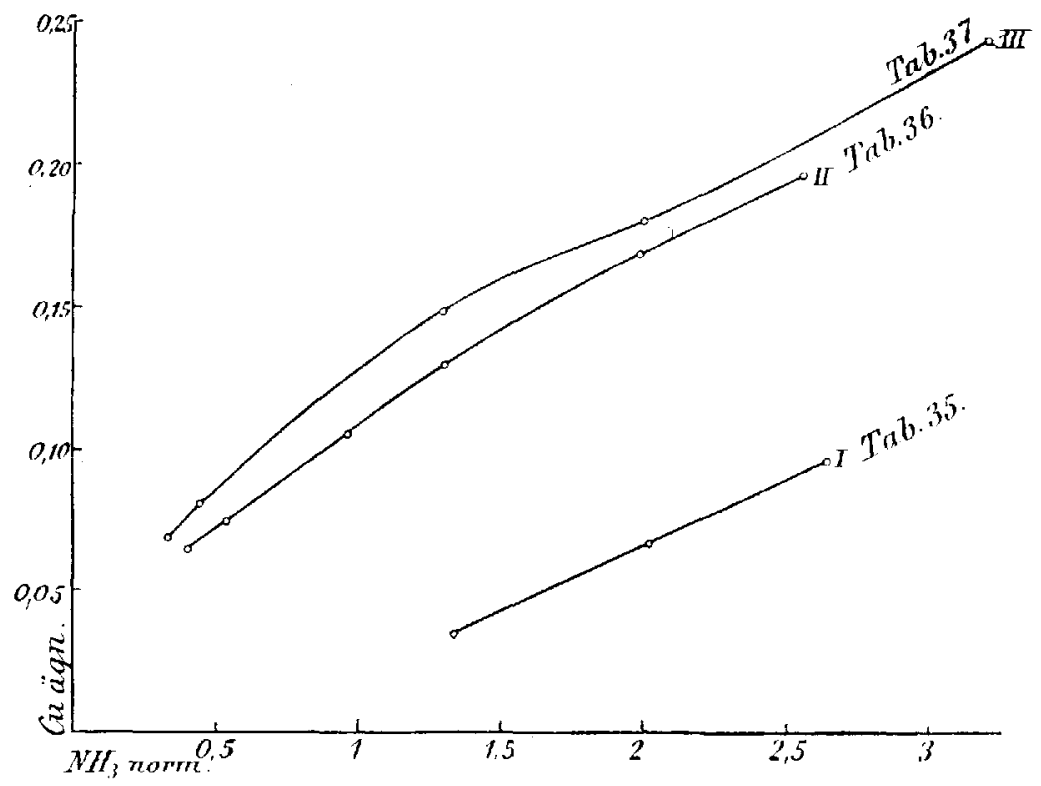

Fig. 7.

Weil praktisch alles Kupfer im Komplex gebunden ist, bekommt man

$$
\mathrm{OH}^{\prime}=2 e
$$

somit von obiger Gleichung

wo $K=\sqrt[3]{\frac{L}{4 k}}$ ist und schliefslich

$$
c=\mathrm{K}\left(\mathrm{NH}_{3}\right) \frac{\mathbf{n}}{3},
$$

$$
K=\frac{e}{\left(\mathrm{NH}_{3}\right)^{\frac{\mathrm{n}}{3}}} .
$$

Wir haben früher erwähnt, dals Dawson und Mc CRAE ${ }^{1}$ durch Untersuchungen über die Verteilung des $\mathrm{NH}_{3}$ zwischen ammonia-

1. c. 
kalischen Kupferoxydlösungen und Chloroform zu dem Schlufs gelangt sind, dafs jedes Atom Kupfer $2 \mathrm{NH}_{3}$ zum komplexen Kation bindet.

Wenn nun der Wert $\mathrm{n}=2$ in der obigen Formel eingesetzt wird, bekommen wir für die Berechnung der Konstante

$$
K=\frac{c}{\left(\mathrm{NH}_{3}\right)^{\frac{2}{3}}} .
$$

Wie man in den Tabellen 36 und 37 sieht, stimmen die mit Hilfe dieser Formel berechneten Konstanten $K$ genügend gut miteinander, und zwar in Tabelle 36 besser als in Tabelle 37.

In kleineren Kupfer und $\mathrm{NH}_{3}-$ Konzentrationen werden die Koustanten grölser, was vielleicht darauf beruhen könnte, dafs die Analysenfehler hier mehr ins Gewicht fallen.

Aus den Löslichkeitsversuchen ist also der Schluls zu ziehen, dafs zum mindesten bei relativ kleinem $\mathrm{NH}_{3}$-Überschufs jedes Atom Kupfer $2 \mathrm{NH}_{3}$ zur Komplexbildung aufnimmt.

Die Resultate stehen in vollkommener Übereinstimmung mit denen yon Dawson und Mo Crat. Auch die genannten Forscher laben bei ihren Untersuchungen Kupferammoniaklösungen angewendet, welche in bezug auf Kupfer relativ konzentriert gewesen sind.

Es ist deshalb ziemlich sicher, dafs die nach Leitfähigkeitsund Hydroxylionenmessungen in den kleinen $\mathrm{NH}_{3}$-Konzentrationen existierenden schwachen Basen die Formel $\mathrm{Cu}_{m}\left(\mathrm{NH}_{3}\right)_{2 m}(\mathrm{OH})_{2 m}$ haben.

Wir haben früher die Ansicht ausgesprochen, dafs die bei grölserem $\mathrm{NH}_{3}$-Überschul's nach den Leitfähigkeitsmessungen existierenden stärkeren Basen auch $\mathrm{NH}_{3}$-reicher, als die in kleinen $\mathrm{NH}_{3}$-Konzentrationen befindlichen schwächeren Basen wären. Ein Vergleich der Leitfähigkeiten von $\mathrm{Cu}(\mathrm{OH})_{2}+\mathrm{NH}_{3}$ mit konstantem Kupfer- und wachsendem $\mathrm{NH}_{3}$-Gehalt mit denen von $\mathrm{CuSO}_{4}+\mathrm{NH}_{3}$ gibt auch Anlals, anzunehmen, dals die stärkeren Kupferammoniakbasen ähnlich wie Kupferammoniumsulfat gebaut sind, also, das jedes Atom Kupfer $4 \mathrm{NH}_{3}$ bindet. Es wäre sehr interessant, diese Annahme experimentell zu prüfen.

Leider fehlen uns jedoch sichere Methoden dazu. Denn nachdem bei den Untersuchungen über Konzentrationsketten keine konstanten Potentiale zu bekommen waren, sind wohl die einzigen Messungen, welche einen Aufschlul's hierüber geben könnten, entweder die $\mathrm{NH}_{3}$ - 
Partialdruckbestimmungen oder auch die Verteilungsversuche des $\mathrm{NH}_{3}$, wie sie von $\mathrm{D}_{A w s o n}$ und $\mathrm{MC}_{\mathrm{C}} \mathrm{CRAE}_{\mathrm{E}}$ ausgeführt sind. Aber wir müssen bedenken, dafs bei so grofsem $\mathrm{NH}_{3}$ - ̈̈berschufs die beiden Methoden sehr ungenaue Werte geben würden, aus welchen nicht viel zu schliefsen wäre.

\section{Löslichkeitsversuche von Nickhydroxyd in Ammoniak.}

Das Nickelhydroxyd wurde in der früher beschriebenen Weise aus einer Nickelammoniumnitratlösung mittels Natronlauge gefällt, in feuchtem Zustande in $\mathrm{NH}_{3}$ von bestimmtem Gehalte gebracht und bei $25^{\circ}$ geschüttelt. Das Nickel wurde wie gewöhnlich elektrolytisch bestimmt.

In folgender Tabelle sind einige so ausgeführte Löslichkeitsversuche zusammengestellt:

Löslichkeitsversuche von Nickelhydroxyd in Ammoniak.

Tabelle 38.

\begin{tabular}{|c|c|c|c|}
\hline Temperatur & $\mathrm{NH}_{3}$ norm. & Ni $g$ pro 1 & $\mathrm{Ni}(\mathrm{OH})_{2}$ äqn. \\
\hline $25^{\circ}$ & 1 & 0.084 & 0.00287 \\
\hline 25 & 2 & 0.170 & 0.00579 \\
\hline 25 & 3 & 0.257 & 0.00875 \\
\hline 25 & 4 & 0.360 & 0.01227 \\
\hline
\end{tabular}

Weil sicherlich mehrere Modifikationen in dem Bodenkörper vorhanden sind, lassen sich aus den erhaltenen Zahlen keine Konstanten berechnen.

Da der in diesen Versuchen angewendete Niederschlag einige Zeit unter Wasser gestanden und die Metallhydroxyde bekanntlich mit dem Alter überhaupt unlöslicher werden, ist es erklärlich, weshalb die erhaltenen Löslichkeiten so klein sind.

Um verschiedene Modifikationen gleichzeitig in dem Bodenkörper zu vermeiden, habe ich denselben Weg wie beim Kupfer angewendet. Aus einer $\mathrm{NH}_{3}$-reicheren Nickelhydroxydlösung wurde $\mathrm{NH}_{3}$ so lange ausgetrieben, bis Nickelhydroxyd ausfiel, und die gesättigte Lösung analysiert. Die auf solche Weise erhaltenen Löslichkeitswerte sind in der Tabelle 39 angegeben. 
Löslichkeitsversuche von Nickelhydroxyd in Ammoniak.

Tabelle 39.

\begin{tabular}{c|l|c|c|c}
\hline Temperatur & $\mathrm{NH}_{3}$ norm. & Ni g pro I & Ni(OH) $)_{2}$ äqn. & $100 \mathrm{~K}$ \\
$255^{\circ}$ & 4.911 & 2.580 & 0.0879 & 1.11 \\
25 & 3.9 & 1.780 & 0.0607 & 1.10 \\
25 & 2.101 & 0.835 & 0.0284 & 1.09 \\
25 & 0.602 & 0.158 & 0.0054 & 1.09
\end{tabular}

Man sieht sofort, dal's die erhaltenen Zahlen viel höber sind, als die in der Tabelle 38 angegebenen. Es ist jedoch zu bemerken, dafs diese Zahlen in keinem Falle die grölste Löslichkeit des $\mathrm{Ni}(\mathrm{OH})_{2}$ in $\mathrm{NH}_{3}$ darstellen. Denn ganz ähnlich wie beim Kupfer bekommt man auch hier verschiedene Löslichkeitskurven, je nach der Modifikation, die den Bodenkörper bildet. ${ }^{1}$

Wenn wir nun in allen Lösungen dasselbe Nickelhydroxyd als Bodenkörper haben, bekommen wir nach dem Massenwirkungsgesetz:

wovon

$$
\begin{aligned}
& \mathrm{Ni} \cdot\left(\mathrm{OH}^{\prime}\right)^{2}=L \\
& \mathrm{Ni} \cdot\left(\mathrm{NH}_{3}\right)^{\mathrm{n}}=k e \text { also } \frac{\left(\mathrm{OH}^{\prime}\right)^{2}}{\left(\mathrm{NH}_{3}\right)^{\mathrm{n}}}=\frac{L}{l e},
\end{aligned}
$$

$$
c=K\left(\mathrm{NH}_{3}\right)^{\mathrm{n}} \text { und } K=c:\left(\mathrm{NH}_{3}\right)^{\frac{\mathrm{n}}{3}} \text {. }
$$

Konowalow ${ }^{2}$ sowie Dawson und Mc $\mathrm{CraE}^{2}$ haben gezeigt, dafs in ammoniakalischen Nickelsalzlösungen jedes Atom Nickel wahrscheinlich $4 \mathrm{NH}_{3}$ bindet. Wenn wir nun annehmen, dafs die freien Nickelammoniakbasen ähnlich wie die ihnen entsprechenden Salze konstituiert sind, müssen wir in der Formel für $n$ den Wert 4 einsetzen und bekommen also

$$
K=\frac{c}{\left(\mathrm{NH}_{3}\right)^{\frac{4}{3}}} .
$$

Ich habe mit Hilfe dieser Formel aus den in der Tabelle 39 befindlichen Zahlen die Konstanten berechnet. Wir bemerken, dafs sie genügend gut miteinander übereinstimmen. Dem komplexen Nickelammoniakhydroxyd kommt also sehr wahrscheinlich die Formel $\mathrm{Ni}_{m}\left(\mathrm{NH}_{3}\right)_{4 m}(\mathrm{OH})_{2 m}$ zu.

\footnotetext{
${ }^{1}$ Vergl. Starck, Ber. deutsch. chem. Ges. 36 (1903), 3840.
}

${ }^{2}$ l. c. 
Die bei relativ kleinem $\mathrm{NH}_{3}$-Überschufs existierenden Nickelammoniakbasen sind also anders gebaut als die entsprechenden Kupferammoniakbasen. Das steht in vollkommener Übereinstimmung mit den Leitfähigkeitsmessungen. Denn bei Nickelammoniaklösungen geben die Leitfähigkeitszahlen keinen Anlafs anzunehmen, dafs bei kleineren $\mathrm{NH}_{3}$-Konzentrationen schwächere und wahrscheinlich dann auch $\mathrm{NH}_{3}$-ärmere Basen in der Lösung vorhanden wären.

\section{Löslichkeitsversuche von Kadmiumhydroxyd in Ammoniak.}

Ganz ähnlich wie beim Kupfer und Nickel ist es sehr schwer, einheitliche Kadmiumhydroxydniederschläge zu bekommen. ${ }^{1}$ Wenn ich aus Kadmiumnitratlösung gefälltes Hydroxyd in feuchtem $\mathrm{Zu}$ stande in $\mathrm{NH}_{3}$ löste, bekam ich Löslichkeitswerte, welche ebenso wie beim Kupfer keinen Aufschlufs über die Komplexbildung geben konnten.

Um nur eine Hydroxydmodifikation in dem Bodenkörper zu bekommen, habe ich wieder denselben Weg, wie beim Kupfer und Nickel, ein wenig modifiziert angewendet. Aus einer Kadmiumhydroxydammoniaklösung wurde $\mathrm{NH}_{3}$ so lange ausgetriben, bis reichlich $\mathrm{Cd}\{\mathrm{OH})_{2}$ ausgefallen war. Weil das so ausgeschiedene Kadmiumhydroxyd ganz kristallinisch ist, war anzunehmen, dafs nur eine beständige Modifikation als Bodenkörper vorhanden war. Nachdem der $\mathrm{NH}_{\mathbf{g}}$-Gehalt der Lösung durch Titration bestimmt war, wurde eine gewisse Menge davon mit einem Teil des Niederschlages abpipettiert, auf ein bekanntes Volumen mit Wasser aufgefüllt und bei $25^{\circ} \mathrm{C}$ in einem Thermostaten geschüttelt. Die $\mathrm{NH}_{3}$-Konzentration der Lösungen war also vorher schon bekannt; der Kadmiumgehalt wurde wie früher durch Analyse als Oxyd bestimmt.

Die erhaltenen Löslichkeitszahlen sind in der Tabelle angegeben.

Löslichkeitsversuche ron Kadmiumhydroxyd in Ammoniak.

Tabelle 40.

\begin{tabular}{c|c|c|c|c}
\hline Temperatur & $\mathrm{NH}_{3}$ norm. & $\mathrm{CdO}$ g pro 1 & $\mathrm{Cd}(\mathrm{OH})_{2}$ äqn. & \multirow{2}{*}{$100 \mathrm{~K}$} \\
\hline \hline $25^{\circ}$ & 0.5 & 0.24 & 0.00374 & 0.95 \\
25 & 1 & 0.62 & 0.00966 & 0.99 \\
25 & 1.8 & 1.33 & 0.02075 & 0.99 \\
25 & 4.6 & 4.92 & 0.07670 & 1.05 \\
\hline
\end{tabular}

1 Vergl. EuLer, l. c. 
Ganz ähnlich wie beim Nickel bekommen wir für die Berechnung mit $n=4$ die in der Tabelle angegebenen Konstanten $K$, die genügend miteinander übereinstimmen. Die Löslichkeitsversuche bestätigen also die Potentialmessungen, nach welchen jedes Atom Kadmium 4 Molekeln $\mathrm{NH}_{3}$ zur Komplexbildung aufnimmt.

Es ist noch zu bemerken, dals wir bei den Potentialmessungen einen relativ grolsen Überschuls von $\mathrm{NH}_{3}$ gehabt haben, während derselbe in den Löslichkeitsversuchen relativ klein ist. Wir sehen also, dals sowohl bei kleinerem wie bei grölserem $\mathrm{NH}_{3}$-Überschuls dieselbe Kadmiumammoniakbase in der Lösung existiert. Dies steht auch in Übereinstimmung mit den Leitfähigkeitsmessungen, welche keinen Anlals anzunehmen geben, dafs bei konstantem Kadmiumgehalt in kleinen $\mathrm{NH}_{3}$-Konzentrationen schwächere, $\mathrm{NH}_{3}$-ärmere Basen in der Lösung existieren würden.

$\mathrm{Zu}$ den Löslichkeitszahlen des $\mathrm{Cd}(\mathrm{OH})_{2}$ in der Tabelle 40 ist noch zu bemerken, dals sie natürlich nur die Löslichkeit dieser Kadmiumhydroxydmodifikation darstellen. Ganz wie beim Kupfer und Nickel bekommt man auch hier je nach der Modifikation des Hydroxyds verschiedene Löslichkeitskurven.

Um das zu illustrieren, gebe ich einen bei $25^{\circ}$ durch Evakuieren erhaltenen Löslichkeitswert an:

$$
\mathrm{Cd}(\mathrm{OH})_{2}=0.105 \text { äqn.; } \mathrm{NH}_{3}=4.5 \text { norm., }
$$

welcher erheblich gröfser ist, als der aus unseren Tabellen entnommene.

\section{Löslichkeitsversuche von Zinkhydroxyd in Ammoniak.}

Das Zinkhydroxyd, welches bei diesen Versuchen erst zur Anwendung $\mathrm{kam}$, ist aus verdünnter Zinksulfatlösung mit einer berechneten Menge Baryumhydrat gefällt und gewaschen, wie früher beschrieben worden ist. In feuchtem Zustande wurde der Niederschlag, welcher neben Zinkhydroxyd also auch Baryumsulfat enthielt, mit $\mathrm{NH}_{3}$ extrahiert und die klare Flüssigkeit dann in ähnlicher Weise wie beim Kupfer in einem Vakuumexsikkator bei $25^{\circ}$ behandelt. Das Zinkhydroxyd scheidet sich kristallinisch aus. Die auf diese Weise erhaltenen Löslichkeitswerte sind in der Tabelle 41 angegeben. 
Löslichkeitsversuche von Zinkhydroxyd in Ammoniak. Tabelle 41.

\begin{tabular}{c|c|c|c}
\hline Temperatur & $\mathrm{NH}_{\mathbf{3}}$ norm. & $\mathrm{ZnO}$ g pro l & $\mathrm{Zn}(\mathrm{OH})_{2}$ äqn. \\
\hline $25^{\circ}$ & 1.287 & 7.28 & 0.1789 \\
25 & 0.825 & 3.84 & 0.0944 \\
25 & 0.311 & 0.85 & 0.0210
\end{tabular}

Ähnliche Löslichkeitsversuche von Zinkhydroxyd in Ammoniak hat schon früher W. Herz ${ }^{1}$ gemacht. Er hat das Zinkhydroxyd aus einer Zinksulfatlösung mit Ammoniak gefällt und bei $20^{\circ}$ geschüttelt. Ein Vergleich der von Henz angegebenen Löslichkeiten mit denen von mir gefundenen zeigt, dals die letztgenannten erheblich niedriger sind, obwohl man, wie beim Kupfer, durch Behandlung der Zinkhydroxydlösung in $\mathrm{NH}_{3}$ höhere Werte bekommen sollte. $\mathrm{HERz}^{2}$ hat auch nachher bemerkt, dafs die von ihm angewendeten Zinkhydroxydpräparate basische Zinksulfate enthielten. Später hat EuLER ${ }^{3}$ Löslichkeitsversuche mit Zinkhydroxyd, welches aus Zinknitrat bereitet war, ausgeführt. Die von EסLER erhaltenen Löslichkeitswerte sind erheblich kleiner als die von Henz und als die meinen.

Weil wahrscheinlich auch das von mir aus Sulfat dargestellte Zinkhydroxyd etwas basisches Sulfat enthalten hat, habe ich noch Löslichkeitsversuche mit einem aus Nitratlösung ausgefällten Zinkhydroxyd ausgeführt. Das gefällte Zinkhydroxyd wurde in feuchtem Zustande in $\mathrm{NH}_{3}$ gebracht und bei $25^{\circ} \mathrm{C}$. geschüttelt. Wie früher, wurde auch hier der Zinkgehalt der Lösungen als Oxyd bestimmt. Die erhaltenen Werte sind in der Tabelle 42 zusammengestellt.

Löslichkeitsversuche ron Zinkhydroxyd in Ammoniak.

Tabelle 42.

\begin{tabular}{c|c|c|c}
\hline Temperatur & $\mathrm{NH}_{3}$ norm. & $\mathrm{ZnO}$ g pro l & $\mathrm{Zn}(\mathrm{OH})_{2}$ äqn. \\
\hline & & & \\
$25^{\circ}$ & 0.321 & 0.34 & 0.0084 \\
25 & 0.643 & 0.845 & 0.0209 \\
25 & 1.215 & 2.70 & 0.0663 \\
25 & 1.928 & 5.07 & 0.1244 \\
25 & 2.570 & 7.01 & 0.1722 \\
25 & 3.213 & 10.16 & 0.2496
\end{tabular}

' Z. anorg. Chem. 30 (1902), 280.

2 z. anorg. Chem. 31 (1902), $35 \%$.

s. 1. c. 
Des besseren Vergleichs wegen habe ich die Löslichkeitskurven von Herz, EULER und mir selbst in Fig. 8 aufgetragen.

Wir bemerken, dafs die von mir gefundene Löslichkeitskurve des aus Nitrat bereiteten Zinkhydroxyds noch niedrigere Löslichkeiten zeigt als die von EULER. Die abweichenden Löslichkeiten

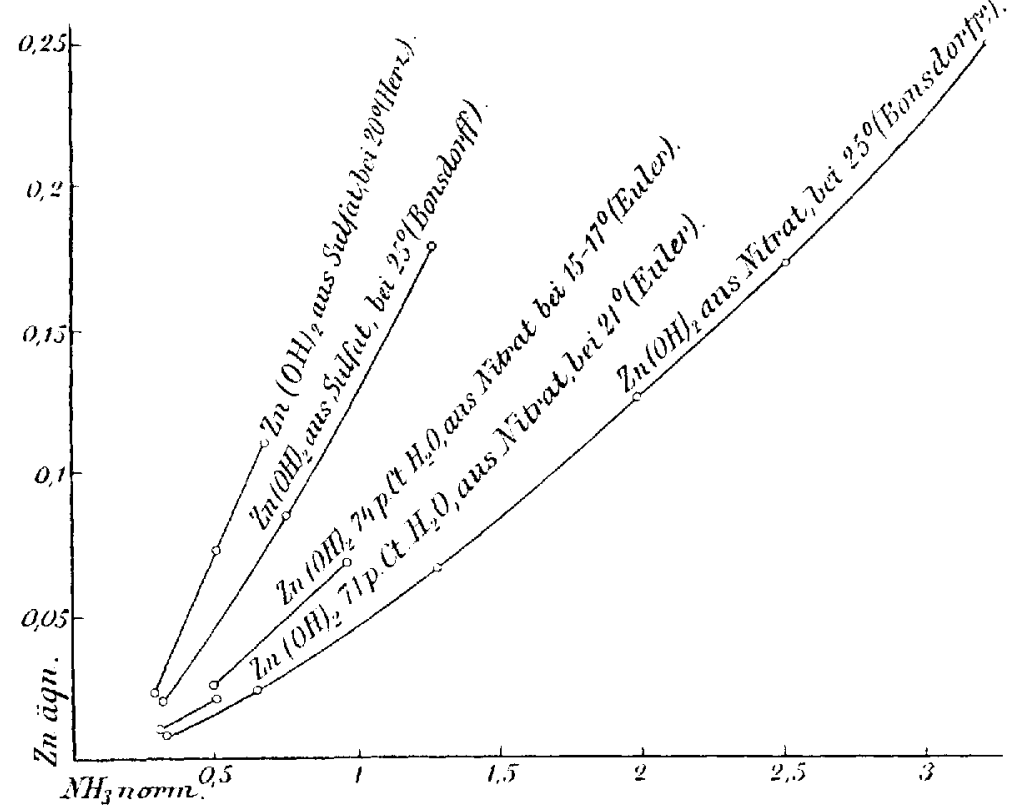

Fig. 8.

beruhen sicherlich auf dem Vorhandensein verschiedener Zinkhydroxydmodifikationen, wie die Zahlen von EuLER auch deutlich zeigen.

Obwohl die viel gröIseren Löslichkeitswerte des aus Zinksulfat bereiteten Hydroxyds vielleicht zum Teil von basischen Sulfaten herrühren, glaube ich doch, dals auch die verschiedenen Hydroxydmodifikationen hierbei eine grofse Rolle spielen.

Aus den erhaltenen Löslichkeitszahlen ergibt sich keine Konstante, welche einer einfachen Komplexbildung entsprechen würde, sicherlich deshalb, weil die Niederschläge Mischungen von verschiedenen Modifikationen sind.

\section{Zusammenfassung der Resultate.}

Durch Potentialmessungen nach der Methode von BodLänder wurde gefunden, dafs das komplexe Kation des Kadmiumammoniak- 
hydroxyds nach der Formel $\mathrm{Cd}_{m}\left(\mathrm{NH}_{3}\right)_{s_{m}}$ zusammengesetzt ist. Durch ähnliche Messungen ergab sich für das Kation des Zinkammoniakhydroxyds die Formel $\mathrm{Zn}_{m}\left(\mathrm{NH}_{3}\right)_{3 m}$.

Beim Kupfer und Nickel konnten keine konstanten Potentiale erreicht werden.

Die Leitfähigkeitsmessungen von Kupferhydroxyd in $\mathrm{NH}_{3}$ ergeben, dafs bei kleineren $\mathrm{NH}_{3}$-Konzentrationen eine oder mehrere schwächere Kupferammoniakbasen in der Lösung vorhanden sind. Ein Vergleich der Leitfähigkeitskurven von Kupferhydiroxyd + Ammoniak mit den entsprechenden Kurven von Baryumhydroxyd + Ammoniak deuten an, dafs von 3-4 norm. Ammoniak ab, eine stärkere Kupferammoniakblase in der Lösung vorherrscht. Wahrscheinlich ist die Zahl der gebundenen $\mathrm{NH}_{3}$-Molekeln bei der stärkeren Base gröfser als bei den schwächeren und zwar gibt ein Vergleich der Kupferhydroxyd-Ammoniaklösungen mit den entsprechenden Lösungen von Kupfersulfat Anlal's anzunehmen, dafs die Zahl der gebundenen $\mathrm{NH}_{3}-$ Molekeln in der stärkeren Base 4 ist.

Die Leitfähigkeitsmëssungen von Nickel-, Kadmiumhydroxydund Silberoxyd in Ammoniak zeigen, dafs sie mit $\mathrm{NH}_{3}$ starke Basen bilden.

Aus den Leitfähigkeitszahlen von Zinkhydroxyd in $\mathrm{NH}_{3}$ ist zu schliefsen, dals $\mathrm{Zn}(\mathrm{OH})_{2}$ im Gegensatz zum Kadmium sehr schwache Ammoniakbasen bildet.

Die Messungen der Hydroxylionenkonzentrationen nach der Methode von KoELrchen bestätigen das Resultat der Leitfähigkeitsmessungen, dafs bei kleinen $\mathrm{NH}_{3}$-Konzentrationen schwächere Kupferammoniakbasen als bei grölserem $\mathrm{NH}_{3}$-Gehalt in der Lösung vorhanden sind. Auch bestätigt die kleine OH-Ionenkonzentration bei Zinkammoniakhydroxyd die gefundenen kleinen Leitfähigkeitswerte.

Die Löslichkeitsversuche von Kupfer-, Nickel-, Kadmiumund Zinkhydroxyd in $\mathrm{NH}_{3}$ zeigen, dafs die genannten Hydroxyde sehr leicht Veränderungen erleiden, weshalb es sehr schwer ist, definierbare Modifikationen zu bekommen.

Doch gelang es, beim Kupfer-, Nickel- und Kadmiumhydroxyd solche zu erhalten. Die aus diesen Löslichkeitszahlen berechneten Konstanten zeigen, dals bei relativ kleinem $\mathrm{NH}_{3}$-Überschurs jedes Atom Kupfer $2 \mathrm{NH}_{3}$ bindet, während ein Atom Kadmium oder Nickel je $4 \mathrm{NH}_{3}$ zur Komplexbildung aufnimmt.

Demnach sind also die komplexen Kupferammoniakbasen bei 
kleinem Überschufs von $\mathrm{NH}_{3}$ nach der Formel $\mathrm{Cu}_{m}\left(\mathrm{NH}_{3}\right)_{2 m}(\mathrm{OH})_{2 m}$ zusammengesetzt, während den Nickel- und Kadmiumammoniakbasen bei allen $\mathrm{NH}_{3}$-Konzentrationen die Formeln $\mathrm{Ni}_{m}\left(\mathrm{NH}_{3}\right)_{4 m} \cdot(\mathrm{OH})_{2 m}$ resp. $\mathrm{Cd}_{m}\left(\mathrm{NH}_{3}\right)_{4 m} \cdot(\mathrm{OH})_{2 m}$ zukommen.

Die vorliegende Arbeit wurde in den Jahren 1902-1904 im chemischen Institut der Universität Breslau ausgeführt.

Es sei mir an dieser Stelle gestattet, dem Vorsteher der anorganischen physikalisch-chemischen Abteilung, Herrn Professor Dr. R. Abegg, für die Anregung zu dieser Arbeit und für das während der Ausführung derselben mir stets gern zuerteilte Interesse, sowie für seine wertvollen Ratschläge meinen herzlichsten Dank auszusprechen.

Breslau, Anorganische und physikalisch-chemisehe Abt. des Chemischen Universitätslaboratoriums.

Bei der Redaktion eingegangen am 11. Juni 1904. 